PNNL- 10831

UC-600

\title{
Modeling Water Retention of Sludge Simulants and Actual Saltcake Tank Wastes
}

C. S. Simmons

July 1996

Prepared for

the U.S. Department of Energy

under Contract DE-AC06-76RLO 1830

Pacific Northwest National Laboratory

Richland, Washington 99352 



\section{DISCLAIMER}

This report was prepared as an account of work sponsored by an agency of the United States Government. Neither the United States Government nor any agency thereof, nor any of their employees, make any warranty, express or implied, or assumes any legal liability or responsibility for the accuracy, completeness, or usefulness of any information, apparatus, product, or process disclosed, or represents that its use would not infringe privately owned rights. Reference herein to any specific commercial product, process, or service by trade name, trademark, manufacturer, or otherwise does not necessarily constitute or imply its endorsement, recommendation, or favoring by the United States Government or any agency thereof. The views and opinions of authors expressed herein do not necessarily state or reflect those of the United States Government or any agency thereof. 


\section{DISCLAIMER}

Portions of this document may be illegible in electronic image products. Images are produced from the best available original document. 


\section{Summary}

The Ferrocyanide Tank Safety Program managed by Westinghouse Hanford Company has been concerned with the potential combustion hazard of dry tank wastes containing ferrocyanide chemicals in combination with nitrate salts. Previous studies have shown that tank waste containing greater than $20 \mathrm{wt} \%$ water could not be accidentally ignited. Moreover, a sustained combustion could not be propagated in such a wet waste even if it contained enough ferrocyanide to burn.

Because moisture content is a key critical factor determining the safety of ferrocyanide-containing tank wastes, physical modeling was performed by Pacific Northwest National Laboratory to evaluate the moisture-retaining behavior of typical tank wastes. The physical modeling reported here has quantified the mechanisms by which two main types of tank waste, sludge and saltcake, retain moisture in a tank profile under static conditions. Static conditions usually prevail after a tank profile has been stabilized by pumping out any excess interstitial liquid, which is not naturally retained by the waste as a result of physical forces such as capillarity.

Through a modeling-based study of waste, water retention in sludge was found to be determined by compression and consolidation, whereas water retention by saltcake is determined mainly by capillarity. Sludge decreases in water content when it is compressed by its own weight or by a drained overburden of saltcake. Based on this study of simulants, sludge is shown to always remain saturated when it dries and shrinks in volume, although the amount of held water has decreased. Sludge, therefore, is a deformable porous medium produced by settling of a particle suspension. Under most tank conditions, as long as surface evaporation is eliminated, sludge retains at least $35 \mathrm{wt} \%$ water. Saltcake, on the other hand, is a precipitated matrix of salt crystals fused together and having a fixed porosity or void fraction. In contrast, saltcake retains water in interstices by capillary action and drains under the downward pull of gravity when a tank is pumped and stabilized. Both waste types are permeable to interstitial liquid movement, and the permeability determines how rapidly the liquid can be removed under tank conditions.

Consolidation behavior of two sludge simulants, In-Farm and U-Plant, was confirmed based on the data from three experiments performed by Westinghouse Hanford Company. These data on moisture expulsion from sludge at various levels of effective stress were used to determine the consolidation characteristics of each simulant. Parameters such as the coefficient of consolidation and liquid conductivity were estimated by fitting mathematical models to the data. By using these estimated parameters, the moisture distribution was predicted for typical tank-size profiles of sludge waste. In a tank sludge profile, the moisture content near the bottom could actually be less than that near the waste surface, according to the consolidation modeling results. This result, however, neglects the influence of surface evaporation.

Drying by evaporation was studied in two additional experiments designed to determine the drying rate of sludge simulants when exposed to various levels of relative humidity $(\mathrm{RH})$ below the initial equilibrium value. Samples of In-Farm and U-Plant simulants, when exposed to air with $32 \% \mathrm{RH}$, eventually dried out entirely. When exposed to $62 \% \mathrm{RH}$, U-Plant simulant dried entirely, but In-Farm simulant retained about $40 \%$ of the original amount of moisture after reaching equilibrium. When In-Farm simulant was exposed to $85 \% \mathrm{RH}$, it gained moisture; but it lost moisture when exposed to $72 \% \mathrm{RH}$. For $50 \%$ of the original moisture amount or greater, the balance between the equilibrium 
$\mathrm{RH}$ and sample moisture content was described by a unique isotherm curve. But for lower moisture content, the RH for vapor in equilibrium with a sample depended on the applied RH exposure level and drying rate. Thus, for moisture contents less than $50 \%$ of the original amount present before drying, there was not a uniquely associated equilibrium value of $\mathrm{RH}$. This result meant that measurements of RH over a sludge sample in a tank could not be used to determine its moisture content unless the drying $\mathrm{RH}$ exposure level was known. Also, the drying rate process was found to conform to a simple liquid diffusion model, and effective diffusion coefficients for the process were estimated for both experiments. These diffusion coefficients, however, were found to be sample-size dependent.

Moisture in saltcake was modeled with a simplified approach by neglecting water vapor flow caused by a tank's thermal gradient. Steady upward flow of salt-saturated liquid in an unsaturated porous medium of saltcake was presumed to control the moisture distribution. The model was formulated based on the hydraulic properties of saltcake as characterized by a capillary holdup height, poresize index, and saturated liquid conductivity. Layers of variable saltcake material were accommodated in the model as well. To obtain the hydraulic parameters for unsaturated conditions, the model was calibrated by matching its numerical calculation to the relative saturation distribution as measured by neutron probe scans. This model for the moisture distribution in an unsaturated saltcake was demonstrated on Tanks BY-104 and TX-105. In both examples, the profiles of variable moisture content were reproduced fairly well. It showed that the surface of BY-104 should remain relatively wet with at least $12 \mathrm{wt} \%$ water. However, a saltcake profile of sufficiently great height will generally dry out near the surface as a result of drainage when stabilized.

This simplified modeling approach points out that surface evaporation rate is the most significant remaining unknown factor controlling surface dryness. More advanced simulation work involving estimation of nonisothermal water vapor movement through saltcake is needed to specify the surface evaporation rate.

The instrumentation for determining waste depth in the Hanford waste tanks is calibrated in inches. While the author has attempted to convert the measurements, where possible, to SI units, in many cases the conversion sacrifices accuracy and an opportunity to compare with the original information. The following table is provided for those who desire to make the conversion.

\begin{tabular}{||l|l|}
\hline \multicolumn{1}{|c|}{ English unit } & \multicolumn{1}{c|}{ Metric (SI) unit } \\
\hline \hline 1 inch & 2.54 centimeter $(\mathrm{cm})$ \\
\hline 1 foot & $30.48 \mathrm{~cm}$ \\
\hline 1 gallon & 3.79 liters $(\mathrm{L})$ \\
\hline 1 kilogallon (kgal) & $3785 \mathrm{~L}$ \\
\hline
\end{tabular}




\section{Acknowledgments}

The work presented in this report was accomplished with the particular help of John Relyea and C. V. King of Westinghouse Hanford Company (WHC) who provided the basic data on sludge simulant physical behavior. The author had numerous informative discussions with John Relyea about the hydraulic properties of sludges.

Jerry McCormack (WHC) first introduced the author to the problem of moisture retention by sludge simulants, and Dave Jeppson (WHC) provided data on the draining small column of In-Farm * sludge simulant that was critical in gaining a better understanding of sludge consolidation behavior. M. Epstein of Fauske and Associates reviewed parts of this work on sludge moisture retention and put it to earlier use for the benefit of the Ferrocyanide Safety Program.

Special thanks are given to Dean Dickinson (WHC) who continually reviewed the progress on this work and made suggestions for improving the emphasis on its application to tank waste issues. J. E. Meacham and R. J. Cash managed this effort to better understand the nature of tank waste through a modeling approach.

Also, thanks are given to Kristin Manke (PNNL) for assembling the report and Sheila Bennett (PNNL) for editing and improving the presentation. Joe Brothers (PNNL) reviewed this report and made many helpful suggestions for improvements. 



\section{Contents}

Summary $\ldots \ldots \ldots \ldots \ldots \ldots \ldots \ldots \ldots \ldots \ldots \ldots \ldots \ldots$ iii

Acknowledgments $\ldots \ldots \ldots \ldots \ldots \ldots \ldots \ldots \ldots \ldots \ldots \ldots \ldots \ldots$

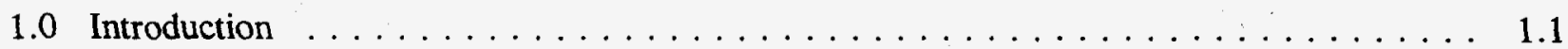

1.1 Tank Waste Forms $\ldots \ldots \ldots \ldots \ldots \ldots \ldots \ldots \ldots \ldots \ldots$

1.2 Contrasting Aspects of Each Waste Form $\ldots \ldots \ldots \ldots \ldots \ldots \ldots$

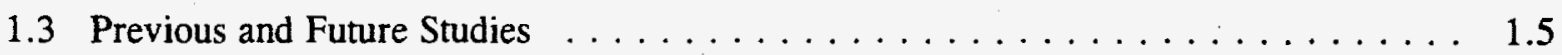

2.0 Water Retention Capability of Ferrocyanide Simulant Sludges $\ldots \ldots \ldots \ldots \ldots \ldots$

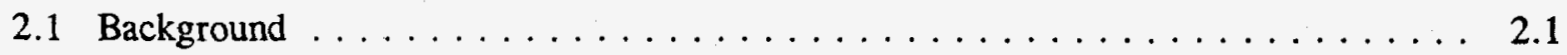

2.2 Physical Properties of Sludge Simulants for Modeling $\ldots \ldots \ldots \ldots \ldots \ldots$

2.3 Particle Size Implications $\ldots \ldots \ldots \ldots \ldots \ldots \ldots \ldots \ldots \ldots \ldots \ldots \ldots$

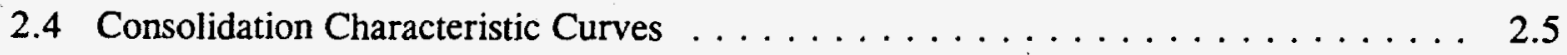

2.5 Small Drainage Column Test $\ldots \ldots \ldots \ldots \ldots \ldots \ldots \ldots \ldots \ldots$

2.6 Verification of Drainage Model by Centrifugation Test $\ldots \ldots \ldots \ldots \ldots \ldots$

2.7 Equilibrium Water Content in an Example Tank Profile . . . . . . . . . 2.15

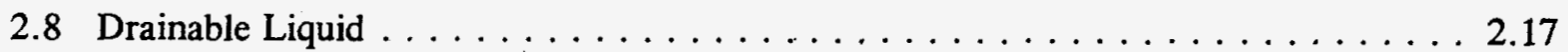

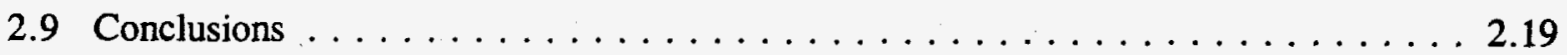

3.0 Drying of Ferrocyanide Sludge Simulants $\ldots \ldots \ldots \ldots \ldots \ldots \ldots \ldots$

3.1 Background $\ldots \ldots \ldots \ldots \ldots \ldots \ldots \ldots \ldots \ldots \ldots \ldots \ldots \ldots \ldots \ldots \ldots$

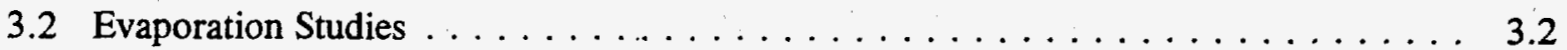

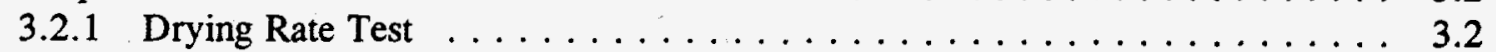

3.2.2 Relative Humidity Measurements $\ldots \ldots \ldots \ldots \ldots \ldots \ldots \ldots$

3.3 Evaporation Modeling $\ldots \ldots \ldots \ldots \ldots \ldots \ldots \ldots \ldots$

3.4 Liquid Diffusion in Drying of Simulants $\ldots \ldots \ldots \ldots \ldots \ldots \ldots$ 


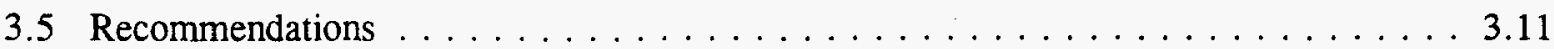

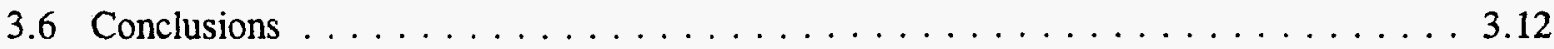

4.0 A Simplified Model of Saltcake Moisture Distribution $\ldots \ldots \ldots \ldots \ldots \ldots \ldots \ldots .1$

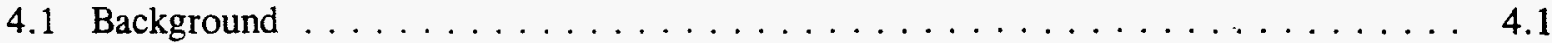

4.2 Saltcake Waste Characteristics $\ldots \ldots \ldots \ldots \ldots \ldots \ldots \ldots \ldots \ldots \ldots . \ldots . . \ldots \ldots$

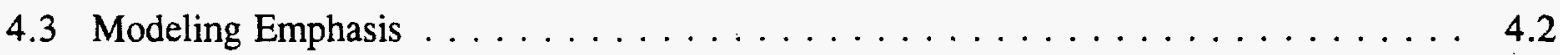

4.4 Hydraulic Property Model $\ldots \ldots \ldots \ldots \ldots \ldots \ldots \ldots \ldots \ldots \ldots . \ldots \ldots \ldots$

4.5 Evaporation Estimation $\ldots \ldots \ldots \ldots \ldots \ldots \ldots \ldots \ldots \ldots \ldots \ldots .6 \ldots \ldots \ldots$

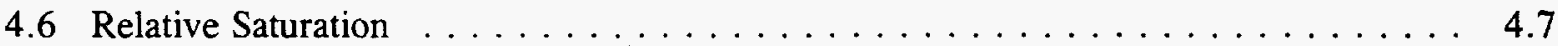

4.7 Modeling Applications $\ldots \ldots \ldots \ldots \ldots \ldots \ldots \ldots \ldots \ldots \ldots \ldots . \ldots \ldots$

4.8 Determining the Pore-Size Index from Pumping $\ldots \ldots \ldots \ldots \ldots \ldots \ldots \ldots .12$

4.8.1 Drainable Porosity $\ldots \ldots \ldots \ldots \ldots \ldots \ldots \ldots \ldots \ldots \ldots \ldots \ldots \ldots \ldots \ldots \ldots \ldots .14$

4.8.2 Surface Moisture Content . . . . . . . . . . . . . . . . 4.16

4.8 .3 Estimation Procedure Limitations . . . . . . . . . . . . . . . . 4.19

4.8 .4 Two Tank Groups . . . . . . . . . . . . . . . . . . . . 4.19

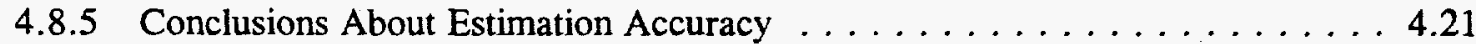

4.9 Surface Dryness Sensitivity $\ldots \ldots \ldots \ldots \ldots \ldots \ldots \ldots \ldots \ldots \ldots \ldots \ldots \ldots \ldots \ldots \ldots \ldots .22$

4.10 Modeling Limitations $\ldots \ldots \ldots \ldots \ldots \ldots \ldots \ldots \ldots \ldots \ldots \ldots . \ldots \ldots$

4.11 Conclusions $\ldots \ldots \ldots \ldots \ldots \ldots \ldots \ldots \ldots \ldots \ldots \ldots \ldots \ldots \ldots \ldots \ldots . .26$

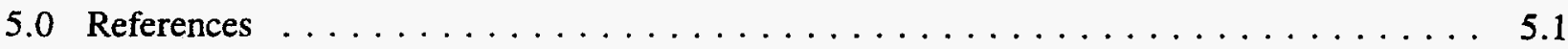

Appendix A - Models of Column Drainage $\ldots \ldots \ldots \ldots \ldots \ldots \ldots \ldots \ldots \ldots \ldots$ A.1

Appendix B - Equivalent Viewpoints of Drainage During Consolidation $\ldots \ldots \ldots \ldots$ B.1

Appendix C - Consolidation of a Thin Sample of Porous Material in a Tempe Cell . . . . . . C.1

Appendix D - Equilibrium Conditions in a One-Dimensional Column of Deformable

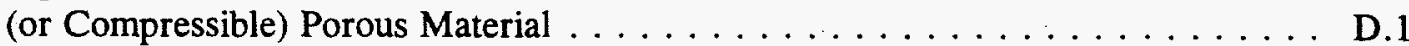

Appendix E - Evaporation from Sludge $\ldots \ldots \ldots \ldots \ldots \ldots \ldots \ldots \ldots \ldots \ldots$ E.1

Appendix F - Steady Upward Unsaturated Flow in a Layered Porous Profile $\ldots \ldots \ldots \ldots$ F.1 


\section{Figures}

2.1 Consolidation Curve for In-Farm-2 Sludge Based on Centrifuge Measurements $\ldots \ldots \ldots$. . . 2.7

2.2 Conversion Curve for Translating Void Ratios into Weight Percent Water Content of

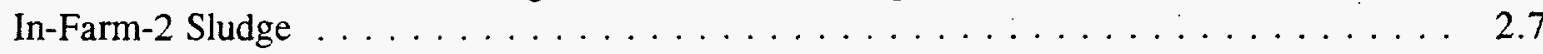

2.3 Consolidation Curve for U-Plant-1 Sludge Based on Tempe Cell Water Retention

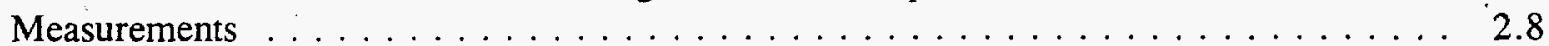

2.4 Average Volumetric Liquid Content Within the Draining Small Column of In-Farm-2 Sludge

2.5 Comparison of Suspension Settling and Liquid Conduction Models for Drainage from the Small In-Farm-2 Sludge Column $\ldots \ldots \ldots \ldots \ldots \ldots \ldots \ldots$

2.6. Water in the In-Farm-2 Sample Taken from Small Column After 60 Days Drainage and Subjected to $500 \mathrm{~g}$ Centrifugation

2.7 Fit of Exponential Liquid Drainage Model to Sample Subjected to $500 \mathrm{~g}$ Centrifugation

2.8 Distributions of Weight Percent Water Content in an In-Farm-2 Sludge Profile Initially $426 \mathrm{~cm}$ High at Hydrostatic Equilibrium Conditions with Closed and Open Bottom

3.1a Percent Loss of Water in Sludge Simulant and Saltcake Samples in 5.6-cm-deep Bottles Exposed to $30 \%$ Relative Humidity at $25^{\circ} \mathrm{C} \ldots \ldots \ldots \ldots \ldots$

3.1b Conversion of Percent Water Loss to Weight Percent in Samples . . . . . . . . . . 3.3

3.2 Evaporative Moisture Flux for Saltcake and Sludge Simulants Exposed to $30 \%$

Relative Humidity

3.3 Relative Humidity Isotherms for Sludge Simulants Dried by Exposure to Relative Humidity Levels of 32 and $62 \% \ldots \ldots \ldots \ldots \ldots$

3.4 Relative Available Moisture Content for the Drying Experiment . . . . . . . . . . . . 3.9

3.5 Relative Available Moisture for U-Plant Simulant Exposed to Four Levels of Constant Relative Humidity

4.1a Three Neutron Probe Scans of Tank TX-118 $\ldots \ldots \ldots \ldots \ldots \ldots \ldots \ldots$

$4.1 \mathrm{~b}$ Neutron Probe Scans in Terms of Relative Saturation for Tank TX-118 . . . . . . . 4.9 
4.2 Relative Saturation Profile for Tank BY-104 Compared with Brooks-Corey

Retention Curve . . . . . . . . . . . . . . . . . . . . . . 4.10

4.3 Moisture Content Profile in Tank BY-104 Estimated by Steady State Model . . . . . . . . 4.11

4.4 Moisture Profile in Tank TX-105 in Terms of Relative Saturation . . . . . . . . . . . 4.12

4.5 Moisture Profile in Tank TX-105 Based on Modeling and Neutron Counting Scan . . . . 4.13

4.6 Drainable Porosity for Pumped Saltcake Tanks Reported by DeWeese (1988) _ . . . . . 4.14

4.7 Correlation Between Saltcake Profile Depth and Liquid Level Decline After Pumping of Interstitial Liquid from a Tank . . . . . . . . . . . . . . . . . . 4.15

4.8 Pumped Interstitial Liquid for Two Tank Groups $\ldots \ldots \ldots \ldots \ldots \ldots \ldots$

4.9 Model Estimated Pumped Interstitial Liquid Compared with the Actual . . . . . . . . . 4.17

4.10 Moisture Retention in the Profiles of Drained Saltcake Waste Tanks . . . . . . . . 4.18

4.11 Weight Percent Water at the Surface of Each Stabilized Tank with the Retention Parameters of the Two Groups $\ldots \ldots \ldots \ldots \ldots \ldots \ldots \ldots \ldots \ldots \ldots \ldots \ldots \ldots \ldots .18$

4.12a Surface Moisture Content for Permeability of 22 darcy and Pore-Size Index of $2.1 \ldots \ldots .22$

4.12b Surface Moisture Content as Weight Percent Water Depending on Evaporative Flux . . . 4.23

4.13a Surface Moisture Content for Permeability of 2 darcy and Pore-Size Index of $2.1 \ldots \ldots .23$

4.13b Surface Moisture Content as Weight Percent Water for Permeability of 2 darcy and

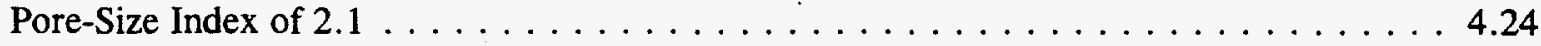

4.14 Surface Moisture Content for Evaporative Flux with Pore-Size Index Reduced to 1.5 . . . 4.24

4.15 Surface Moisture Content for Evaporative Flux with Pore-Size Index Increased to $3 \ldots \ldots 4.25$ 


\section{Tables}

2.1 Properties of Simulant Sludges Related to Moisture Content $\ldots \ldots \ldots \ldots \ldots$

2.2 Consolidation Parameters for Simulant Sludges $\ldots \ldots \ldots \ldots \ldots \ldots \ldots \ldots$

2.3 Water Quantity Expelled or Drained Under Closed and Open Bottom for Equilibrium

Conditions with In-Farm-2 Simulant Sludge $\ldots \ldots \ldots \ldots \ldots \ldots \ldots \ldots \ldots$

2.4 Water Quantity Expelled or Drained Under Closed and Open Bottom for Equilibrium

Conditions with U-Plant-1 Simulant Sludge . . . . . . . . . . . . 2.18

2.5 Time for Consolidation of In-Farm-2 Sludge Profile $\ldots \ldots \ldots \ldots \ldots \ldots$

3.1 Percent Loss of Initially Available Moisture when Exposed to RH Below

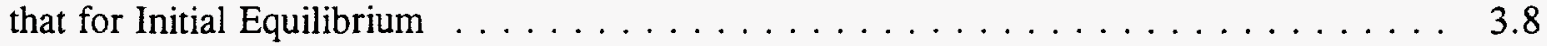

3.2 Values of $\mathrm{D} / \mathrm{L}^{2}$ Above and Below the Dividing Value of $\mathrm{W} \ldots \ldots \ldots \ldots$

3.3 Values of $\mathrm{D} / \mathrm{L}^{2}$ Above and Below the Dividing Value of $\mathrm{W} \ldots \ldots \ldots \ldots \ldots$

4.1 Pore-Size Index for an Exact Match of the Pumped Interstitial Liquid Amount $\ldots \ldots$. . 4.20 


\subsection{Introduction}

The Hanford Site in southeastern Washington State has 177 single- and double-shell radioactive waste tanks grouped into 18 tank farms. Some of these tanks contain ferrocyanide and organic chemicals mixed with nitrate and nitrite salts, chemicals that might potentially constitute a combustion or explosion hazard if ignited. The tanks are kept on a Watch List until deemed safe from such an occurrence.

These tanks also usually contain substantial amounts of moisture. The moisture distribution in a stabilized tank is critical information for resolving safety concerns that are being addressed by both the Ferrocyanide and Organic Safety Programs managed by Westinghouse Hanford Company. The presence of moisture at sufficient levels keeps organic chemical or ferrocyanide wastes combined with nitrate salts from being a combustion hazard, if those chemicals are present in high enough quantities to sustain ignition. This modeling work was performed by Pacific Northwest National Laboratory to assist Westinghouse Hanford Company with evaluating the safety of tank waste. The work focuses exclusively on the inherent moisture retaining behavior of the two typical tank waste types, sludge and saltcake. The modeling is primarily concerned with the so called "free moisture" that is not chemically bound to the solid materials and is potentially free to be either drained or evaporated from the wastes. This work also helps characterize the waste properties for evaluating safety (Meacham et al. 1995). Safety criteria for the Ferrocyanide Watch List Tanks are discussed by Postma et al. (1993). Criteria for whether ferrocyanide waste can propagate a combustion are described by Fauske et al. (1995), while an assessment of safety for tanks containing ferrocyanide waste is made by Grigsby et al. (1996).

This section examines the moisture retention behavior of typical tank wastes. Section 2.0 addresses the estimation of hydraulic parameters for sludge, and other sections attempt to estimate, using physical modeling, how wet the waste surface remains (Sections 2.7 and 2.8): Sections 3.0 and 4.0 consider further the drying of the waste surface in a tank. In a tank, the waste is subjected to drying when water is pumped out to keep the waste from possibly leaking into the ground (this pumping is called stabilization). Water is also lost to evaporation, which occurs because the tanks have a thermal gradient within and are usually passively vented through filters to the atmosphere. Drainage by pumping or evaporation can potentially dry a waste surface, depending on the physical water retention behavior of the waste.

\subsection{Tank Waste Forms}

The waste in tanks usually takes two physical forms: settled sludge or crystallized saltcake. A tank's waste profile may contain mainly only one of these forms or both forms as layers. Usually, a layer of saltcake rests on the sludge when both waste forms are present. For current information on amount of each waste type held in each Hanford tank, see the monthly report, Tank Farm Surveillance and Waste Status Summary Report (Hanlon 1993). These wastes are porous materials containing hundreds of kilogallons of interstitial liquid that is either trapped in the saltcake or sludge; some liquid may stand as supernatant on top of the sludge or saltcake. These liquids include water and soluble salts. The interstitial liquid in saltcake is probably a salt-saturated brine. 
Examples of ferrocyanide waste tanks with saltcake over the sludge layer are in the BY Farm. Tanks containing mainly sludge are typical of the $\mathrm{C}$ and $\mathrm{T}$ Farms. Tanks in the TX Farm contain mainly saltcake. The single-shell tanks in these farms have a 75 -ft diameter and hold 530 to $750 \mathrm{kgal}$ of waste depending on their height. Waste commonly stands 2 to $20 \mathrm{ft}$ deep in the Ferrocyanide Watch List tanks. Diagrams of the tank systems along with waste inventory can be found in the monthly Tank Farm Surveillance and Waste Status Summary Report. Hanford tank waste volumes have traditionally been reported in kgal. See Hanlon (1993) for typical tank volumes. One gallon is equal to 3.8 liters; one inch of waste height is equal to $2.54 \mathrm{~cm}$. The tanks were originally designed for a specific capacity in gallons.

The physical mechanisms that control liquid retention in each form of tank waste are well known. Saltcake is subject to gravitational drainage, and liquid is expelled from sludge by any compression, which causes consolidation. However, the hydraulic parameters that control liquid retention and movement in these wastes have not been quantified adequately to make predictions about moisture status. Section 2.0 addresses the estimation of hydraulic parameters for sludge.

Previous modeling has emphasized sludge consolidation under self-weight for tanks containing only sludge (Epstein et al. 1994). Sludge waste was shown to resist drying out by gravity drainage. However, sludge may be vulnerable to drying out at the surface by evaporation. The same concern applies to saltcake after tank stabilization or after salt-well liquid pumping that drains the waste.

\subsection{Contrasting Aspects of Each Waste Form}

Any decrease of liquid content at a tank's waste surface, as caused by draining or drying, is a primary concern for maintaining waste in a safe condition. Processes of draining or drying tank waste usually cause interstitial liquid to be conducted from one location to another. To know whether a particular waste form might become critically dry requires knowing how rapidly liquid can move through the waste by conduction.

The rate of conduction of liquid through all tank waste forms is determined by the permeability of the waste medium. Both saltcake and sludge type wastes are difficult to describe as drying occurs, when caused by pumping or by surface evaporation, because the permeability changes while the liquid content decreases. The change in permeability depends on how or if the solid matrix structure of the particular waste is modified by being drained or dried.

Thus, permeability is a key hydraulic parameter in ascertaining waste form. Permeability is the property of a porous medium that determines how rapidly liquid will flow through a porous medium under an unopposed hydraulic gradient, that is, a hydraulic system not in a static equilibrium condition. Permeability is essentially a measure of the open cross-sectional area available within a medium for liquid conduction; it reflects the size of pores passing through the medium, and the pore sizes are related to some extent to the size of grains or solid structures forming the medium. Permeability divided by the liquid's viscosity determines the liquid's hydraulic conductivity used in Darcy's law to model flow under a hydraulic pressure gradient field. 
Each waste form has permeability to interstitial liquid, but the waste forms behave differently. Saltcake has a somewhat fixed pore structure, whereas sludge does not. The salt grains are in contact to form a mostly rigid matrix, while the particles or grains in sludge are not necessarily fully forced together. Saltcake is the excess precipitated salt that was not soluble in the available salt-saturated liquid originally dumped into the tank. The saltcake matrix formed when the salt-saturated liquid cooled. Also, salt crystals can grow or dissolve over time, changing the structure of the medium. At present, the structure of typical saltcake may not be adequately characterized to model flow through it, although simulant saltcake has been studied. In contrast, sludge particles are mainly insoluble chemicals, with all soluble salts mainly in the surrounding liquid. The solid matrix structure of sludge waste is deformable and shrinks whenever liquid is removed. However, shrinkage of sludge can continue only to a point where it also resembles a solid and rigid saltcake matrix.

An appropriate constitutive theory describing the hydraulic properties of these two distinct tank waste forms must take into account the physical characteristics described in the previous paragraphs. Modeling moisture flow in tank waste must deal with the dependence of permeability on the porous matrix nature. The first approach of this modeling study was to relate hydraulic properties of tank waste to its grain size distribution. However, neither theory nor particle size data were adequate to accomplish this. The approach taken here was to presume a macroscopic model for liquid flow in waste and to confirm it by seeing if it conformed to available data. An approach based on building a theoretical pore-scale mathematical model for permeability was excluded because the success was too unpredictable.

The liquid permeability, in darcy units, for saltcake is typically about a thousand or even ten thousand times greater than that for sludges (fractions of a millidarcy for sludge simulants). Consequently, interstitial liquid in saturated saltcake can be drained relatively rapidly by pumping from a salt well; sludge cannot. Saltcake is mainly a rigid medium when drained; when liquid is expelled from sludge the volume is consolidated. The interstices of saltcake empty when drained; in sludge they do not, it always remains saturated until a shrinkage limit is achieved. Sludge remains liquid-saturated when consolidated, whereas saltcake becomes unsaturated. This is the major difference in how saltcake and sludge behave when interstitial liquid is removed or conducted out.

The concept of permeability for porous media in the subsurface is discussed in a basic text by Freeze and Cherry (1979), which contains a more technical discussion of permeability. The subsurface has forms of porous media that resemble saltcake and sludge waste in most ways with regard to liquid flow behavior. However, the discussion given here is intended to inform a reader that permeability is not a single quantity that remains the same as the waste is transformed by draining or drying. For this reason, a complicated constitutive theory for hydraulic properties of tank waste is required to predict drying behavior and must be incorporated in a numerical simulator or computer model to predict how a waste's moisture content will be changed by pumping or drying.

The overburden of a saltcake layer will also contribute to sludge compression in tanks like BY-104. The expelling of liquid from sludge over time can force additional liquid up into an overlying saltcake, thus increasing its wetness over time, provided the sludge was not already fully consolidated under the overburden. Thus, long-term settling of sludge under a saltcake layer could contribute to re-wetting the saltcake following stabilization and would be manifested as a gradual rise in the interstitial liquid level (ILL), after being drawn down to the capillary holdup height above the sludge layer. Also, following 
pumping, liquid held in the unsaturated zone above holdup height (and at distance from the salt well) would continue draining downward and accumulating on the sludge layer until a new hydrostatic equilibrium is achieved. How long this rebound of ILL would last would depend on the liquid retention and conductivity for the unsaturated zone. Whether this rebound process needs to be modeled is uncertain, although it does produce a further decrease in moisture in the compressed sludge layer below a saltcake overburden. However, the dryness of a sludge layer protected above by a saltcake overburden is probably not a combustion concern.

In a saltcake waste, the volumetric liquid content (VLC) is less than its maximum saturation value at the saltcake's porosity for any height above the ILL, provided that the ILL falls below the surface. In a saltcake porous medium, the liquid content is maintained by capillary rise above the ILL. A part of the ILL height, which is in the liquid saturated zone, is held up by capillary pressure. If a salt layer were pumped out to its greatest amount possible from a penetrating salt well, an ILL height called the capillary fringe or holdup height would remain held by capillary rise. Also, the capillary holdup is the height of the ILL in the saltcake above the standing liquid level in a salt well. The VLC distribution in the profile of a saltcake is a direct reflection of the capillary liquid retention relation for the particular porous medium. Thus, to estimate the moisture content distribution in a drained and stabilized (all remaining liquid is retained by capillarity against gravity) saltcake waste, the retention relation must be known or measured.

Given the volumetric liquid distribution in a saltcake profile and presuming the interstitial liquid is saturated with soluble saltcake, the weight percentage of water in the bulk medium can be immediately estimated. Weight percent water is given by

$$
\mathrm{wt} \% \text { water }=\mathrm{P}_{\mathrm{w}} \times\left(\frac{\text { liquid density }}{\text { bulk density }}\right) \times \text { liquid content }
$$

where $\mathrm{P}_{\mathrm{w}}=$ percent water in the salt-saturated liquid.

The bulk density of saltcake in this formula is dependent on the porosity, or void fraction (called void), and the present VLC. The equation for bulk density is

$$
\text { bulk density }=\text { grain density } \times(1-\text { void })+\text { liquid density } \mathrm{x} \text { liquid content. }
$$

For Tank BY-104, the void fraction was reported to be as great as 0.46 by Grigsby et al. (1992). Grain density and liquid density were reported to be $2.09 \mathrm{~g} / \mathrm{cc}$ and $1.45 \mathrm{~g} / \mathrm{cc}$, respectively. Because the maximum that liquid content could be, as a fraction, is equal to void, the bulk density would be about $1.8 \mathrm{~g} / \mathrm{cc}$ for saturated saltcake. However, Grigsby et al. (1992, Table 4-5) reported $1.61 \mathrm{~g} / \mathrm{cc}$, which possibly indicates a somewhat drained salt sample before being measured. Percent water of supernatant ( $\mathrm{Pw}$ ) was found to be $48 \%$ for Tank BY-104. These values give about $20 \mathrm{wt} \%$ water for saltcake. If the higher, saturated bulk density were used, the value would be about $18 \mathrm{wt} \%$. Thus, the typical weight percent water of saltcake is about $20 \mathrm{wt} \%$, when saturated with liquid. But in the unsaturated zone above the ILL, the value would be reduced by the fraction of liquid content that remained held up by capillarity following stabilization. For instance, if liquid content was $50 \%$ of void, the weight percent of water drops to about $11 \%$. 
Therefore, compared with sludges, which typically have no less than $40 \mathrm{wt} \%$ water even when consolidated, the weight percent of water of drained saltcake is likely to be substantially less than $20 \mathrm{wt} \%$. This occurs even though the amount of void space in the saltcake still retains a substantial quantity of liquid.

Therefore, an important consideration for saltcake is the holdup height. If this value were large, say 3 or $4 \mathrm{ft}$, then the layer would remain nearly saturated even when stabilized. On the other hand, a very thick saltcake layer could be very dry near the surface on a weight percent basis, and the holdup height for very large salt grains would be relatively small (e.g., a few inches). Hence, estimating the holdup height to evaluate moisture conditions under equilibrium stabilized conditions is important.

\subsection{Previous and Future Studies}

Because obtaining tank saltcake samples and making direct capillary liquid retention measurements is very difficult and costly, the Ferrocyanide Program management team suggested that past studies on saltcake properties be examined carefully for relevant information. A critical review of the most relevant manuscripts was performed. An analysis of holdup height based on manuscripts by Handy (1975), Kirk (1980), Metz (1976), Strachan (1975), and especially by Atherton (1974) was performed. A formula given by Atherton and reproduced and employed by Grigsby et al. (1992, Eq. 4-5, p. 4-93) is a valuable, simple means for estimating capillary holdup height from porosity; liquid surface tension, liquid density, and typical grain-size diameter for the porous medium. But the formula has not been applied to a saltcake type of porous medium.

The formula stems from some early experimental work done by Dombrowski and Brownell (1954), who developed a correlation between holdup height (also called drain height) and the measured permeability for various particle sizes and shapes of certain granular porous media. Fluids with different densities and surface tensions are also used to fully develop the correlation for a range of licuid properties. Unfortunately, the authors leave the impression that there is always a certain level of residual liquid held just above the holdup height, only about $7.5 \mathrm{vol} \%$. But this is a special consequence of the homogeneous (narrow) size distribution of particle packs used in their experiments. More spread in the particle size distribution will generally produce a more gradual reduction of liquid content above the holdup height.

Although Handy's and Strachan's estimates of saltcake permeability (22 darcy and 2 darcy, respectively) seemed reasonable, their measured holdup heights seemed to underestimate the possible capillary rise that is consistent with grain size when based on Atherton's formula. Strachan was the only one to attempt a complete measurement of the liquid retention relation; however, his measurement of a liquid retention relation appears flawed and could not be applied to modeling saltcake.

Examination of a report on Tank BY-104 auger samples taken near the saltcake waste surface by Beck et al. (1992) indicated high capillary retention of 17 to $20 \mathrm{wt} \%$ water 3 to $4 \mathrm{ft}$ above the presumed ILL. This result seems consistent with the Atherton formula's estimate of holdup for a grain size range reported by Strachan for a simulant saltcake. Unfortunately, the crystal size distribution was 
destroyed by the method of digesting Tank BY-104 salt samples in pure water before measuring particle sizes. It is the crystal grain size that is most relevant for determining liquid retention in saltcake. Future particle size distribution measurements of tank wastes should try to obtain the crystal grain sizes as well as insoluble particle sizes.

The Atherton formula could also be used to reconcile the result that capillary holdup in sludge would not be great unless the porosity was quite low (around 30 to $50 \mathrm{vol} \%$ ), such as that associated with highly compressed sludge. For sludge with 85 to 95 vol\% porosity, which was typical of the In-Farm and U-Plant simulants and the sludge samples used by Risenmay, ${ }^{a}$ the capillary rise for small particle sizes ( 5 to $10 \mu \mathrm{m}$ ) would be only a fraction of a foot, instead of the 10 to $20 \mathrm{ft}$ reported by Grigsby et al. (1992). This result further confirms that liquid is held strongly in sludges by forces other than capillarity, as was previously believed. It further supports the concept that electrolytic forces or ionic separation forces hold the fine particles together in sludge. Considerable stress must be applied to sludge material to force particles closer together and thereby expel excess liquid when the volume is compressed. Thus, if a leak did occur, sludge would drain by consolidation under the stress of its own weight or overburden, whereas saltcake would drain due to the gravitational gradient associated with the liquid's density.

Future modeling work should attempt to relate permeability with the retention relation calculated from the grain-size distribution of a granular medium. A model could be based on the soil physics work by Arya and Paris (1981), who constructed the pore size distribution determining the capillary pressure from the particle grain sizes. Using the method of Tyler and Wheatcraft (1989), an undetermined fitting parameter in this retention model can be evaluated from the fractal dimension of the particle size distribution when the distribution is consistent with the simple theory. Usually, however, this parameter would be calibrated to actual measurements of liquid retention for a sample. Beginning with this retention model and a measurement of saturated conductivity, the conductivity as a function of decreasing VLC could then also be estimated. Mishra et al. (1989) further examined the uncertainty of parameters in the Arya-Paris model; this information can also be applied. The Arya-Paris model, however, is a considerable simplification for the complexity of a saltcake crystal matrix, and it is by no means certain at this time how well it could predict the actual hydraulic properties of saltcake. Thus the model's validity remains to be tested in the future for saltcake simulants and actual tank core samples.

(a) Internal letter, August 1985, to D. L. Flyckt from H. R. Risenmay, Rockwell International. "Consolidation Tests of Synthetic Waste Sludges." Letter No. 65455-85-088. 


\subsection{Water Retention Capability of Ferrocyanide Simulant Sludges}

\subsection{Background}

Three experiments have been evaluated that describe the simulant sludge's capability to retain water against the pull of gravity and thereby resist drying out by drainage. The experiments are described as follows:

1) Drainage of a 8-in.-long column of In-Farm-2 simulant with accumulated outflow of supernatant measured for two years (Jeppson and Wong 1993)

2) Centrifugation of In-Farm-2 simulant at various levels of gravity in a tube with an open-end frittedglass filter ${ }^{(a)}$

3) Expulsion of supernatant from U-Plant-1 simulant in a Tempe cell with applied air pressure. ${ }^{(b)}$

In all three experiments, the loss of supernatant volume from the samples was associated with an equal reduction of bulk volume. This occurred regardless of whether the supernatant was expelled by 1) natural drainage, 2) increased gravitational force, or 3) applied air pressure. Because the samples remained liquid-saturated as they shrank, all experiments were found to manifest consolidation. In draining the small column, the load was produced by the sample's self-weight.

The consolidation curve describes the process in terms of void ratio, which is the volume of supernatant per volume of sludge solids in a sample, and the effective stress, $\mathrm{s}^{\prime}$, which is the pressure that acts to force sludge particles together. Effective stress is the difference between the applied stress (load), s, and the pore-liquid pressure, p. Effective stress at a location can increase if the load increases or the pore-liquid pressure is reduced. An increáse in effective stress causes consolidation when it occurs, provided the medium is not already compressed to the maximum density. Also, the consolidation curve illustrates the repulsive forces that hold sludge particles apart and attractive forces that simultaneously retain liquid in the sludge. In this section, some of the basic physical properties of the sludge simulants that were studied in the three experiments are described (Section 2.2). The implication of the particle size relationship to measured properties is considered in Section 2.3 , and the three experiments are discussed in Sections 2.4 and 2.5. Finally, a model of how a tank size profile might behave given the characterization of the consolidation properties is presented in Section 2.6. A study of the rheology of each sludge would be needed to understand the physical nature of ionic forces that bind the sludge particles and liquid together. Such detailed physical-chemical mechanisms were not studied here.

(a) Westinghouse Hanford Company internal memo, 1994, from G. S. Barney. "Results of Centrifuge Drainage Tests for Simulant In Farm-2 Ferrocyanide Sludge." Internal Memo 12120-94-028.

(b) Westinghouse Hanford Company internal memo, 1994, from J. F. Relyea. "The Drying of Sodium Nickel Ferrocyanide at Constant Relative Humidity." Internal Memo 8H110-HFR-94-054. 


\subsection{Physical Properties of Sludge Simulants for Modeling}

Three simulant materials were used to study the moisture-holding capability of ferrocyanide waste tank sludges. Two simulants, In-Farm and U-Plant, are synthetic reconstructions of actual waste streams, while kaolin clay in a $50 \mathrm{wt} \%$ water mix mimics the physical behavior of sludges. Each of the three simulants constitutes a compressible porous medium of very fine insoluble particles. More than $90 \%$ of the population of particles have diameters less than the clay-size limit of $2 \mu \mathrm{m}$. In this context, the simulants all resemble a wet clay or possibly a clay-water suspension. However, the important nature of electric charges on the simulant particles may not be the same as for clays.

The physical state of these simulants is determined by the moisture or water content, which is the ratio of the water mass divided by the solids mass, usually expressed in percent. In-Farm and U-Plant synthetics also include a substantial amount of salts, mainly sodium nitrate or nitrite, that contribute to making the weight percent of water in the sludge less than what would be indicated by the traditional water content. Because different amounts of water or soluble salts can be lost from sludge by drainage or evaporation, specifying both the water and salt concentrations (weight percents) to characterize a sludge sample at any particular time is necessary.

Table 2.1 provides the initial physical properties of simulants, as generally required to describe the behavior of sludge by modeling. Table 2.1 indicates the high VLC of the sludge simulants relative to kaolin.

Table 2.1. Properties of Simulant Sludges Related to Moisture Content

\begin{tabular}{|c|c|c|c|}
\hline Simulant Property & In-Farm-2(a)(b) & U-Plant $1^{(b)}$ & $\begin{array}{c}\text { Kaolin } \\
50 \% \text { Water }^{(c)}\end{array}$ \\
\hline Specific Gravity for Supernatant & 1.27 & 1.21 & 1 \\
\hline Water Wt\% of Liquid & 61.9 to 73.6 & 71.8 & 50 \\
\hline Specific Gravity for Simulant & 1.39 & 1.265 & 1.444 \\
\hline Water $\mathrm{Wt} \%$ of Sludge & 51 to 52 & 67.5 & 50 \\
\hline Salts Wt \% of Sludge & 31.4 to 18.7 & 26.5 & 0 \\
\hline Solids Wt $\%$ of Sludge & 17.6 to 29.3 & 6.0 & 50 \\
\hline Water Content \% & 290 to 177 & 1125 & 100 \\
\hline Liquid Content Volumetric \% & 90.1 to 77.3 & 98.3 & 72.2 \\
\hline \multicolumn{4}{|c|}{$\begin{array}{l}\text { (a) The second set of values given depends on whether a certain fraction of salts is included with } \\
\text { the solids. mass by assuming that the water fraction of the supernatant is known: } 74 \text { wt } \% \text { water. } \\
\text { (b) The actual composition of In-Farm simulant was measured gravimetrically by Relyea by first } \\
\text { evaporating all water and then washing out soluble salts from the remaining insoluble particles. } \\
\text { The first set of entries for In-Farm and the U-Plant stem from these measurements of simulant } \\
\text { composition. } \\
\text { (c) Values are estimated using a particle specific gravity of } 2.6 \text {. }\end{array}$} \\
\hline
\end{tabular}


The insoluble particle densities were also measured to be $2.8 \mathrm{~g} / \mathrm{cc}$ and $3.3 \mathrm{~g} / \mathrm{cc}$ for In-Farm and U-Plant simulants, respectively. These particle density values combined with percent composition in Table 2.1 imply sludge densities of $1.405 \mathrm{~g} / \mathrm{cc}$ and $1.258 \mathrm{~g} / \mathrm{cc}$ for In-Farm and U-Plant material at VLCs of $91.2 \%$ and $97.7 \%$, respectively. Therefore, U-Plant simulant has a smaller mass of particles and a larger water content than In-Farm.

Void ratio, compression index, and consolidation coefficient are physical properties commonly used to describe the consolidation behavior of deformable materials such as sludge. Table 2.2 lists values for these consolidation-related physical properties. In this modeling work, a reasonable assumption was that all salts were soluble in the liquid component during drainage by consolidation. The presumption is that sludge has a great deal of excess water that would likely dissolve all available salt, and the sludge particles are composed of primarily insoluble precipitated chemicals such as are found in ferrocyanide waste.

Void ratio is the physical variable used in consolidation theory to describe the compression of a deformable porous medium such as the synthetic sludges when subjected to a load. For sludge, it is assumed that the void volume is filled with liquid and the bulk remains saturated with liquid. The compression index, which is the change in void ratio divided by the difference in the logarithm (base 10) of the effective stress causing that change, is a soil mechanical measure of how much a porous medium will be compressed by a load. (It is the slope of the consolidation curve on a semilog scale and is independent of the pressure scale used to express the effective stress.) The void ratio change increases with an increase in compression index for a fixed range of effective stress.

The consolidation coefficient reflects both the compressibility and the rate of flow of liquid from a consolidating porous medium. It is the diffusion coefficient (units of squared length/time) for how rapidly excess pore liquid pressure will be reduced as compression occurs by an applied load. The load may stem entirely from the sludge profile's own self-weight under various boundary conditions, but any overburden on a sludge profile, such as saltcake layers, would also contribute compression stress. The excess pore pressure is that prevailing above the pressure level in the system when final equilibrium is reached and consolidation stops (except for secondary consolidation associated with the long-term rearrangement of sludge particles). Table 2.2 gives parameters for the consolidation behavior of the simulant sludges.

Table 2.2. Consolidation Parameters for Simulant Sludges

\begin{tabular}{|l|c|c|c|}
\hline \multicolumn{1}{|c|}{ Parameter } & In-Farm-2 & U-Plant-1 & $\begin{array}{c}\text { Kaolin } \\
\text { 50\% Water }\end{array}$ \\
\hline \hline Void Ratio Beginning & 3.4 & 57. & 2.6 \\
\hline Compression Index & 0.92 & 17.5 & 0.28 \\
\hline Consolidation Coefficient $\left(\mathrm{cm}^{2} /\right.$ day) & 11.6 & 0.54 & 40 to 100 \\
\hline
\end{tabular}


Data for In-Farm simulant in Table 2.2 derives from centrifugation tests. The consolidation coefficient was obtained by fitting a simplified model of compression to the rate of liquid drainage produced by $500 \mathrm{~g}$ centrifugation of a $2-\mathrm{cm}$-long sample retained by a glass filter disk. For U-Plant, the coefficient was estimated from the rate of liquid expulsion from a Tempe cell with a porous plate to retain the sludge sample and filter the liquid. Air pressure was applied to the sample in the Tempe cell to cause consolidation as supernatant is expelled. The value was estimated for 300 to $500 \mathrm{~cm}$ of water pressure.

For kaolin, the compression index was estimated from a consolidation curve obtained in a study of kaolin and montmorillonite clays (Sridharan and Rao 1973). The value is also obtained by using the reported liquid limit of $49 \%$ in a linear correlation equation given by Das (1979) in his basic textbook on soil mechanics. Liquid limit is the value of water content for which the porous material behaves like a homogeneous fluid when the liquid content is greater. It becomes plastic for lower water content. Below the lower limit of the plastic range (called plastic limit) of $29 \%$, kaolin becomes semisolid; it becomes solid at the shrinkage limit. These water content limits are used to describe the state of a cohesive porous medium and are called Atterberg limits. The consolidation coefficient for kaolin was also found from a correlation with the liquid limit (Das 1979, Figure 6.20, p. 108) based on various clays.

The compression index divided by the initial void ratio is proportional to volume compressibility and provides a better indicator of relative volume change. These values are $0.27,0.31$, and 0.11 for In-Farm, U-Plant, and kaolin, respectively. Kaolin is much less compressible than the synthetic sludges.

The time to achieve a specified degree of relative consolidation is proportional to the square of initial profile height divided by the consolidation coefficient. Thus, consolidation would occur most rapidly for kaolin and least rapidly for U-Plant simulant. A 10-cm-high profile, for example, would consolidate in about one day for kaolin, nine days for In-Farm, and 185 days for U-Plant simulated wastes. Thus U-Plant synthetic sludge would remain wet when drained by consolidation compared with kaolin over the same time frame (modeling drainage caused by consolidation from typical-size tank profiles filled with synthetic sludges is discussed in Section 2.7 and Appendix D).

\subsection{Particle Size Implications}

The synthetic sludges exhibit hydraulic behavior similar to that of clay porous material because the particle size distribution has a similar or even greater fraction of particles with diameters less than the clay fraction limit of $2 \mu \mathrm{m}$. Also, the synthetic sludges appear to be flocculated sediments in the high salt concentration of mainly sodium nitrate. Strong electrical or ionic forces appear to be involved with the interparticle forces. The similarity of the synthetic sludge's montmorillonite clay and compressibility behavior suggests this conclusion. However, specific tests involving introduction of fluids with different dielectric properties have not been performed to support this hypothesis. Sridharan and Rao (1973) demonstrated how consolidation behavior clays such as kaolin and montmorillonite are governed by different interparticle forces. In kaolin, shearing forces at an interparticle scale (mechanical contacts) control compression behavior. Montmorillonite behavior, however, is controlled by longrange, electrically diffuse, double-layer repulsive forces. 
From the observed behavior of synthetic sludges, which seem plastic at the water content levels in Table 2.1, the liquid limits are similar to montmorillonite's limit, about $300 \%$ or higher. Kaolin, however, cannot support as much water and still remain plastic or semisolid. At water contents greater than the liquid limit, the shear stress is less than $2.5 \mathrm{kPa}$ (Das 1979).

Jepson and Wong (1993) report that the median particle diameter for synthetic sludges is about 0.75 to $0.8 \mu \mathrm{m}$. When the synthetic sludges become dry enough to become plastic and act as a porous medium containing liquid, the air entry pressure for displacing fluid from pores with a size approximating particle dimensions would be on the order of hundreds of $\mathrm{kPa}$ : The expression for the void ratio is 2(liquid surface tension)/(pore radius). But shear stress would be about two orders of magnitude less. This is why high-pressure bubbles can be created in the synthetic sludges without displacing fluid from the interstitial space. Bubbles can exist that support many hundred centimeters of sludge overburden without displacing fluid from the particle matrix.

The fact that median particle diameter as measured by volume distribution, differs between In-Farm and U-Plant synthetics suggests that particles are aggregated to different extents. However, the basic particle size is about the same. For bottom fractions, by volume distribution, In-Farm-2 has a median diameter of about $16.4 \mu \mathrm{m}$, whereas U-Plant has $4.0 \mu \mathrm{m}$. Dividing the median diameter based on volume by that based on number distribution gives a measure of how many particles form an aggregate. About 21.6 particles for In-Farm and 5.4 for U-Plant fit in an aggregate. The ratio $21.6 / 5.4$ reflects the relative solid particle mass for the two synthetic sludges. However, the particle density for In-Farm is $2.8 \mathrm{~g} / \mathrm{cc}$ and for U-Plant is $3.3 \mathrm{~g} / \mathrm{cc}$. Thus, the solid particle mass ratio is $(21.6 \times 2.8) /(5.4 \times 3.3)$, or 3.4. By comparison, from Table 2.1, the ratio of solid mass fractions is about 3 . This suggests that a correlation may exist between the relative solid particle mass and the particle diameter by volume distribution in tank sludges. This also suggests why the water content, which is the water to solids mass ratio, is about three times greater for U-Plant - when the variation in the amounts of water and salts in each synthetic is not considered.

\subsection{Consolidation Characteristic Curves}

The consolidation curve is the relationship between void ratio and effective stress in a sludge sample when it has reached a hydrostatic equilibrium. Defining this curve requires determining both quantities simultaneously in the measurement device.

The void ratio can be found from the VLC, as can the percentage of water in both sludge and supernatant. The VLC can be calculated from the fractional mass loss using the densities of the sludge (initial value) and the supernatant. The equation for the void ratio is

$$
(\mathrm{Vi}-\mathrm{W} / \mathrm{G}) /(\mathrm{V}-\mathrm{Vi})
$$

$$
\text { where } \begin{aligned}
\mathrm{Vi} & =\text { initial liquid volume } \\
\mathrm{W} & =\text { mass of supernatant drained } \\
\mathrm{G} & =\text { specific gravity of supernatant } \\
\mathrm{V} & =\text { sludge bulk volume. }
\end{aligned}
$$


Here, the density of reference water is taken as unity in calculating the volume reduction, $W / G$, produced by drainage in each experiment.

Effective stress in the centrifuge and Tempe cell tests is determined in different ways depending on boundary conditions. In both devices, the pressure in the liquid at the outflow porous disk, through which liquid is expelled by increased gravitational force or applied pressure, is at the atmospheric level. At each stage of either increased acceleration due to gravity or applied air pressure, the supernatant is expelled by the excess pressure in the pore liquid, until that pressure returns to hydrostatic equilibrium with the boundary condition. In the centrifuge measurements, the average effective stress acting at the midpoint of the approximately $1-\mathrm{cm}$-long samples is calculated, while taking into account shrinkage of length upon reaching each stage of equilibrium at increased acceleration due to gravity. In the glass tube with a fritted glass filter at the end, the effective stress is caused by the weight of sludge above the midpoint and the additional pull of the liquid weight below the midpoint, with weight determined by the acceleration due to gravity applied by the centrifuge. In the Tempe cell test, the effective stress equals the applied air pressure when equilibrium is reached, with liquid pressure reaching the atmospheric value inside.

Thus, the consolidation curve is simply the relationship between the liquid content of a sample, expressed as a void ratio, and the effective stress acting on the sample when equilibrium is reached.

Stress is expressed in terms of water head, which is the height of a column of water that would exert the pressure at the bottom. Head equals the pressure divided by the weight density of water.

Figure 2.1 shows the consolidation curve calculated for In-Farm-2 simulant from centrifuge measurements at $1 \mathrm{~g}, 10 \mathrm{~g}, 20 \mathrm{~g}, 50 \mathrm{~g}, 100 \mathrm{~g}$, and $2000 \mathrm{~g}$. An analytical curve is fitted through the measured points to estimate values between actual measurements and to make this interpolation possible for modeling.

The solid line in Figure 2.1 represents the actual model consolidation curve used to describe InFarm-2 sludge simulant. Because the consolidation response was taken as a linear function of effective stress head in the range of 1 to $10 \mathrm{~cm}$ of water column height, the line appears curved on the logarithmic scale. This cusped (cuspated) curve expresses the result that the functional character of the consolidation curve is assumed to change abruptly for the convenience of performing calculations. However, the curve is still a continuous description of consolidation behavior overall. An entirely log-linear fit of the data in Figure 2.1 would have constituted a less precise representation of the consolidation curve. But the curve does become linear on the logarithmic scale for values of stress head greater than $100 \mathrm{~cm}$ of water. The model curve indicates that the consolidation behavior could change abruptly in different intervals of applied stress head.

The weight percent water content in an In-Farm-2 sample corresponding to a particular void ratio is given in Figure 2.2. Over a void ratio of 3.4 to nearly 1, In-Farm simulant changed water content from 52 to $34 \mathrm{wt} \%$. These curves will later be related to the water content distributions in a typical tank profile.

Figure 2.3 shows the consolidation curve obtained for U-Plant-1 simulant sludge. Results are presented directly in terms of weight percent water instead of void ratio, using a conversion. The 


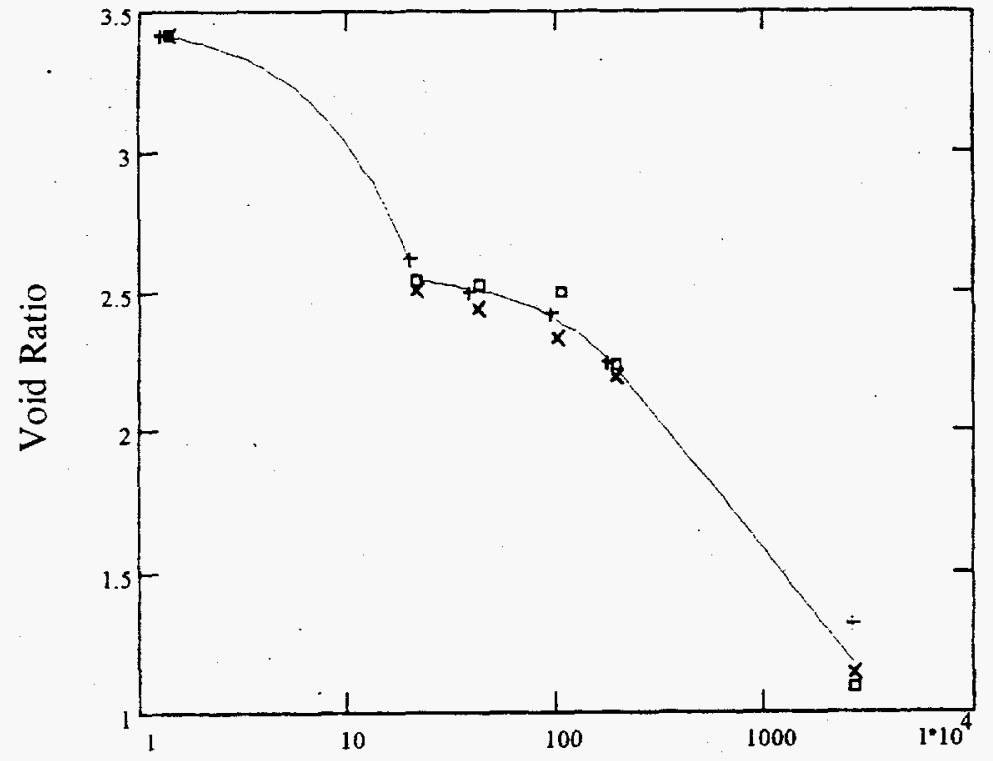

Effective Stress Head ( $\mathrm{cm}$ of water)

Figure 2.1. Consolidation Curve for In-Farm-2 Sludge Based on Centrifuge Measurements. Initial sludge density is $1.39 \mathrm{~g} / \mathrm{mL}$; supernatant specific gravity is 1.27 . Water fractions are $52 \mathrm{wt} \%$ in sludge and $73.6 \mathrm{wt} \%$ in supernatant. Sludge density reaches $1.51 \mathrm{~g} / \mathrm{mL}$ at the minimum void ratio (at $2000 \mathrm{~g}$ ), and samples shrink to about $50 \%$ of starting length. The symbols indicate replicate data points.

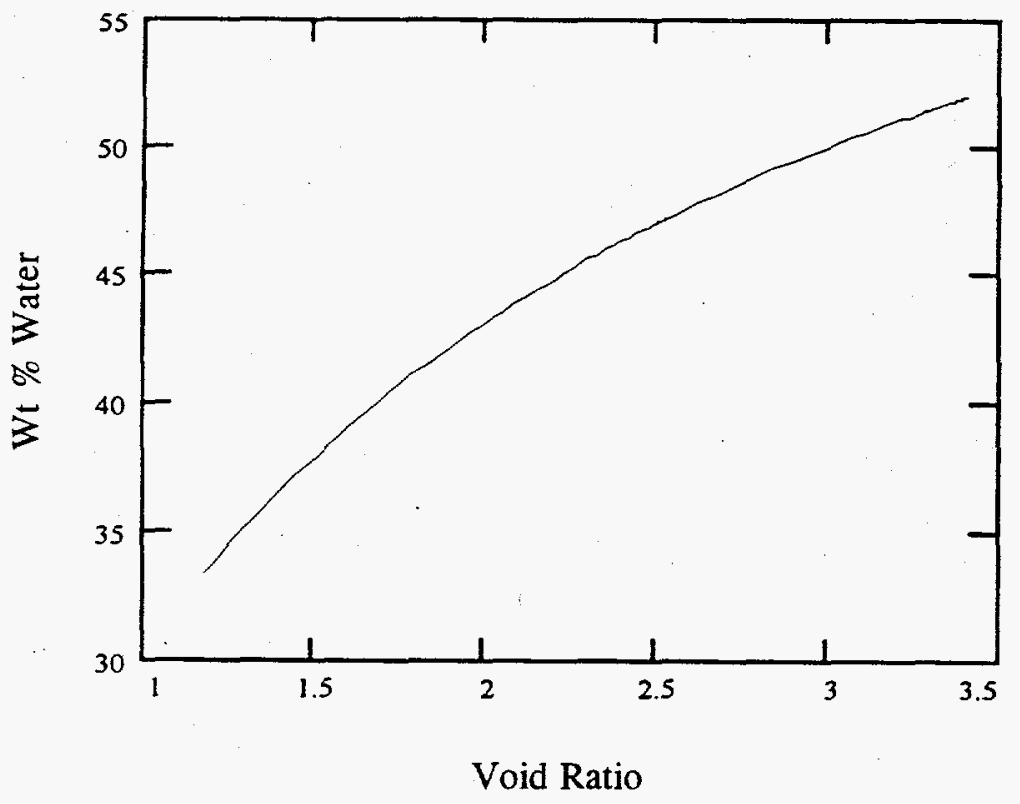

Figure 2.2. Conversion Curve for Translating Void Ratios into Weight Percent Water Content of In-Farm-2 Sludge. Covers range of centrifugation test. 


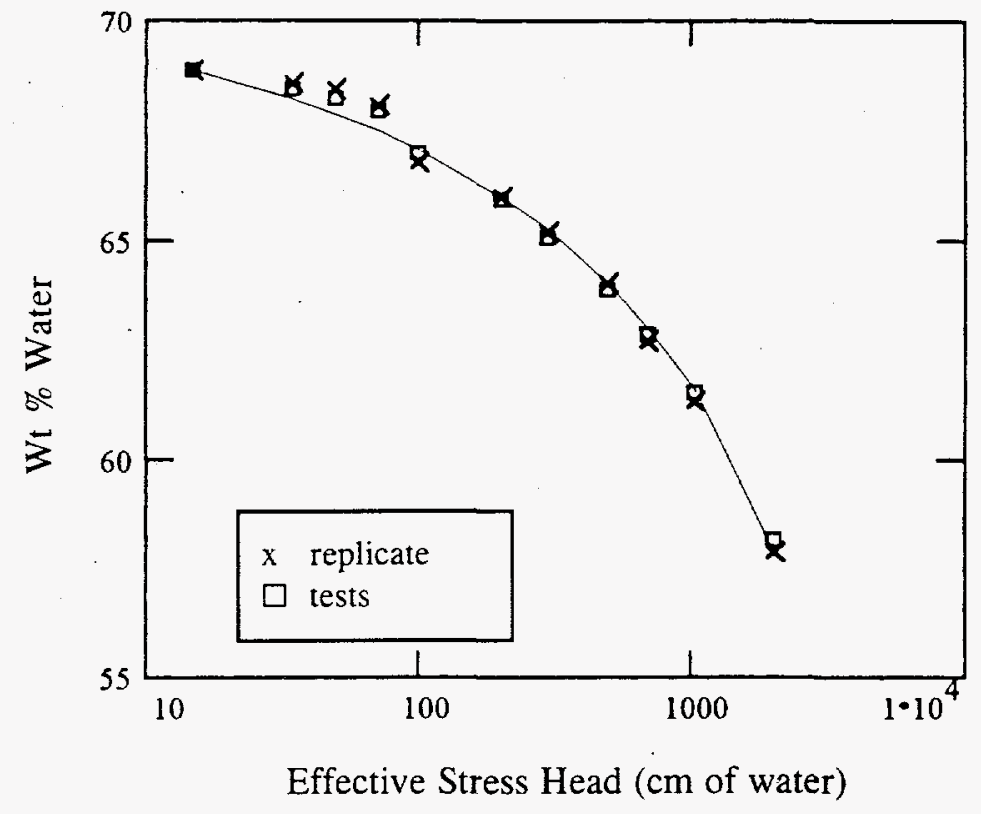

Figure 2.3. Consolidation Curve for U-Plant-1 Sludge Based on Tempe Cell Water Retention Measurements. The measurements were based on an initial $69 \mathrm{wt} \%$ water in sludge and $74 \mathrm{wt} \%$ water in supernatant.

actual curve in terms of void ratio is nearly linear on a logarithmic scale for effective stress head. This means that the consolidation curve is described by a single slope parameter called the compression index. The equation for the compression index is - de/d $\left(\log s^{\prime}\right)$ where $e$ is the void ratio. The curve for In-Farm-2 (Figure 2.1) measured by centrifugation is more complicated and requires more than this single index to represent it.

Effective stress in the two consolidation curves (Figures 2.1 and 2.3) ranges from a few centimeters to more than $2,000 \mathrm{~cm}$. This is a greater range of stress than is expected to occur in a typical tank, so the minimum water contents indicated would not occur in an actual tank profile. However, by using the curves in Figures 2.1 and 2.3, the weight percent water can be found from the calculation of effective stress in the profile.

For the two types of bottom boundary conditions in a tank, closed and open, the effective stress head under final equilibrium is given by the following

$$
\begin{aligned}
& \mathrm{h}^{\prime}=(\mathrm{Gs}-\mathrm{G}) \mathrm{Z} \quad \text { (closed) } \\
& \mathrm{h}^{\prime}=(\mathrm{Gs}-\mathrm{G}) \mathrm{Z}+\mathrm{GL} \quad \text { (open) }
\end{aligned}
$$


where $\mathrm{Gs}=$ bulk sludge specific gravity (final value reached after consolidation)

$\mathrm{G}=$ specific gravity of supernatant

$\mathrm{Z}=$ depth from the surface

$\mathrm{L}=$ height of settling.

The open bottom condition increases the effective stress everywhere in the profile by the term $\mathrm{G} \mathrm{L}$, which may be the dominant term if Gs is only slightly larger than $G$ and the buoyant stress (first term) is relatively small.

For In-Farm-2, the specific gravity for the sludge ranges from 1.39 , initial value, to 1.52 at an effective stress of about $2,600 \mathrm{~cm}(10.21 \mathrm{~cm}=1 \mathrm{kPa})$. The supernatant has $\mathrm{G}$ equal to 1.27 . In a $610-\mathrm{cm}$ (20-ft) -high profile of In-Farm-2 sludge, the maximum $\mathrm{h}^{\prime}$ (closed) would be about $153 \mathrm{~cm}$. With an open bottom, about $775 \mathrm{~cm}$ would be added everywhere. The maximum would be $928 \mathrm{~cm}$, occurring at the bottom, and corresponding to a void ratio of 1.6 with $39 \mathrm{wt} \%$ water. The surface would be less compressed with a void ratio of 1.67 and $40 \mathrm{wt} \%$ water. With a closed bottom, the sludge could consolidate to only a void ratio of 2.3 and $45.5 \mathrm{wt} \%$ water, while the top would remain at $52 \mathrm{wt} \%$ water.

Considerable time would be required to make the transition from the closed bottom to the open bottom equilibrium distribution of water. To calculate the time taken to drain for open conditions requires an estimate of the liquid conductivity and a calculation of the flow rate using Darcy's law; this information is not part of the consolidation characteristic behavior. The small column drainage experiment provides such an initial estimate of liquid conductivity.

\subsection{Small Drainage Column Test}

A small column of In-Farm-2 simulant with an open bottom (sludge retained by screen and a porous filter paper) has drained for nearly two years. Originally, the experiment was set up to determine how dry a sludge sample would become if allowed to drain freely under gravity. The mass of the drained supernatant has been accumulated and measured over time. With this information and the presumption that the sample remains saturated as it consolidates, the average VLC in the column can be calculated as shown in Figure 2.4.

Also shown in Figure 2.4 is the apparent VLC determined as if the sludge did not shrink. This apparent value is based on assuming a fixed sample volume equal to the column volume. The apparent value decreases substantially, indicating drying; however, the actual VLC decreases very little because shrinkage compensates by decreasing the overall bulk volume containing the liquid. The apparent VLC is what would apply to a rigid porous material that does not consolidate.

The apparent VLC still describes the drainage with consolidation because it is proportional to the void ratio, which is the appropriate variable to quantify the process. The ratio of apparent VLC to its initial value, $77.3 \mathrm{vol} \%$, equals the ratio of void ratio to its initial value, 3.41. The range of VLC seen in Figure 2.4 corresponds to a range of $53 \mathrm{wt} \%$ to $49 \mathrm{wt} \%$ water. 


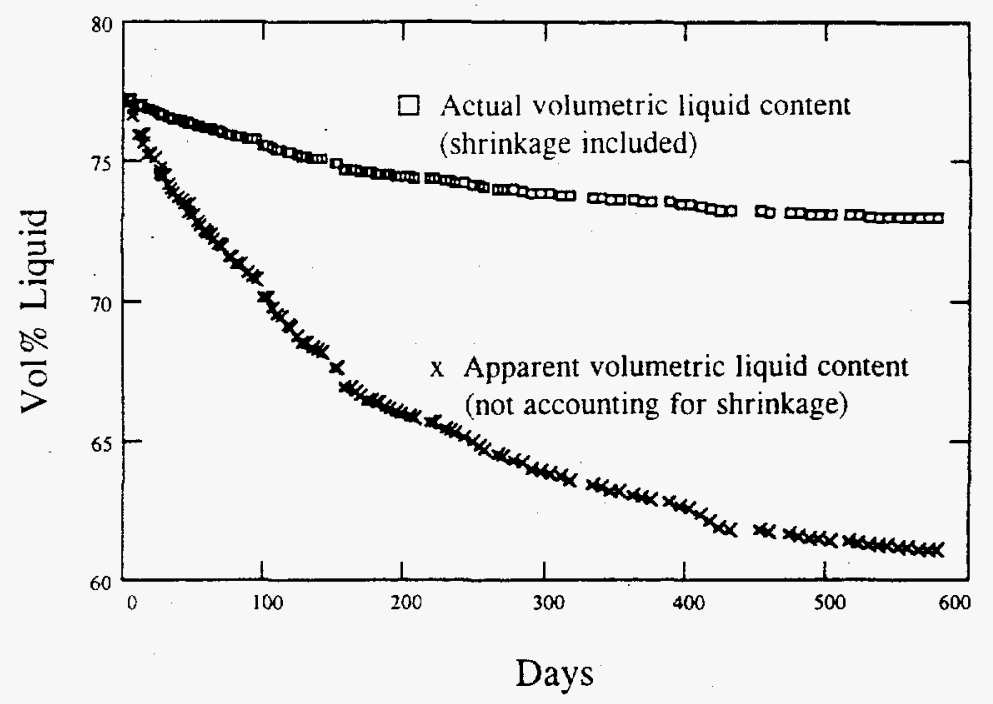

Figure 2.4. Average Volumetric Liquid Content Within the Draining Small Column (8-in. high) of In-Farm-2 Sludge. Symbols are individual measurements based on the liquid weight drained over time. The sludge has gone from $53 \mathrm{wt} \%$ water to $49 \mathrm{wt} \%$.

In Figure 2.4, the apparent VLC appears to approach asymptotically a lower limit of 61 to $60 \mathrm{vol} \%$. By using the consolidation characteristic of Figure 2.1, the average void ratio for attaining equilibrium with an open bottom is about 2.6 , corresponding to $59 \mathrm{vol} \%$, indicating that the drainage is now approaching completion. However, consolidation theory indicates that the drainage could continue forever at diminished rate.

Most importantly, by using the minimum final void ratio, 2.6 , the maximum settling or shrinkage can be estimated. A reduction of length equal to about $3.4 \mathrm{~cm}$ from the initial $18.4-\mathrm{cm}$-high sludge mass is predicted. Recently, the column was opened, and after reconforming the shrunk sludge mass to the column walls, the actual linear shrinkage was measured to be about $3: 8 \mathrm{~cm}$. Given the uncertainty in the initial sludge density, this agreement seems to confirm consolidation as the mechanism for drainage. To further test the theory, a sample of sludge was taken and its water content measured. The surface sample gave a water content of $45 \mathrm{wt} \%$, whereas the trend indicates $48 \mathrm{wt} \%$. Therefore, the surface was thus somewhat drier than predicted - a possible result of long-term evaporation through an open vent port at the column's top.

Three conceptual models have been derived for the drainage based on different assumptions (see Appendixes A and B). These models all imply that the drainage is decreasing exponentially in time when expressed in terms of a degree of consolidation or, equivalently, a relative saturation based on apparent VLC. The time constant for the decrease is about 186 days. That is, the degree of consolidation is $1-S$, where $S$ is the relative saturation represented by the equation $S=\left(e-e_{f}\right) /\left(e_{o}-e_{f}\right)$, where $e$ is void ratio and $e_{f}$ is final void ratio. Thus the equation $\ln (S)=-t / T$, with $T=186$ days, fits the data trend very well. Figure 2.5 displays the model fit to a selected few data points. (The fit is based on all data points, however.) 


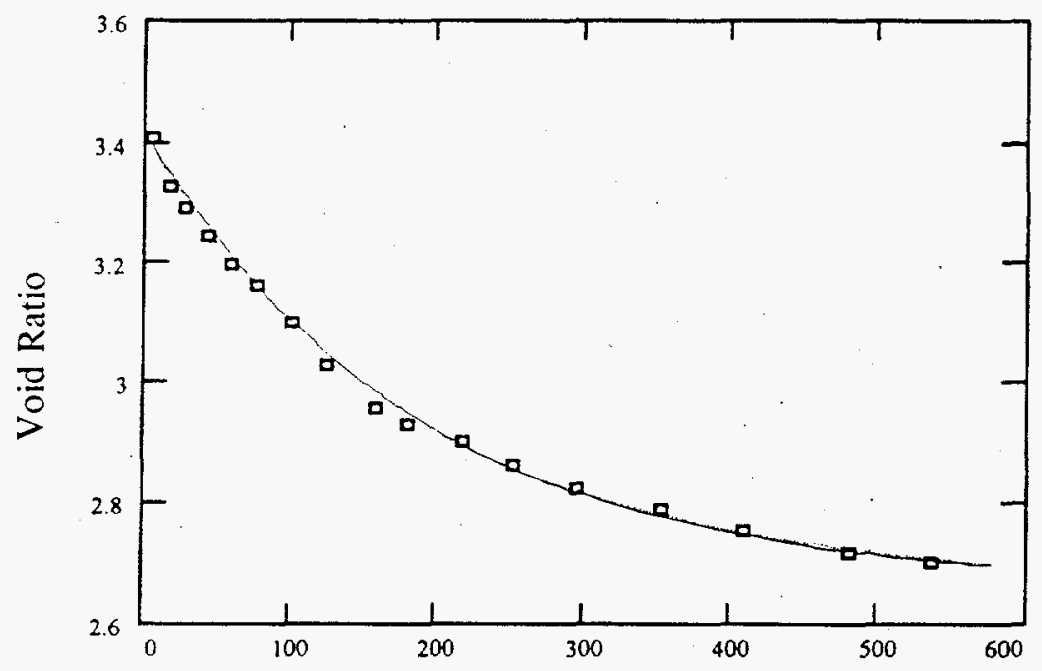

Time (days)

Figure 2.5. Comparison of Suspension Settling (solid line) and Liquid Conduction (dashed line) Models for Drainage from the Small In-Farm-2 Sludge Column. Squares are a subsampled set of the measurements.

One conceptual model for drainage with consolidation is based on suspension settling using a formula for Stoke's particle settling velocity, which is proportional to the density difference between the solid and liquid components multiplied by the squared particle diameter. The equation for the time constant, which is the time required by a particle with Stoke's velocity to traverse 10 times the settled length, is (Appendixes A and B)

$$
\mathrm{T}=10 \mathrm{~L}\left(1+\mathrm{e}_{\mathrm{f}}\right) /\left[\left(1+\mathrm{e}_{\mathrm{o}}\right) \mathrm{Vs}\right]
$$

where $\mathrm{T}=$ time constant

$\mathrm{L}=$ initial column length

$\mathrm{e}_{\mathrm{o}}=$ initial void ratio

$\mathrm{V}_{\mathrm{s}}=$ Stoke's particle settling velocity.

Using an estimate of $2.38 \mathrm{~g} / \mathrm{cc}$ for particle density, $1.27 \mathrm{~g} / \mathrm{cc}$ liquid density, and particle diameter of $0.75 \mu \mathrm{m}$ Epstein et al. (1994) found that the model fit the data nearly perfectly. The particle diameter used is the median determined for In-Farm-2, reported by Jeppson and Wong (1993). A limitation in the model, however, is that the final void ratio attained, $e_{f}$, is not known based on theory; it must be shown in the data as a fitting parameter. 
Another model that can be derived for the time constant is based on the conductivity of sludge and the consolidation curve. This model accounts for the fact that a final equilibrium is eventually reached. Using the consolidation curve, the final void ratio is determined by that equilibrium. In this model, the equation (Appendixes $\mathrm{A}$ or $\mathrm{C}$ ) for $\mathrm{T}$ is

$$
\mathrm{T}=\mathrm{L}^{2} \mathrm{Av} /\left[2 \mathrm{Ko}\left(1+\mathrm{e}_{\mathrm{o}}\right)\right]
$$

where $\mathrm{Av}=$ coefficient of compressibility for a linear segment of the consolidation curve

$\mathrm{Ko}=$ starting conductivity at the initial void ratio

$\mathrm{e}_{\mathrm{o}}=$ initial void ratio.

The sludge conductivity as a function of void ratio is assumed to equal $\mathrm{Ko}(1+\mathrm{e}) /\left(1+\mathrm{e}_{0}\right)$, so that it decreases linearly with the void ratio. A well-known combination of parameters, $\mathrm{Ko}\left(1+\mathrm{e}_{0}\right) / \mathrm{Av}$, called the coefficient of consolidation, appears in the derived equation for the time factor. A traditional variable used in consolidation analysis is $\mathrm{t} / 2 \mathrm{~T}$, called the time factor. For In-Farm-2, Av is $0.044 \mathrm{~cm}^{-1}$ for the effective stress range of 0 to $20 \mathrm{~cm}$, and $\mathrm{Ko}$ is estimated to be $0.009 \mathrm{~cm} /$ day.

The starting conductivity at the initial void ratio is either estimated from the fit to the data, as in Figure 2.5 , or measured directly and independently to confirm the simple model. In any case, the model provides an inverse estimation procedure for finding the starting conductivity.

A third, similar model, based on conductivity and drainage under an assumed constant hydraulic gradient during consolidation, yields a starting conductivity of $0.013 \mathrm{~cm} / \mathrm{day}$, a value not substantially different than that found with the previous models. Appendix B further explains mathematically why the suspension settling and liquid conduction models appear to give an equivalent or indistinguishable description of sludge consolidation. However, Figure 2.5 is meant to show that either explanation of consolidation could be accepted based on the small drainage column experiment.

\subsection{Verification of Drainage Model by Centrifugation Test}

The exponential drainage model fits the trend well over a substantial period of two years. However, in the small column experiment, the change in void ratio or water content was not as large as might occur in a much larger system involving greater effective stress. To verify the model further, a special centrifugation test was run using In-Farm-2 simulant sludge. The sample was taken from the small column after being subjected to drainage for two years. It began with about $45 \mathrm{wt} \%$ water.

Previous centrifugation had attempted to measure the consolidation curve by determining when equilibrium was achieved. In this experiment, however, the objective was to frequently measure the supernatant expelled with time. In this way, the drainage curve could be obtained using a small sample.

Two replicates were subjected to $500 \mathrm{~g}$, which produced about $900 \mathrm{~cm}$ of effective stress head in the samples. Figure 2.6 shows the calculated weight percent water in the samples. The samples were 


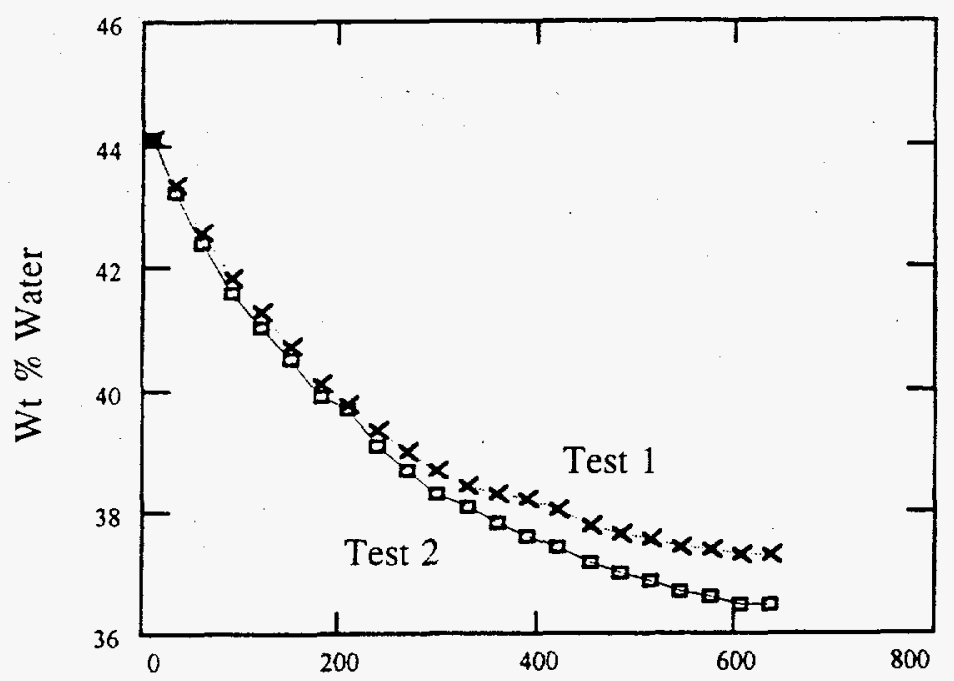

Time (min)

Figure 2.6. Water in the In-Farm-2 Sample Taken from Small Column After 60 Days Drainage and Subjected to $500 \mathrm{~g}$ Centrifugation. Two replicate tests are shown. Sample measured $45 \mathrm{wt} \%$ water at the column's surface.

driven to about $37 \mathrm{wt} \%$ water in only 10 hours. The lowest points with void ratios of 1.33 and 1.39 fell near the consolidation curve in Figure 2.1, even though this test was on a different sample of InFarm-2 simulant sludge.

Figure 2.7 demonstrates that the exponential model again fits the drainage curve over this greater range, with a time constant between 0.12 day and 0.13 day. The model's validity or invariance could be tested by checking whether the Stoke's settling velocity would be scaled (multiplied) by the increased (unit)g. It was found that the time constant based on the same densities and particle size for the small column experiment at one gravity would be about one-fifth of that measured (5.3 times too small).

A geotechnical calculation of the particle specific gravity, $\mathrm{Gp}$, is related to the initial bulk sludge specific gravity, $\mathrm{Gs}_{0}$, by the following formula:

$$
G p=G s_{o}\left(1+e_{o}\right)-G e_{o}
$$

Then, the changing sludge specific gravity over the entire range of void ratio is given by

$$
\mathrm{Gs}=(\mathrm{Gp}+\mathrm{Ge}) /(1+\mathrm{e})
$$

The particle specific gravity found to apply was 1.72 at $500 \mathrm{~g}$. On the other hand, the particle specific gravity of 1.8 applied to the $1 \mathrm{~g}$ drainage in the column. Thus, this apparent particle density did not 


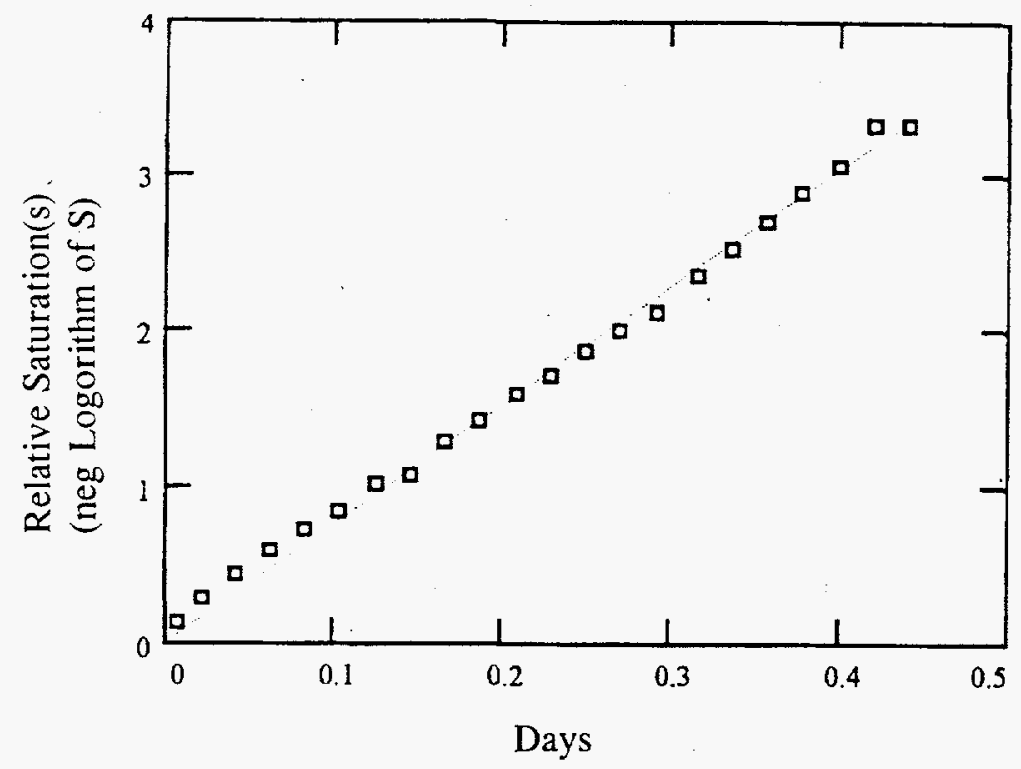

Figure 2.7. Fit of Exponential Liquid Drainage Model to Sample Subjected to 500g Centrifugation. Time constant is the reciprocal slope of the line and equals 0.132 day. Time constant of replicate (not shown) is 0.12 day. Maximum volumetric solid fractions are 0.435 and 0.422 , respectively, after beginning with 0.32 .

vary much over the consolidation range studied for the In-Farm- 2 simulant sludge. The particle specific gravity found is much less than the pycnometer-determined value of 2.38 found for the settling model. Also, the particle density of $2.38 \mathrm{~g} / \mathrm{cc}$ is believed to have been determined on a dried sample still containing the supernatant salts. Thus, this density may not represent the actual sludge particles but part of the salt fraction as well. During consolidation, the specific gravity of the sludge changed from 1.41 to 1.46 , while the void ratio went from 2.13 to 1.36 (replicate average).

Using this apparent particle density, $1.72 \mathrm{~g} / \mathrm{cc}$, and a particle diameter of $0.51 \mu \mathrm{m}$ produced the correct time constant for $500 \mathrm{~g}$. Clearly, this geotechnical estimate of particle density that is consistent with the calculated void ratio and supernatant specific gravity (containing all sludge salts) is generally smaller than the true sludge particle solid density. This density appears to represent particles assembled into aggregates (flocs) with greater occupied volume when in the presence of the supernatant than the particles dried with the supernatant salts removed.

The drainage model that relates the time constant to the Stoke's velocity has promise as a predictive tool provided the final asymptotic void ratio is estimated using the measured characteristic curve and the calculated effective stress. By equating this model's time constant with the one defined by the conduction model, a method is found that could relate the macroscopic conductivity to particle size and density. However, a better rationale for selecting those physical parameters from independent measurements is needed before such a method can be proven. 


\subsection{Equilibrium Water Content in an Example Tank Profile}

The models of drainage discussed previously are approximations for judging the flow in relatively small systems. The variation of moisture and supernatant flow in the profile are not accounted for in these simplifications; only the average of spatially distributed water content has been considered. Such models are meant to help determine the constitutive equations, which are effective stress versus void ratio and conductivity versus void ratio, that are required to apply a general flow equation incorporating consolidation. The prediction of dynamic changes in a consolidating sludge profile is a particularly difficult problem in view of the nonlinear response of the shrinkage to the acting effective stress, especially with heterogenous material in the form of sludge layers.

However, fortunately, the equilibrium distribution of the water content in a deformable porous medium can be calculated exactly provided the consolidation curve has been measured. Equations can be formulated for both closed and open bottom boundary conditions (see Appendix D). The derivation uses the relationship between total solid mass to a particular depth and the effective stress head acting there. The effective stress head satisfies the equation

$$
\mathrm{h}^{\prime}=(\mathrm{Gp}-\mathrm{G}) \mathrm{m}+\mathrm{h}^{\prime} \mathrm{o}
$$

where $\mathrm{m}$ is the material coordinate, defined as the integral of the volumetric solid fraction, $1 /(1+\mathrm{e})$, from the surface to a particular depth $Z$. For a closed bottom, h'o is the overburden load, and for open bottom, h'o includes the extra effective stress of the liquid column, $G \cdot L$, where $L$ is the unknown profile depth, which will depend on the final equilibrium. The total solid mass storage over the profile, mo, is known and is a constant. The total liquid storage, So, over the profile of depth $\mathrm{L}$ satisfies

$$
\text { So }+ \text { mo }=\mathrm{L}
$$

However, the liquid storage is also the integral of the void ratio as a function of the effective stress head, $e\left(h^{\prime}\right)=e\left[(G p-G) m+h^{\prime} o\right]$, with respect to the material coordinate over its entire range, which is from zero to the total solid mass storage over the profile. These relationships determine the unknown profile depth. In general, the liquid storage, $S_{z}$, to any depth $Z$, satisfies the equation

$$
S_{z}+m=Z
$$

(Note: S has a different definition in Appendix D than in Appendixes A or B.) These implicit relationships are then solved for the void ratio distribution $\mathrm{e}(\mathrm{z})$ depending on depth $\mathrm{z}$.

Figure 2.8 demonstrates this calculation for a typical size tank filled with In-Farm-2 simulant sludge. A hypothetical change of boundary conditions is described in this figure, which describes how the hypothetical moisture distribution would appear under the boundary condition of first a closed bottom and then an open bottom in which liquid would escape the waste profile. The consolidation curve in Figure 2.1 is used to calculate the void ratio distribution in the profile. In Figure 2.8, the liquid filled void ratio was converted to weight percent water using the percent water in both sludge and supernatant. In consolidating from the uniform profile to that with a new distribution in balance with the self-weight stress held up by a closed bottom, liquid would be expelled upward. That is, liquid would flow upward relative to the settling solid mass. 


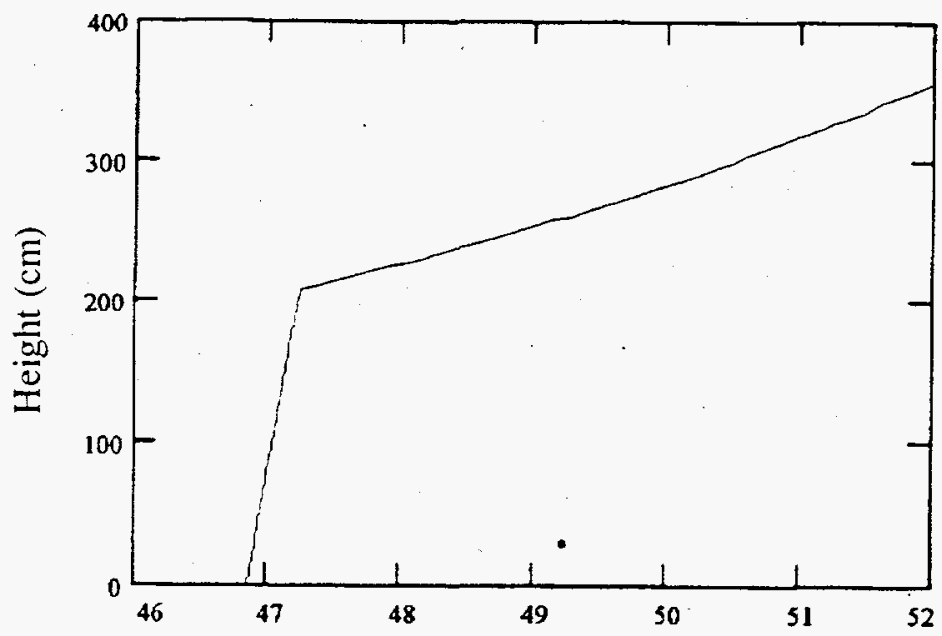

Percent Water Weight

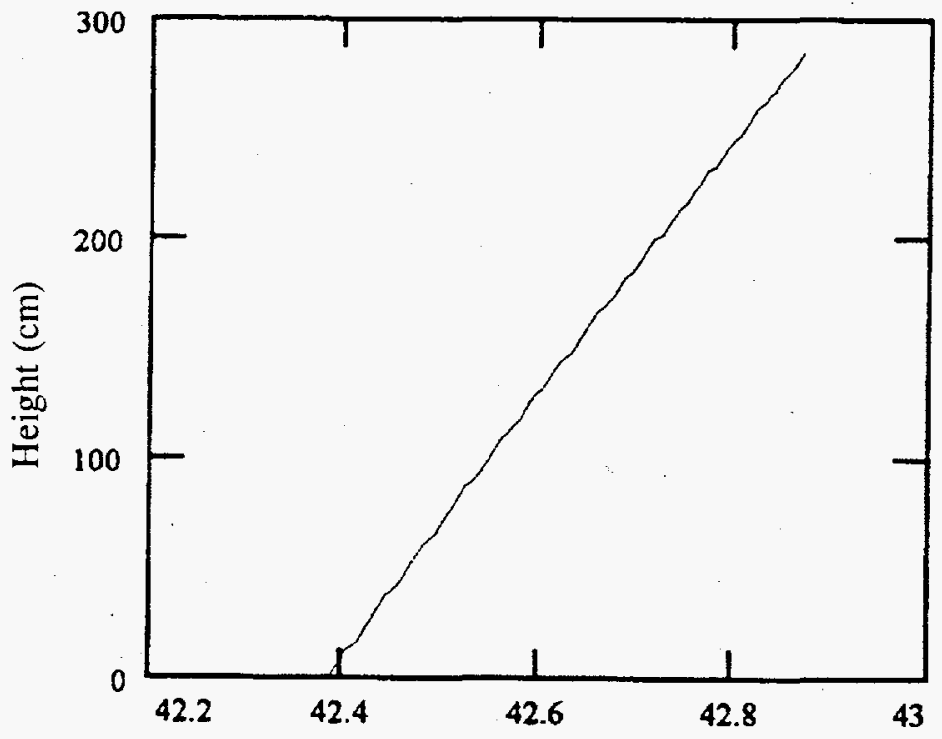

Percent Water Weight

Figure 2.8. Distributions of Weight Percent Water Content in an In-Farm-2 Sludge Profile Initially $426 \mathrm{~cm}$ (14 ft) High at Hydrostatic Equilibrium Conditions with Closed and Open Bottom. Sludge has $52 \mathrm{wt} \%$ water initially. With closed bottom, the profile settles to height $356 \mathrm{~cm}$ (16\% strain). With open bottom, profile further settles to $285 \mathrm{~cm}$ (further $20 \%$ strain). For tank with 75 -ft diameter, profile expels about $75 \mathrm{kgal}$ supernatant when settled on closed bottom. Another $78 \mathrm{kgal}$ would drain in shrinkage to open-bottom conditions. 
For the closed bottom, the weight percent water keeps the initial value at the top, and consolidation is greatest at the bottom. About $75 \mathrm{kgal}$ of supernatant would be expelled above the settled solids surface. Because the consolidation process is highly irreversible, pumping off the standing liquid would not affect the void ratio distribution after equilibrium is established. The sludge profile would settle from $426 \mathrm{~cm}$ to $356 \mathrm{~cm}$, constituting a $16 \%$ shrinkage.

If the bottom was then opened to allow liquid to flow out, the excess pore-pressure would reduce, and the sludge would consolidate further as effective stress increased. The excess pore-liquid pressure prevailing from the closed bottom relative to the open condition would reduce until a new hydrostatic pressure distribution was reached for the open boundary condition. In going from the closed to the open condition, another $78 \mathrm{kgal}$ would drain. The profile would settle further to $285 \mathrm{~cm}$, constituting another $20 \%$ shrinkage.

At equilibrium with an open bottom, the profile water content distribution becomes relatively uniform, but the greater consolidation still occurs at the bottom, where effective stress is greatest. The final average VLC would be $66 \%$ after beginning with $77 \%$. Average sludge specific gravity would increase to 1.45 from its initial 1.39 .

The major limitation of these calculations is that the rate of approach to the final equilibrium distribution is not estimated. Flow modeling would be required with the liquid conductivity estimated as a function of changing void ratio.

\subsection{Drainable Liquid}

The amount of liquid that could drain by consolidation from a breached tank profile is given in Tables 2.3 and 2.4 for the two simulants, In-Farm-2 and U-Plant-1. A tank at the Hanford Site has a 75 -ft diameter. The amount expelled up is determined by equilibrium with a closed bottom, beginning with a uniform distribution of sludge density. The amount drainable in going from closed bottom to open-bottom conditions is given by the drainable liquid. Settling is the percent fraction of the given initial profile depth. Final dryness is given in the last table entry.

The rate at which consolidation can occur is described in Table 2.5. Degree of consolidation is the ratio

$$
\left(e_{o}-e\right) /\left(e_{o}-e_{f}\right)
$$

where $\begin{aligned} \mathrm{e} & =\text { present value of the void ratio } \\ \mathrm{e}_{\mathrm{o}} & =\text { initial void ratio } \\ \mathrm{e}_{\mathrm{f}} & =\text { final void ratio. }\end{aligned}$


Table 2.3. Water Quantity Expelled or Drained Under Closed and Open Bottom for Equilibrium Conditions with In-Farm-2 Simulant Sludge (initial moisture 52 wt \%)

\begin{tabular}{|c|c|c|c|c|}
\hline $\begin{array}{c}\text { Initial Sludge } \\
\text { Depth } \\
(\mathrm{cm})\end{array}$ & $\begin{array}{c}\text { Closed Bottom } \\
\text { Expelled Up } \\
(\mathrm{kgal})\end{array}$ & $\begin{array}{c}\text { Open Bottom } \\
\text { Drainable } \\
\text { (kgal) }\end{array}$ & $\begin{array}{c}\text { Settling } \\
(\%)\end{array}$ & $\begin{array}{c}\text { Surface Dryness } \\
\text { (wt \% water) }\end{array}$ \\
\hline \hline 60 & 2.3 & 11.7 & 21.6 & 46.7 \\
\hline 80 & 4.2 & 15.3 & 22.4 & 46.5 \\
\hline 120 & 9.3 & 22 & 24.0 & 46.0 \\
\hline 270 & 41 & 46 & 29.5 & 44.3 \\
\hline 340 & 56 & 60 & 31.3 & 43.6 \\
\hline 440 & 79 & 81 & 42.8 & 42.8 \\
\hline
\end{tabular}

Table 2.4. Water Quantity Expelled or Drained Under Closed and Open Bottom for Equilibrium Conditions with U-Plant-1 Simulant Sludge (initial moisture $67.7 \mathrm{wt} \%$ )

\begin{tabular}{|c|c|c|c|c|}
\hline $\begin{array}{c}\text { Initial Sludge } \\
\text { Depth } \\
(\mathrm{cm})\end{array}$ & $\begin{array}{c}\text { Closed Bottom } \\
\text { Expelled Up } \\
(\mathrm{kgal})\end{array}$ & $\begin{array}{c}\text { Open Bottom } \\
\text { Drainable } \\
(\mathrm{kgal})\end{array}$ & $\begin{array}{c}\text { Settling } \\
(\%)\end{array}$ & $\begin{array}{c}\text { Surface Dryness } \\
\text { (wt \% water) }\end{array}$ \\
\hline \hline 60 & 0.4 & 17 & 26.6 & 66.1 \\
\hline 80 & 0.8 & 25 & 29.7 & 65.9 \\
\hline 120 & 2.2 & 42 & 34.1 & 65.5 \\
\hline 270 & 13.6 & 112 & 42.8 & 64.7 \\
\hline 340 & 22.4 & 145 & 45.3 & 64.4 \\
\hline 440 & 38.3 & 191 & 48.0 & 64.1 \\
\hline
\end{tabular}

Table 2.5. Time (Years) for Consolidation of In-Farm-2 Sludge Profile (consolidation changes from closed to open bottom conditions)

\begin{tabular}{|c|c|c|c|c||}
\hline \multirow{2}{*}{$\begin{array}{c}\text { Sludge Depth } \\
(\mathrm{cm})\end{array}$} & \multicolumn{2}{|c|}{ Years to Reach Degree of Consolidation } & \multirow{2}{*}{ Final Wt\% Water } \\
\cline { 2 - 5 } & $25 \%$ & $50 \%$ & $95 \%$ & 47.5 \\
\hline 18 & 0.07 & 0.28 & 1.6 & 47.0 \\
\hline 60 & 0.03 & 0.13 & 0.74 & 46.8 \\
\hline 80 & 0.06 & 0.24 & 1.4 & 46.3 \\
\hline 120 & 0.14 & 0.55 & 3.2 & 44.6 \\
\hline 270 & 0.7 & 2.8 & 16. & 44.0 \\
\hline 340 & 1.0 & 3.8 & 22. & 43.7 \\
\hline 440 & 1.5 & 6.1 & 35. & \\
\hline
\end{tabular}


The 18-cm-high profile reflects the small experimental drainage column. Calculations are based on the consolidation coefficient, which derives from estimates of supernatant conductivity and the compression index for the sludge. Degree of consolidation is a function of a dimensionless time factor (Tv):

$$
\mathrm{TV}=\mathrm{t} \cdot \mathrm{CV} / \mathrm{L}^{2}
$$

where $\mathrm{t}=$ time

$\mathrm{Cv}=$ coefficient of consolidation

$\mathrm{L}=$ profile depth.

The coefficient of consolidation equals

$$
\left(1+e_{0}\right) \mathrm{K} / \mathrm{Av}
$$

where $\quad \mathrm{K}=$ supernatant conductivity

$\mathrm{Av} /\left(1+\mathrm{e}_{\mathrm{o}}\right)=$ coefficient of volume compressibility.

Compressibility is found from the consolidation curve in terms of a compression index, $\mathrm{Cc}$, which is the change in void ratio divided by the difference in the logarithm of effective stress head causing the change. The compression index is the slope of the consolidation curve with a semilog scale for effective stress head. Av equals $\mathrm{Cc} /\left(2.303 \mathrm{~h}^{\prime}\right)$ where $\mathrm{h}^{\prime}$ is a maximum effective stress head for the size of profile and the density of the sludge.

The degree of consolidation as a function of the time factor, Tv, for the particular boundary conditions is determined by the Terzaghi theory (Das 1983). The Terzaghi theory describes how the excess pore liquid pressure in the medium diminishes as consolidation takes place. As excess pore pressure decreases during consolidation, the effective stress head (net pressure between particles) increases as the self-weight load is transferred onto the contacts between particles. This transfer of load squeezes particles closer together and causes consolidation, or reduction in void ratio of the compressible medium. Changing the boundary conditions from closed to open bottom starts reducing the pore liquid pressure to reach a new final equilibrium distribution for which drainage flow stops.

\subsection{Conclusions}

Several conclusions can be drawn from the studies discussed in this section. An important observation is that simulant sludges drain by consolidation while remaining liquid-saturated. The point at which simulants become desaturated has not yet been discovered in the tests described here. Consolidation profiles show the greatest liquid loss at the bottom and the least at the surface. Therefore, the drainage behavior in sludge is the opposite of that exhibited by a rigid porous medium such as sand or saltcake. The sludge simulants have the ability to retain high water contents even though substantial amounts can be drained by gravity. Direct measurement of the consolidation characteristic is essential to predict the water retention capability of sludge. Sludge simulants cannot drain naturally any more than is allowed by the final equilibrium distribution of the void ratio as determined by the specific 
consolidation characteristic curve and the applicable boundary condition. Centrifugation is perhaps the fastest and most efficient way to test the hydraulic properties of simulant sludges with only a small sample. Centrifugation also allows for testing over a greater range of effective stresses in the least time. 


\subsection{Drying of Ferrocyanide Sludge Simulants}

\subsection{Background}

Westinghouse Hanford Company performed two simulant drying experiments to acquire the necessary measurements of how rapidly sludges can dry out. These were small-scale tests of moisture evaporation whose objective was to establish basic parameters from which the information could be extrapolated to the scale of a waste tank system. This work was performed to help determine relevant parameters that could be used to estimate drying behavior in an actual tank system.

Tank wastes likely dry out at the surface at a rate proportional to the RH difference between the sludge and the tank air space. If the RH in the tank air space dropped when in equilibrium with wet sludge, possibly as a result of air exchange with the outside atmosphere, then the sludge surface could dry out.

Drying depends on the rate of heat conduction to the moisture evaporating surface and the amount of heat available to vaporize water. On the other hand, the drying rate is limited by how rapidly moisture can flow to the surface, as a consequence of hydraulic gradients acting within the sludge. Permeability of the sludge is also a factor in determining how rapidly moisture can replenish a drying surface.

Consolidation behavior and drying are related processes for simulant sludges, because evaporation causes shrinkage in volume. Shrinkage is associated with an increase of internal effective stress and a reduction in liquid pore pressure, which causes liquid flow toward the surface. An analytical understanding of the coupling between evaporation and shrinkage is required to model the retention of moisture in a tank sludge.

Sludge simulants also contain substantial amounts of nitrate salts, which lower the moisture equilibrium vapor pressure and influence the drying rate. These high salt concentrations bring about a different change in sludge than is caused by consolidation. During drying, the salt remains and precipitates from solution. However, consolidation caused by gravity drainage or mechanical compression removes both salt in solution and water. During consolidation, the supernatant salt concentration remains about the same, but drying increases salt concentration until precipitation occurs, which increases the mass of insoluble solid material. Because of this conceptual difference in drying and drainage, the moisture content of sludge is not conveniently expressed in terms of the state variable, void ratio, as used to describe consolidation. Instead, moisture content is expressed on a dry-weight basis, as the percentage of water mass relative to the combined salts and solids mass.

To gain a quantitative understanding of sludge moisture evaporation, drying experiments on sludge were recently analyzed. Section 3.2 discusses the evaporation studies, Section 3.3 describes the evaporation modeling, and Section 3.4 discusses the liquid diffusion in the drying of simulants. 


\subsection{Evaporation Studies}

Two experiments were completed by King (1994) and Relyea ${ }^{(a)}$ of Westinghouse Hanford Company to test the hypothesis that the rate of drying is proportional to the difference in RH between the sludge surface and the air above. A preliminary analysis of these important experiments is provided in this section.

\subsubsection{Drying Rate Test}

King (1994) exposed samples of In-Farm-1, U-Plant-1, and Tank BY-104 saltcake simulants to a $30 \%$ constant $\mathrm{RH}$ at $25^{\circ} \mathrm{C}$. A standard saturated solution of sodium nitrate was also subjected to drying. Samples were contained in 5.6-cm-deep bottles with an open top exposed to a low RH. The moisture loss with time was measured over 4,500 hours. Figure 3.1a displays the loss for 3,000 hours. The points shown are an interpolated subset of the original data, which are more numerous and closely spaced. The samples dried out with a continuously decreasing amount of contained water. Both InFarm-1 and U-Plant-1 dried to contain less than $10 \%$ of the initially available water in 3,000 hours. The sodium nitrate standard completely dried out in a shorter period of time, whereas the Tank BY-104 saltcake simulant still retained $80 \%$ of the available water, although it contained only about 8.8 wt $\%$ initially. In contrast to saltcake, the In-Farm and U-Plant sludge samples were reported to contain initially $43 \mathrm{wt} \%$ and $51 \mathrm{wt} \%$ moisture, respectively. The final moisture was $3.7 \mathrm{wt} \%$ for In-Farm-1; U-Plant-1 dried out entirely. Tank BY-104 saltcake simulant still contained about 7 wt \% water after 4,500 hours.

To find the weight percent water in simulants as drying occurs, a conversion from percent loss of available water is provided in Figure $3.1 \mathrm{~b}$ (see also Appendix E).

This experiment demonstrated that the surface of these sludge simulants is vulnerable to substantial evaporative drying to the $5.6-\mathrm{cm}$ depth over about 125 days. In contrast, considerable mechanical pressure, up to many atmospheres, would be required to consolidate (compress) sludge to the observed dryness. Thus, evaporation is much more effective in removing water from sludge than consolidation by gravity drainage. Thus, we can conclude that evaporative drying is much more of a potential hazard to ferrocyanide waste than is gravitational drainage for reducing the moisture content of the sludge, especially at the surface.

The evaporative flux for this experiment was computed and found to be consistent with diffusion of water out of the samples. Figure 3.2 demonstrates the rate of drying in the various samples. The flux generally decreases smoothly by about an order of magnitude for sodium nitrate and U-Plant simulant as the drying advanced into the sample bottle or as the contained moisture declined. The evaporative flux for In-Farm simulant did not decrease as much as for the others. The plots in Figure 3.2 indicate, generally, the expected behavior that evaporative flux becomes less as the amount of available moisture becomes less. A slight increase of evaporative flux for sodium nitrate is likely a computional inaccuracy in determining the rate from the drying data in Figure 3.1a. Instead, the drying rate of

(a) Reylea, J. F. 1994. “The Drying of Sodium Nickel Ferrocyanide at Constant Relative Humidity." Internal Memo 8H110-HFR-94-054, Westinghouse Hanford Company, Richland, Washington. 


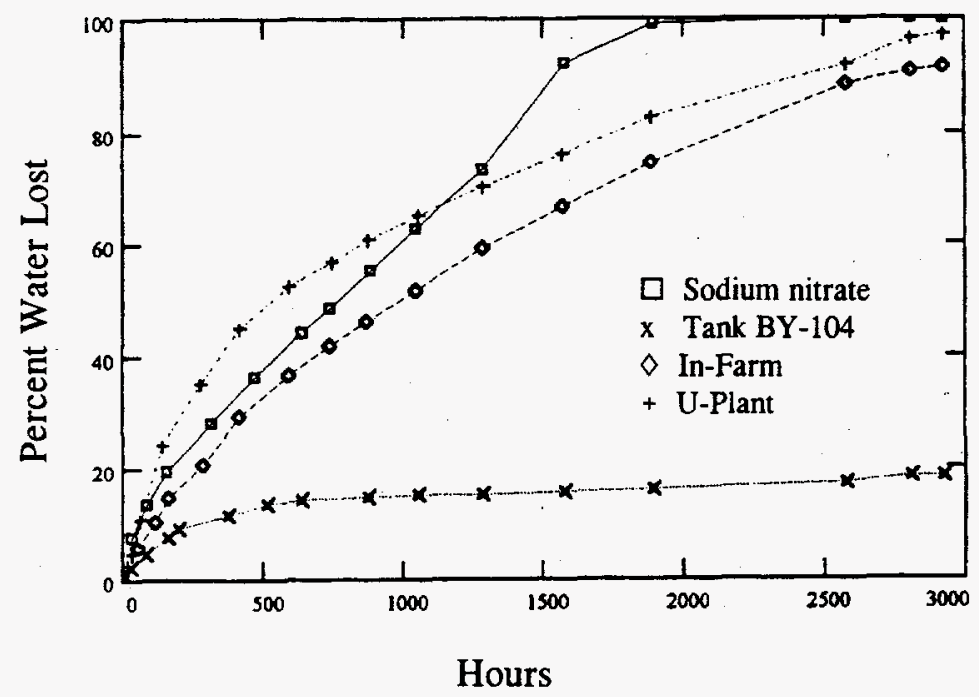

Figure 3.1a. Percent Loss of Water in Sludge Simulant and Saltcake Samples in 5.6-cm-deep Bottles Exposed to $30 \%$ Relative Humidity at $25^{\circ} \mathrm{C}$ (King 1994)

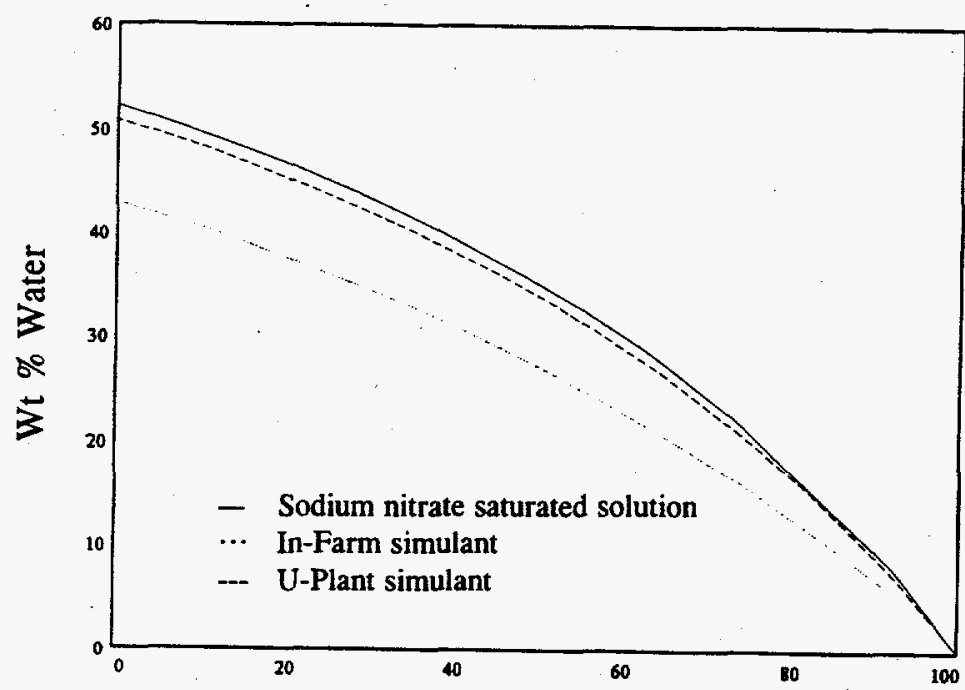

Percent Loss Available Water

Figure 3.1b. Conversion of Percent Water Loss to Weight Percent in Samples (King 1994) 


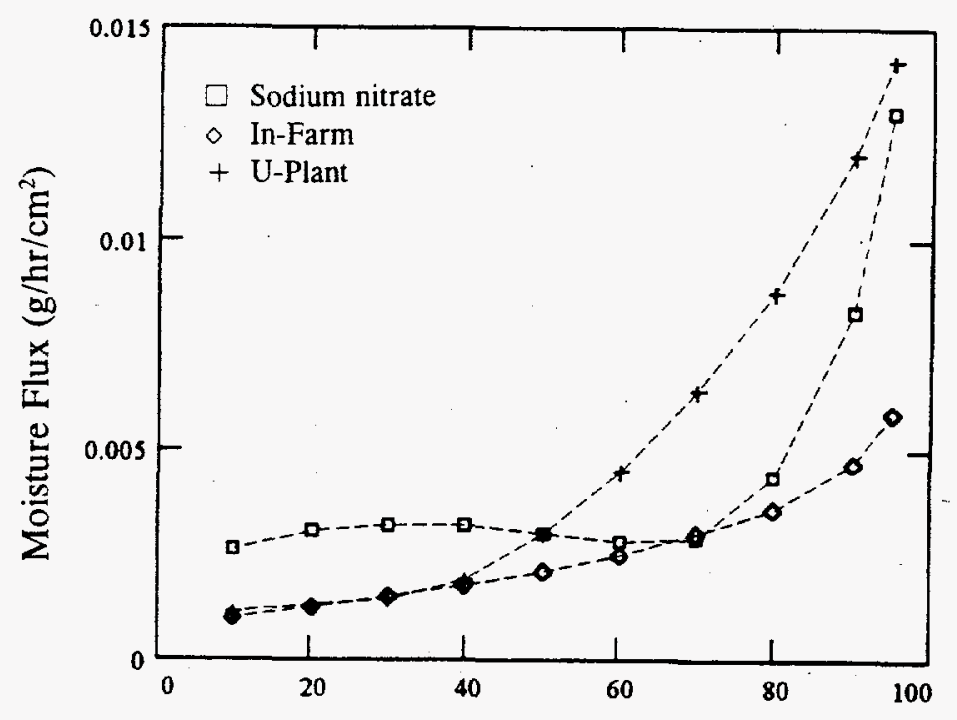

Available Moisture (\%)

Figure 3.2. Evaporative Moisture Flux for Saltcake and Sludge Simulants Exposed to $30 \%$ Relative Humidity

sodium nitrate is more likely approximately constant for available moisture less than $70 \%$. A reason is not know for why the evaporative fluxes are different for the particular simulants. The drying process was also influenced by the movement and precipitation of high salt concentrations in the supernatant. However, no attempt was made in this preliminary study to distinguish the moisture movement and the induced salt movement. They are treated as a composite process.

Because evaporation removes only the water component of the sludge simulant, expressing moisture content in terms of the percentage that could be initially available for evaporation is useful. Given the percentage of remaining available moisture, and the initial weight percent of water for a sample, finding the present weight percent of water in a sample is easy (see Appendix E). The small sample bottles holding the simulants were kept in sealed, controlled relative humidity chambers containing a saturated solution of calcium chloride to maintain a fixed humidity. Details of the test design are described by King (1994).

Figure 3.2 shows that the rate of evaporation from the surface of the saturated solution of sodium nitrate becomes nearly constant after the time required to lose about $20 \%$ of the available water (see Figure 3.1). Apparently, a substantial time was needed to reach an evaporative rate equilibrium in the controlled humidity chamber. However, the sludges display a continuously decreasing moisture flux, in contrast to the sodium nitrate solution. Apparently, the drying sludge surface impedes the evaporation rate.

For U-Plant simulant, the flux is greater than that for the saturated sodium nitrate solution for a time, probably because the concentration of sodium nitrate salt in this simulant remains below saturation. In contrast, the salt concentration in the In-Farm simulant is higher, and the moisture flux is less 
than in the saturated solution standard. The evaporative flux from sludge is also limited in an unknown way by the permeability and how rapidly liquid is able to conduct upward through the sample bottle.

Overall, as expected, the saturated sodium nitrate solution that initially filled the bottle was dried to the same degree (about $90 \%$ moisture loss) as the sludge samples, in about half the time, or 1,500 hours. Clearly the sludge impedes the evaporation process when the available moisture falls below about $50 \%$. However, In-Farm simulant always evaporated the slowest.

In this experiment the samples could eventually become entirely dry, because the RH sink is lower, at $30 \%$, than the level that could be maintained at equilibrium with the sludge retaining some water. Another experiment was devised to measure the extent of dryness when sludge was exposed to less severe drying conditions and is described in the next section.

\subsubsection{Relative Humidity Measurements}

Relyea measured the RH isotherms for In-Farm-1 and U-Plant-1 simulants, including the wetting isotherm in a Westinghouse Hanford Company internal report. ${ }^{(2)}$ Isotherms at constant temperatures were obtained by measuring the equilibrium RH over samples dried to various water contents. These curves represent what would be the RH in air, at equilibrium, over a sludge sample containing a certain fraction of the initially available water. These measurements are shown in Figure 3.3.

Samples were dried by exposure to four different levels $(32,62,76$, and $85 \%)$ of constant $R H$ established by saturated solutions of magnesium chloride $\left(\mathrm{MgCl}_{2}\right)$, ammonium nitrate $\left(\mathrm{NH}_{4} \mathrm{NO}_{3}\right)$, sodium chloride $(\mathrm{NaCl})$, and potassium chloride $(\mathrm{KCl})$, respectively. Beyond the loss of the first 40 to $50 \%$ of the available water, the isotherms become different depending on the exposure level of $\mathrm{RH}$. The RH was lower at a particular moisture content for samples exposed to lower RH conditions.

Figure 3.3 shows four such isotherms for In-Farm and U-Plant data fit to analytical curves for two RH exposures: 32 and $62 \%$. The curves exhibit the same characteristics but are distinct, and they give different $\mathrm{RH}$ values corresponding to the same percent initial water content, below about $50 \% \mathrm{RH}$. The isotherm for In-Farm simulant exposed to $32 \% \mathrm{RH}$ shows the same character. These data demonstrated that the particular isotherm applicable to the evaporation process will depend on the drying rate or the strength of the $\mathrm{RH}$ sink. This result is believed to reflect the nonuniformity of drying with depth in a sample.

The common analytical form that fits the isotherms displays a salt precipitation-like transition for which the RH remains nearly constant over an interval of changing moisture content. The analytical description is essential for modeling the $\mathrm{RH}$ gradient between air and a sludge surface at a particular moisture content. The curves provide the means to interpolate the data.

Moreover, Relyea found that the rewetting isotherm for dried simulants occurred at a much higher RH than the drying curve. Thus, sludge simulants will adsorb water back if exposed to a RH higher

(a) Reylea, J. F. 1994. "The Drying of Sodium Nickel Ferrocyanide at Constant Relative Humidity." Internal Memo 8H110-HFR-94-054, Westinghouse Hanford Company, Richland Washington. 


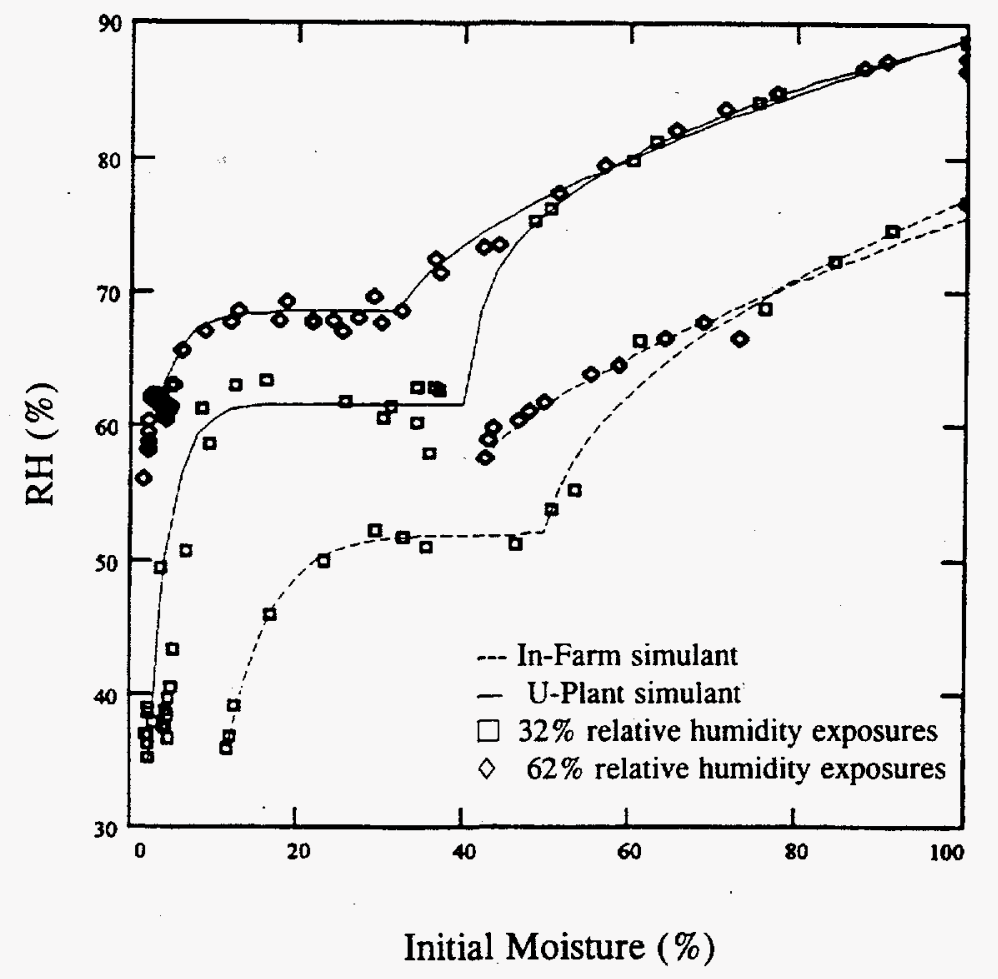

Figure 3.3. Relative Humidity Isotherms for Sludge Simulants Dried by Exposure to Relative Humidity Levels of 32 and $62 \%$. Curves are the same analytical equation fit to the data but with different parameter values.

than the equilibrium value. In-Farm simulant showed this behavior for $85 \% \mathrm{RH}$ exposure. In this manner, the RH isotherms display hysteresis behavior. The behavior indicates that the physicalchemical nature is irreversibly altered by drying below the moisture content where salts precipitate from the sludge. The sodium nitrate and nitrite concentrations are believed to mainly determine the RH isotherm above $50 \%$ initial water content. But the ferrocyanide solids further reduce the equilibrium RH along the drying isotherm, indicating a stronger water-retaining capability of sludge that has not been previously dried.

\subsection{Evaporation Modeling}

The RH isotherms, in analytical form, and the drying rate measurements can be combined to estimate the evaporation flux from a surface exposed to an RH less than the 30 to $32 \%$ used in the experiments. To obtain this estimate, the evaporative flux, as measured in the drying experiment by King (1994), is assumed to be proportional to the vapor density gradient that acts from the drying surface into air with a fixed ambient $R H$. The evaporative flux, $q(w)$, as given in Figure 3.2 , can be rescaled by a ratio of $\mathrm{RH}$ differences as follows: $\{[(\mathrm{RH}(\mathrm{w})-\mathrm{RHn}] /[\mathrm{RH}(\mathrm{w})-\mathrm{RHo}]\} \mathrm{q}(\mathrm{w})$. The evaporative flux $\mathrm{q}(\mathrm{w})$, used is that originally measured as a function of water content, $w$, for the sample when exposed to the reference RHo. The rescaled evaporative flux for a new RHn is thus obtained, using the isotherm function $\mathrm{RH}(\mathrm{w})$ given in Figure 3.3. A simple model for a varying 
evaporation rate can thus be derived based on the above assumption that shows that a sample will come to equilibrium with a water content, w, corresponding to RHn. Given that RHn is larger than RHo, the time will usually be longer than that measured for RH. A more precise description of the rescaled evaporative flux calculation is given in Appendix E.

The calculation, which is performed by a simple program, eliminates the need to repeat experiments (having the same profile depth) for higher RH exposures to find evaporative flux. However, the diffusional depth that determines the vapor density gradient is implicitly assumed to remain the same function of the water content regardless of the RH exposure and the evaporation rate. This is an approximation; a simple equation, however, is derived that gives the new approximate drying time for a higher $\mathrm{RH}$. The ratio of $\mathrm{RH}$ differences defined in the previous paragraph determines a scaling of the time required to dry to equilibrium under exposure to the higher RHn value. Table 3.1 provides example calculations. Entries for the $\mathrm{RH}$ are the RHn values. The calculation method is described in Appendix E.

One difficulty, however, is that the $\mathrm{RH}(\mathrm{w})$ curve changes depending on the $\mathrm{RH}$ exposure level, RHo, as discovered by Relyea ${ }^{(a)}$ (see Figure 3.3). In Table 3.1, the isotherm for RH exposure of $32 \%$ (reference value RHo) was used for RHn entries below $60 \%$, and the isotherm for $62 \% \mathrm{RH}$ exposure was used for those at $60 \%$ or above. Unfortunately, the method has difficulty when the value of RHn falls near and a little below the point where the isotherm exhibits a precipitation-like transition and when $\mathrm{RH}(w)$ has a flat segment where it does not change. This causes the calculation to yield an extremely long time to reach equilibrium under $\mathrm{RHn}$, because the flux is predicted to be very small by the scaling rule, while the water content falls within the flat segment of the $\mathrm{RH}(\mathrm{w})$ curve (see Figure 3.3).

As a consequence of this modeling difficulty, the time to reach equilibrium as given in Table 3.1 varies irregularly as RHn increases. Values for an RHn of 35\% are about the same as those for $30 \% \mathrm{RH}$ exposure. The time decreases again at a higher RHn. Note that In-Farm simulant would gain water at $80 \%$ or higher RH. Apparently, this simple conceptual model does not account for flux changes as a function of moisture content inside a sample or for the importance of the surface moisture content as drying occurs.

\subsection{Liquid Diffusion in Drying of Simulants}

A standard drying analysis (Porter et al. 1984) was performed for the two experiments described in Section 3.2. Both experiments measured the loss of moisture over time from the simulants when exposed to RH sinks. The information is described in terms of drying curves.

(a) Reylea, J. F. 1994. “The Drying of Sodium Nickel Ferrocyanide at Constant Relative Humidity." Internal Memo 8H110-HFR-94-054, Westinghouse Hanford Company, Richland, Washington. 
Table 3.1. Percent Loss of Initially Available Moisture when Exposed to RH Below that for Initial Equilibrium. The time required to achieve the relative humidity with $98 \%$ of the maximum possible moisture lost is based on scaling the evaporative flux with a ratio of $\mathrm{RH}$ differences.

\begin{tabular}{|c|c|c|c|c||}
\hline $\begin{array}{c}\text { Relative } \\
\text { Humidity } \%\end{array}$ & $\begin{array}{c}\text { U-Plant } \\
\text { Loss }\end{array}$ & $\begin{array}{c}\text { In-Farm } \\
\text { Percent } \\
\text { Loss }\end{array}$ & $\begin{array}{c}\text { U-Plant } \\
98 \% \text { Loss }\end{array}$ & $\begin{array}{c}\text { In-Farm } \\
\text { Time (day) } \\
\text { Loss }\end{array}$ \\
\hline 35 & 98 & 88 & 118 & 102 \\
\hline 40 & 97.5 & 87 & 139 & 128 \\
\hline 45 & 97 & 84 & 171 & 189 \\
\hline 50 & 96 & 77.5 & 228 & 467 \\
\hline 55 & 94.5 & 48.5 & 363 & 119 \\
\hline 60 & 97 & 53.5 & 137 & 75 \\
\hline 65 & 95 & 40 & 260 & 119 \\
\hline 70 & 66.5 & 23 & 156 & 150 \\
\hline 75 & 56 & 2.2 & 210 & 94 \\
\hline 80 & 40 & NA & 153 & NA \\
\hline 85 & 19 & NA & 114 & NA \\
\hline NA = not applicable. & & & \\
\hline
\end{tabular}

A simple form of drying curve was found that describes the decrease of moisture over time for all samples when exposed to different levels of $\mathrm{RH}$. The curve is expressed in terms of the relative available moisture content, $\mathrm{W}_{\text {rel }}$. This relative quantity, $\mathrm{W}_{\text {rel }}$, is traditionally defined by the following equation:

$$
\mathrm{w}_{\mathrm{rel}}=(\mathrm{w}-\mathrm{wf}) /(\mathrm{wi}-\mathrm{wf})
$$

where $\mathrm{w}=$ actual moisture content on a dry-weight basis

$\mathrm{wf}=$ final water content at equilibrium with the $\mathrm{RH}$ exposure

wi $=$ starting water content.

In evaporation analysis, the relative available moisture content is also called the "unaccomplished moisture change." The evaporation is $100 \%$ unaccomplished initially and $0 \%$ unaccomplished (complete) at the end of drying.

By simple diffusion theory, the logarithm of the relative available moisture content depends approximately linearly on time for the entire volume of the sample. The moisture content represents the average over the sample volume. This means that the drying curve on a semi-log plot would be nearly 
linear in time for an ideal diffusional process with a constant diffusion coefficient. The effective liquid diffusion coefficient, $D$, is determined then from the exponential drying equation:

$$
W_{\text {rel }}=\exp \left(-2.467\left(\mathrm{D} / \mathrm{L}^{2}\right) t\right)
$$

where $L$ is the sample thickness. See Appendix $E$ for more information on the determination of the effective liquid diffusion coefficient.

Figure 3.4 shows the drying curves for the samples held in the 5.6-cm-deep bottles exposed to $30 \%$ RH. Curves for U-Plant simulants exposed to other levels of RH are shown in Figure 3.5. If . expressed in terms of percent moisture loss over time, the drying curves in Figure 3.5 would be quite distinct, because various amounts of moisture would be lost when exposed to the different RH levels. However the curves nearly come together when expressed in terms of relative available moisture.

The curves in Figures 3.4 and 3.5 are not single straight lines but usually can be divided into two connected, nearly linear parts (Appendix E). The slopes of these two parts can be interpreted as liquid diffusion coefficients. The larger liquid diffusion rate is associated with greater downward slope. Thus, two diffusion coefficients and a relative moisture value defining the transition between the two parts of a curve are sufficient to create an approximate characterization of each drying curve. The linear fit in the first part for higher relative moisture values is generally very good with minor scatter from the line, indicating close conformity to ideal diffusion behavior. The second part, however, is much less regular or repeatable.

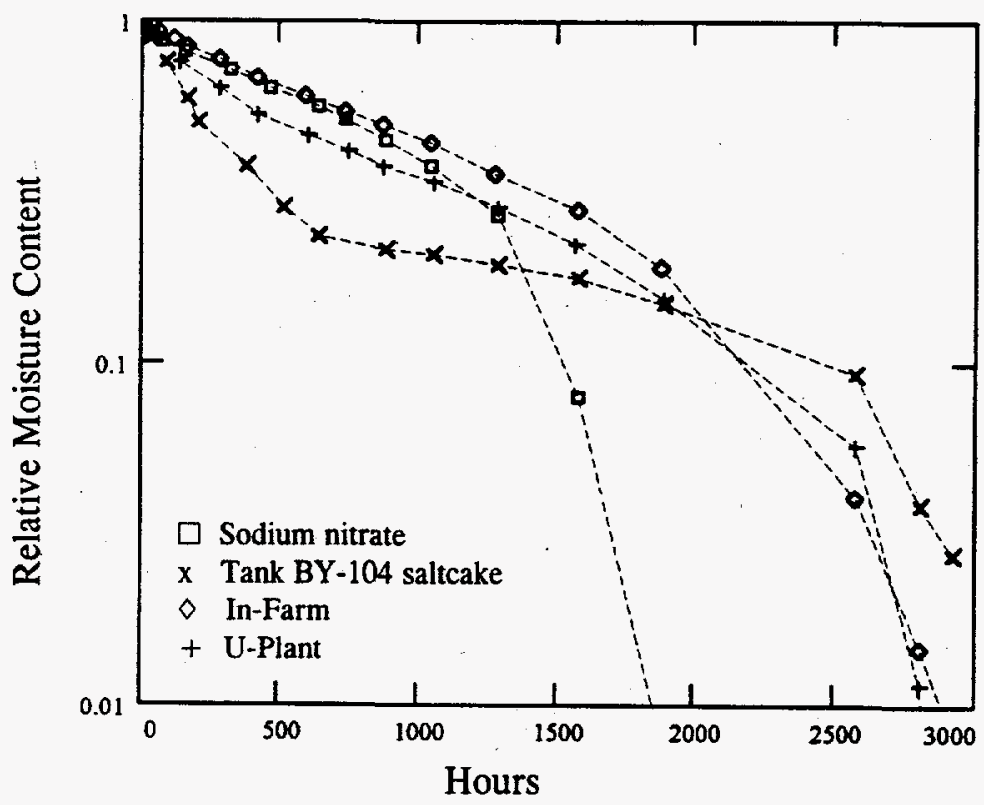

Figure 3.4. Relative Available Moisture Content for the Drying Experiment (King 1994). Maximum percent moisture loss for U-Plant and In-Farm simulants is estimated from the drying measurements by J. F. Relyea (WHC) at $32 \%$ humidity. 


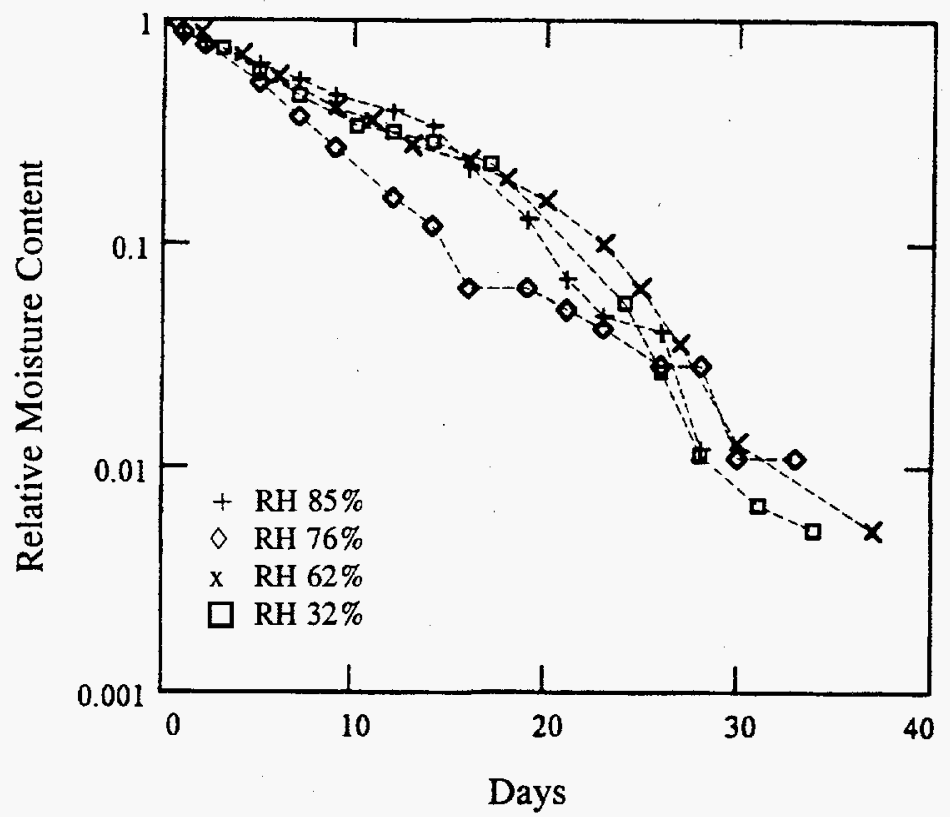

Figure 3.5. Relative Available Moisture for U-Plant Simulant Exposed to Four Levels of Constant Relative Humidity

Values of $\mathrm{D} / \mathrm{L}^{2}$ for the first and second part of the drying curve that conforms to the exponential drying equation (3.1) are given in Table 3.2 for King's experiment. Table entries are multiplied by $\mathrm{L}=5.6 \mathrm{~cm}$ to obtain the liquid diffusion coefficient in $\mathrm{cm} /$ days.

Table 3.3 gives the diffusion coefficients for $\mathrm{L}=0.5 \mathrm{~cm}$. The important result to notice in Table 3.3 is that the values for the effective liquid diffusion coefficient, $D$, are about the same except for an $\mathrm{RH}$ of $76 \%$. Thus, the relative rates of drying are about the same regardless of RH exposure. This suggests that a common diffusion coefficient applies regardless of different evaporation rates produced by different RH exposure levels.

Table 3.2. Values of $\mathrm{D} / \mathrm{L}^{2}$ Above and Below the Dividing Value of $\mathrm{W}$. Units are $1 /$ day.

\begin{tabular}{|l|c|c|c|}
\hline \multicolumn{1}{|c|}{ Material } & $\begin{array}{c}\mathrm{D} / \mathrm{L}^{2} \text { Above the } \\
\text { Dividing Value }\end{array}$ & $\begin{array}{c}\text { D/L } \\
\text { Dividing Value }\end{array}$ & Dividing Value of W \\
\hline \hline Sodium Nitrate & 0.009 & 0.06 & 0.290 \\
\hline Saltcake & 0.024 & 0.004 & 0.208 \\
\hline In-Farm & 0.008 & 0.03 & 0.208 \\
\hline U-Plant & 0.01 & 0.13 & 0.066 \\
\hline
\end{tabular}


Table 3.3. Values of $\mathrm{D} / \mathrm{L}^{2}$ Above and Below the Dividing Value of $\mathrm{W}$. Units are $1 /$ day.

\begin{tabular}{|c|c|c|c|c|c|c|}
\hline \multirow{2}{*}{$\begin{array}{c}\text { Relative } \\
\text { Humidity } \\
(\%)\end{array}$} & U-Plant ${ }^{(a)}$ & In-Farm & U-Plant & In-Farm & U-Plant & In-Farm \\
\hline & \multicolumn{2}{|c|}{$\begin{array}{c}\mathrm{D} / \mathrm{L}^{2} \text { Above the Dividing } \\
\text { Value of } \mathrm{W}\end{array}$} & \multicolumn{2}{|c|}{$\begin{array}{l}\mathrm{D} / \mathrm{L}^{2} \text { Below the Dividing } \\
\text { Value of } \mathrm{W}\end{array}$} & \multicolumn{2}{|c|}{ Dividing Value of $\mathrm{W}$} \\
\hline 85 & $\begin{array}{l}0.035 \\
0.029\end{array}$ & NA & $\begin{array}{l}0.103 \\
0.083\end{array}$ & NA & $\begin{array}{l}0.254 \\
0.313\end{array}$ & NA \\
\hline 76 & $\begin{array}{l}0.058 \\
0.053\end{array}$ & 0.06 & $\begin{array}{l}0.045 \\
0.063\end{array}$ & 0.03 & $\begin{array}{l}0.024 \\
0.053\end{array}$ & 0.079 \\
\hline 62 & $\begin{array}{l}0.038 \\
0.038\end{array}$ & 0.031 & $\begin{array}{l}0.081 \\
0.128\end{array}$ & 0.046 & $\begin{array}{l}0.155 \\
0.145\end{array}$ & 0.063 \\
\hline 32 & $\begin{array}{l}0.038 \\
0.038\end{array}$ & 0.032 & $\begin{array}{l}0.088 \\
0.119\end{array}$ & 0.113 & $\begin{array}{l}0.201 \\
0.141\end{array}$ & 0.21 \\
\hline
\end{tabular}

The drying curves indicate that a diffusion-like process occurs during drying, and a transition occurs when about $20 \%$ of the relative moisture available for evaporation remains; this transition from saturated to unsaturated flow associated with shrinkage during drying is thought to coincide with the increase in downward slope and the correspondingly increased effective diffusion coefficient. The time scale of the exponential decrease of the relative moisture content is proportional to the sample thickness squared divided by the liquid diffusion coefficient.

The diffusion coefficients so obtained, however, depend on the thickness of the samples. Those for the 5.6-cm depth are about a factor of 30 times greater than those for the 0.5 -cm-thick samples used for the RH measurements of Relyea's experiment. Thus, these diffusion coefficients are not an inherent property of sludge but represent the flow dynamics at a particular length scale.

\subsection{Recommendations}

A mechanistically more detailed experiment is needed to determine the exact balance in evaporation rate and hydraulic flow that determines the rate of moisture loss. Modeling can test hypotheses about how the physical mechanisms are coupled. The data gathered so far provide a good basis on which to further test the resistance of sludge simulants to drying out.

Also, further study is needed to determine the relationship between consolidation behavior and shrinkage caused by evaporation. More advanced experiments are needed to measure the dependence of pore liquid pressure on shrinkage caused by evaporation and consolidation to determine how rapidly liquid will flow toward an evaporating sludge surface for a deep profile. The present scoping experiments on evaporation of small simulant samples do not provide the detail information about internal 
flow mechanisms; however, measurements of moisture evaporation from sludge simulants are important new information about the water retention characteristics of such materials.

\subsection{Conclusions}

Measurements of the drying rate for small samples of sludge simulants and saltcake when exposed to air with $30 \% \mathrm{RH}$ for 3,000 hours, and the RH isotherms for various levels of drying exposure (85, 76,62 , and $32 \% \mathrm{RH}$ ) were obtained. An isotherm gives the balance between the sludge's moisture content and the air's RH in equilibrium with the material's surface.

This study found that the flow of moisture, including the dissolved salt migration, toward the evaporating surface of simulants behaves like a diffusion process. But the process exhibits two distinct drying rate periods. The first period may be associated with saturated flow; the second may constitute unsaturated conditions. No initial period of constant-rate evaporation was observed. Effective liquid diffusion coefficients were estimated for the samples; these are effective for bulk drying because they depend on the size (scale) of the sample.

The measured RH isotherms do not produce a unique or single curve, because the particular curve branch depended on how fast that level of constant $\mathrm{RH}$ exposure caused drying. Also, isotherms showed a salt precipitation-type transition, during which $\mathrm{RH}$ does not vary but moisture content changes. A common analytical expression that could fit the $\mathrm{RH}$ isotherm data was found nevertheless.

These tests indicate that, for lower moisture contents (less than $50 \%$ of the original moisture), the amount of moisture held near the sludge surface in a tank cannot be accurately determined from RH measurements alone. However, for higher moisture contents, the equilibrium RH, is essentially determined by the nitrate salt concentration in solution, and a single curve does apply. To use the RH isotherm to estimate moisture content from RH measurements, the sludge type (In-Farm or U-Plant) must be known.

A cutoff limit for in-tank RH when sludge may become critically dry might be established. Below $50 \% \mathrm{RH}$, for instance, the sludge samples become almost entirely dry at equilibrium conditions. Away from equilibrium, the RH will not reflect the sludge moisture condition.

The salt-precipitation transition also makes it difficult to scale the drying rate for smaller RH gradients, based on measurements of evaporative flux for a larger gradient, as produced by the $30 \% \mathrm{RH}$ exposure. That isotherm curves are not unique also confounds the extrapolation to other conditions. A future predictive model for evaporation must account for this complexity of $\mathrm{RH}$ isotherms. 


\subsection{A Simplified Model of Saltcake Moisture Distribution}

\subsection{Background}

This section contains a description of simplified physical model of the moisture distribution in a saltcake waste tank profile. This mathematical model emphasizes the physical influences of capillary phenomena, neglects thermal effects that induce moisture vapor flow, and describes the likely moisture distribution that occurs in a saltcake waste profile that has been stabilized and drained by pumping. When the "drainable" interstitial liquid in a saltcake profile has been pumped out, then the final distribution of liquid is determined mainly by capillarity. Once stabilized, a tank waste moisture distribution appears to change little over years, as indicated by neutron probe scanning. Thus the assumption is made that a post-stabilized moisture distribution is static or is in a steady-state condition. A steady long-term evaporation of moisture at the waste surface may also determine the moisture distribution in conjunction with a saltcake's hydraulic properties. Because the horizontal variability of waste properties is unknown, a one-dimensional vertical perspective is taken in the model.

\subsection{Saltcake Waste Characteristics}

The hydraulic characteristics of actual saltcake in waste tanks are not known; the radioactivity of saltcake core samples has precluded any direct measurement of properties by standard laboratory methods. Mechanical measurements of hydraulic properties that require manipulation of core samples have not been obtained because of the radioactivity hazard. Simulants of a particular waste have been characterized instead. Still, replicating an unknown saltcake waste to determine its related in-tank hydraulic properties has been difficult.

Handy (1975) and Strachan (1975) performed some of the earliest measurements of hydraulic properties for simulant saltcake. However, no proof exists that their simulants were comparable to actual saltcake in Hanford tanks. The contrasting physical aspects of tank waste types were reviewed in a Westinghouse Hanford Company quarterly report (Cash et al. 1995).

The dryness of a drained saltcake profile depends on the specific hydraulic properties of this waste form and the profile height. A higher saltcake profile will generally drain at the surface to a lower moisture content than found in a smaller profile. The principles of unsaturated flow in a porous matrix determine the final liquid distribution in a drained saltcake waste profile. Modeling incorporates these principles in terms of hydraulic properties to estimate the moisture distribution in saltcake.

Because manufacturing simulant saltcake that is physically representative of actual tank waste is difficult, modeling is especially helpful in estimating saltcake's hydraulic properties. Modeling can be used to infer the hydraulic property values that are consistent with the observed moisture distributions in stabilized tanks. A relative measure of the moisture distribution in tank waste is obtained from neutron probe scans taken in a liquid observation well (LOW). This information, combined with the principles of unsaturated liquid retention and flow in a porous medium can be used to infer the parameter values for a saltcake's hydraulic properties. 
Simulant saltcakes have been developed (Wanner 1993), but these samples were produced mainly to measure mechanical properties such as bulk density and shear strength. Thermal conductivity measurements were also attempted, with varying degrees of success. Hydraulic properties for the simulated saltcake, however, were not measured. The characterization of Tank BY-104 simulant reported by Wanner (1993) provided qualitative information that saltcake is indeed a porous matrix with a complicated structure. The porous structure is a result of the specific waste processing history. No effort, however, was made to evaluate the distribution of interstices or pore sizes. The simulant was primarily designed to determine mechanical properties to test core sample drill bits. Wanner (1993) reported a bulk density of about $1.41 \mathrm{~g} / \mathrm{cc}$ for the Tank BY-104 simulated saltcake dried to $5 \mathrm{wt} \%$ moisture. This remaining moisture probably constitutes hydrated water. Hydraulic analysis is. concerned with the free liquid - not the chemically bound water - held in the interstices.

\subsection{Modeling Emphasis}

A simplified model for the steady evaporation of moisture from a saltcake waste surface was devised based on the principles of unsaturated liquid flow in a rigid porous matrix. The mathematical development is described in Appendix $\mathrm{F}$ and is based on a presumed constant upward liquid flux.

Even in a closed tank, moisture is continually evaporating from the waste surface because of the heat load, and then recondensing on the cooler tank walls. The water that condenses on the tank cover and sides returns to the waste in a continuous cycle, while heat is transferred to outside the tank. The greatest possible drying of the waste surface would be expected if the entire surface heat transfer occurred via evaporation, instead of partly by convection and radiation as it actually does. Thus, the greatest possible evaporation can be conceived to occur in a tank when all heat transferred at the waste surface is converted into evaporative flux via latent heat of vaporization. On the other hand, evaporation cannot occur at a rate that exceeds how rapidly liquid (brine) can flow upward to maintain the surface moisture. When moisture is evaporated at the surface of an unsaturated porous medium, capillary forces draw liquid upward against gravity to maintain the VLC there.

A simplified model for steady, upward unsaturated flow driven by an evaporative liquid flux based on the heat transfer rate was formulated and programmed following the concepts just described. This mathematical model (Appendix F) is simplified because it does not yet account for the diffusion of water vapor through the liquid-drained interstices or air-filled voids of the saltcake, as driven by the thermal gradients that are present. It is also only a vertical, one-dimensional evaluation of moisture flow. More general modeling analysis must consider the importance of equilibrium vapor pressure gradients for causing water vapor flow.

A solution to this simplified model follows the approach first given by Gardner (1958) for describing evaporation from a soil. Marshal and Holmes (1979) in their soil physics text further describe the flow equation's solution for a layered profile of porous media.

Another simplification is the neglect of dissolved salt transport caused by upward liquid flow. When the water component of the interstitial liquid is evaporated at the surface, the salt that exceeds local solubility with the saltcake would be precipitated. This surface accumulation of dissolved salts with evaporation is well known (Marshal and Holmes 1979). A continuous buildup of salt mass would 
gradually alter the local hydraulic properties over time, because the distribution in the porous structure would change. This transport of salt is neglected also in the present modeling approximation. However, because the model is matched to the existing moisture conditions in a tank's saltcake profile, the hydraulic properties are determined in a way that is consistent with the present state. Future modeling analysis must consider the long-term influence of saltcake dissolution and salt transport.

An isothermal waste profile is assumed such that changes in liquid surface tension and viscosity are neglected. Liquid surface tension is not expected to vary substantially for the usual range of temperature observed in tank waste (Grigsby et al. 1992). Changes of viscosity with temperature and with dissolved salt concentration would affect the local variation of liquid conductivity; however, such variations can be introduced into the modeling solution when they are known for the steady flow conditions. Furthermore, spatial variations in the viscosity are considered a minor influence when compared with the more considerable uncertainty of the intrinsic permeability, which determines the liquid's hydraulic conductivity. In any event, a fixed spatial pattern for the interstitial liquid's properties, such as density, surface tension, and viscosity, could be introduced into the model when such information is available from tank sampling.

\subsection{Hydraulic Property Model}

The well-known and accepted empirical formulas for hydraulic properties, called the Brooks-Corey model, are employed in this solution for the steady upward unsaturated flow (Campbell 1985). These formulas are assumed to describe a wide range of granular porous media types (soils) and to also apply to saltcake. A laboratory study would be necessary to confirm this assumption, but past studies of simulant saltcake have confirmed that it is a porous medium and retains brine by capillarity, similar to sands (Handy 1975).

The Brooks-Corey model for the liquid capillary retention relation is the following equation:

$$
\mathrm{h} / \mathrm{ho}=\left[\left(\mathrm{VLC}_{\mathrm{s}}-\mathrm{VLC}_{\mathrm{f}}\right) /\left(\mathrm{VLC}-\mathrm{VLC}_{\mathrm{f}}\right)\right]^{\mathrm{b}}
$$

$$
\text { where } \begin{aligned}
\mathrm{h} & =\text { suction head } \\
\text { ho } & =\text { holdup height } \\
\mathrm{VLC}_{\mathrm{s}} & =\text { volumetric liquid content, saturated } \\
\mathrm{VLC}_{\mathrm{r}} & =\text { volumetric liquid content, residual } \\
\mathrm{VLC} & =\text { volumetric liquid content } \\
\mathrm{b} & =\text { pore-size index for the porus medium. }
\end{aligned}
$$

Note that the saturated value usually equals the porosity. The height of interstitial liquid rise, $\mathrm{h}$, is that achieved in a static equilibrium condition without any liquid movement; $h$ is the matrix suction head in units of liquid column height for its own density (i.e., as depends on the liquid's specific gravity). Matrix suction head is the negative of the matrix potential energy per unit weight of the particular liquid. (Note that $h$ is a measure of the capillary pressure that holds the liquid up above the ILL in a drained saltcake.) If $h$ is less than holdup height, the saltcake is entirely liquid saturated. Here the holdup height equals the difference between the ILL and the standing liquid level as seen in a salt well. 
The pore-size index can be estimated from the pumping response of tanks having a certain drainable porosity (DeWeese 1988). The concept of drainable porosity was discussed by DeWeese to explain why different waste profiles contained relatively different amounts of liquid. Drainable porosity reflects the amount of liquid that can be gravity-drained or pumped to achieve a profile equilibrium distribution of liquid. The important result is that the profile-averaged pore-size index for a saltcake profile can be determined from the pumping response of a tank that has been stabilized by assuming that equation (4.1) applies. The change in total liquid storage from a saturated profile to a final drained equilibrium distribution as a result of pumping out a known quantity of liquid is relatable to the poresize index. This was found to apply to a group of tanks in the TX Tank Farm containing entirely saltcake waste.

However, the estimation approach, apparently, was not accurate when applied to tanks in the BY Tank Farm having a saltcake layer over sludge. The saltcake profiles in the BY tanks underwent considerable consolidation when pumped, yielding a much greater drainage quantity than could have been extracted from the final reduced saltcake profile. That is, the drainable porosity for BY tanks did not reflect the porous properties of the post-stabilized saltcake. This resulted in a pore-size index that is much smaller (an average of 0.5 ) than that found for a group of TX saltcake tanks having pore-size index values ranging from 1.2 to 4.5 (an average of 2.1). A pore-size index of 0.5 to 0.7 would be typical of coarse sands. Granular media with a pore-size index of about 2.1 retain more liquid when the same residual and saturated liquid contents apply.

The original plan to characterize tank waste was to estimate liquid retention parameters directly from particle size distributions for saltcake samples by using certain theoretical formulas. The plan's method was discussed in a quarterly report (Cash et al. 1995). The accuracy of that method, however, was questionable because the true crystal grain size distribution for actual tank saltcake is not available. An alternative approach is to infer the hydraulic parameters such as pore-size index by matching the modeling predictions to either pumping response information or to neutron probe scan data for selected tanks.

Presuming that the Brooks-Corey model equation is relevant, the unsaturated liquid conductivity is given by the following equation:

$$
\mathrm{K} / \mathrm{Ks}=\left[\left(\mathrm{VLC}-\mathrm{VLC}_{\mathrm{r}}\right) /\left(\mathrm{VLC}_{\mathrm{s}}-\mathrm{VLC}_{\mathrm{r}}\right)\right]^{(2 \mathrm{~b}+3)}
$$

where $\mathrm{Ks}$ is the liquid saturated conductivity for saltcake. Derivation of this model uses a distribution of capillary pore sizes based on the retention equation (4.1). Combined with the retention equation (4.1), these hydraulic functions are sufficient to model the unsaturated liquid movement in saltcake having a rigid porous matrix.

The unknown hydraulic parameter, i.e., the liquid saturated conductivity, can be found from laboratory column tests (Handy 1975) or by a pumping drawdown test (Metz 1976). Kirk (1980) reviewed the extent of what is known for the hydraulic properties of tank waste.

The liquid saturated conductivity (units of length per time) is determined from the permeability (in darcy units) of the porous medium and the liquid's viscosity, $\mathrm{cP}$. Handy (1975) found a permeability of 22.2 darcy for a synthetic saltcake with a liquid density of $1.43 \mathrm{~g} / \mathrm{cc}$ and viscosity of $12.5 \mathrm{cP}$. This 
was equivalent to a liquid saturated conductivity of $0.0025 \mathrm{~cm} / \mathrm{s}$, for this supernate. Using this value as a reference conductivity, Kref, the liquid saturated conductivity for different liquid properties and permeability could be estimated by property scaling:

$$
\mathrm{Ks}=(\text { darcies/22.2)(12.5/viscosity })(\text { liq. density/1.43) Kref }
$$

Darcy's law is combined with this estimated hydraulic conductivity to calculate the liquid's flow rate. The Darcy liquid flow velocity, $\mathrm{q}$, is given by

$$
q=-K(h) \cdot(d h / d z+1)
$$

where $\mathrm{K}(\mathrm{h})=$ hydraulic conductivity as function of suction head

$\mathrm{dh} / \mathrm{dz}=$ matrix suction head gradient

$\mathrm{z}=$ depth, measured positive downward from the surface.

Darcy flow velocity has units of volume per area per time or length per time and is a volumetric flux with the same units as the liquid saturated conductivity. In Darcy's law (Eq. 4.3), the flow is driven by the sum of the matrix suction head gradient, $\mathrm{dh} / \mathrm{dz}$, and the gravitational potential gradient, which is unity here. Here $h$ must be expressed in units of the rise height for the particular liquid's density. Note that the static equilibrium condition for which there is no flow, $q=0$, is determined by $\mathrm{dh} / \mathrm{dz}+1=0$. This defines the static distribution of VLC in the profile. An upward net flow is associated with a positive Darcy liquid flow velocity. If $\mathrm{dh} / \mathrm{dz}<-1$, then the liquid moves upward.

In Eq. (4.3), $\mathrm{K}$ is expressed as a function of $\mathrm{h}$ by using Eq. (4.1) and (4.2) to eliminate VLC. For steady flow conditions, the Darcy liquid flow velocity must be constant over the profile, and Eq. (4.3) can be solved for the value of $h$ at each depth. Then using Eq. (4.1) gives the distribution of the VLC with $\mathrm{z}$. The solution applies to each layer with different parameter values to describe a heterogeneously layered profile. A Mathcad ${ }^{\circ}$ program called LAYERS was written to solve this problem and to perform the calculations, as described in Appendix F.

In this model, the Darcy liquid flow velocity is determined by the rate of water evaporation at the surface. However, only a fraction of the liquid that moves toward the surface can evaporate because the rest of the mass is salt. Letting $E$ be the evaporation rate (units $\mathrm{g} / \mathrm{s} / \mathrm{cm}^{2}$ of water), $q$ and $E$ are related by

$$
E=(P w / 100) \text { (liquid density) } q
$$

where $\mathrm{Pw}$ is weight percent water of the liquid. The heat flux, $\mathrm{J}$, in units $\mathrm{W} / \mathrm{m}^{2}$ transferred by evaporation is

$$
J=(\text { water latent heat of vaporization })(10,000) E
$$

Latent heat of water vaporization is about $2,450 \mathrm{~J} / \mathrm{g}$ at standard temperature. 
The liquid flow model makes it clear what hydraulic parameters are needed to examine the possible dryout of saltcake. The required parameters are the following:

- Holdup height for capillary rise, ho

- Pore-size index, b

- Permeability, or saturated conductivity, Ks

- Liquid surface tension

- Viscosity

- Depth to the stabilized ILL.

Then the Darcy liquid flow velocity must be established based on the fraction of surface heat flux that is partitioned into moisture evaporation with the latent heat transfer. The approach for estimating this evaporation flux, E, is discussed in Section 4.5.

By formulating this model, the most important physical parameters that control moisture distribution are identified; this determines the properties of saltcake waste samples that should be measured to adequately assess the safety of the driest conditions possible.

To determine the conversion from VLC to weight percent water in the saltcake for any depth, the following quantities must be known:

- Salt grain particle density

- Interstitial liquid density

- Actual interstitial porosity

- Percent water of salt-saturated liquid.

The VLC predicted by the model for any depth can then be used to estimate weight percent water. The conversion formula is discussed in Cash et al. (1995) and given in Appendix F.

\subsection{Evaporation Estimation}

D. R. Dickinson computed the water vapor flux based on diffusion and the water vapor concentration gradient associated with the temperature gradient in a waste profile. ${ }^{(a)}$ This calculation is common in soil physics and is called the thermal water vapor flux. The thermal vapor diffusivity is the product of the water vapor diffusion coefficient in air, tortuosity factor, vapor-filled porosity, $\mathrm{RH}$, temperature slope of the saturation water vapor concentration, and an enhancement factor. Vapor flux is then the product of this vapor diffusivity and the local temperature gradient, $\mathrm{dT} / \mathrm{dz}$. Dickinson did not include the enhancement factor that accounts for increased vapor flux caused by microscopic temperature

(a) Dickinson, D. R. December 14, 1994. "Calculation of Potential for Dryout of Saltcake Surface." Letter 94-111-DRD to R. J. Cash and D. H. Turner, Westinghouse Hanford Company, Richland, Washington. 
gradients acting across air-filled pores between liquid-filled pores. The enhancement factor could be 5 to 10 times as noted by Campbell (1985), but it approaches unity as the liquid content vanishes or as the porous medium becomes dried.

Dickinson calculated that the total surface heat flux is between 3 to $5 \mathrm{~W} / \mathrm{m}^{2}$ for typical tanks $\left(3.4 \mathrm{~W} / \mathrm{m}^{2}\right.$ for a tank with a $2 \mathrm{~kW}$ heat load, like BY-104). He found about $0.033 \mathrm{~g} / \mathrm{s}$ water vapor flow by thermal diffusion from an entire surface, which is equivalent to about $0.2 \mathrm{~W} / \mathrm{m}^{2}$. He used a measured temperature gradient of about $15^{\circ} \mathrm{C} / \mathrm{m}$ to obtain this evaporation rate; he noted that this evaporation rate is about two times greater than the amount that could be lost by a tank breathing or by exchange with the outside atmosphere. If enhanced, this thermal vapor flux might be 1 to $2 \mathrm{~W} / \mathrm{m}^{2}$, which is a substantial fraction of the total surface heat transfer in a tank. Clearly this quantity of water vapor is not lost through breathing, so the water must be condensed on cooler tank walls to be returned into the waste.

An approach for estimating the required temperature gradient to calculate the thermal vapor flux is suggested here because it is not usually directly measured. The total surface heat flux should equal the waste thermal conductivity multiplied by the required derivative, $\mathrm{dT} / \mathrm{d} z$, near the surface. This total heat flux is a percentage, about $50 \%$ to $70 \%$, of the entire tank heat load distributed over the waste surface area (facing a tank's headspace). Thus, the calculation of water vapor flux calls for the additional parameters:

- Saltcake thermal conductivity

- Tank waste heat load, watts output.

\subsection{Relative Saturation}

The ratio of VLCs appearing as the argument in the Brooks-Corey model for the hydraulic properties in Eq. (4.1) and (4.2) is called the relative saturation:

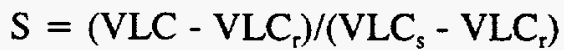

The value of the relative saturation ranges from zero to unity. To calibrate the model for actual tank moisture conditions, this variable is related to the neutron probe counts rate taken in LOWs. If the neutron count rate data taken over past years in many tanks could be calibrated to determine the actual VLC at each profile location, then the relative saturation could be calculated directly and used in adjusting the flow model to fit actual measurements. Because the count rate tends to drift from session to session for each profile scan, normalizing the scans for a common relative range is necessary.

Letting $\mathrm{Cmin}$ and $\mathrm{Cmax}$ be the minimum and maximum count rates, $\mathrm{C}$, for a particular measurement session, and letting Cmin be selected for a depth where the VLC takes its residual value (approximately), the ratio $(\mathrm{C}-\mathrm{Cmin}) /(\mathrm{Cmax}-\mathrm{Cmin}) \mathrm{can}$ be a measurement of the relative saturation at each depth where the count rate is measured. Also, the maximum count rate is assumed to be associated with the saturated liquid content. This equality of saturation estimates is based on the assumption that unknown linear calibration factors defined for each profile location would factor out of the calculation of the relative saturation based on count rate. Given that the unknown calibration is not always actually 
linear, this assumption, of course, produces an unknown error in estimating the relative saturation. However, the estimated relative saturation derived from neutron probe counts is still useful for an approximate model calibration.

Figures $4.1 \mathrm{a}$ and $4.1 \mathrm{~b}$ demonstrate the conversion of count rate data to relative saturations over the waste profile of Tank TX-118. A percent relative saturation is defined by multiplying by 100 . Curves that are different in Figure 4.1a are brought together in a common range in terms of relative saturation in Figure 4.1b. Because count rate values near the waste surface are less than the selected reference, $\mathrm{Cmin}$, the relative saturation drops below zero or is negative for a height above the reference. Only the range of positive relative saturation values, however, would be relevant to movement of liquid with a VLC greater than the residual value. The relative saturation can be used to evaluate the "true" relative changes that occur in the moisture distribution over time. It turns out that the average relative saturation over the Tank TX-118 profile has been increasing from 1986 to 1994 from 74 to $84 \%$. Such an increase, however, does not necessarily suggest that the volume of liquid is increasing over time. Without knowing the change in saturated liquid content at each profile location, the relative saturation cannot be converted to the actual VLC needed to calculate the actual. liquid storage in the profile. The trend in relative saturation gives only a measure of the relative moisture changes - not the actual.

Location of the reference height for the minimum count rate was arbitrarily chosen as about $8 \mathrm{ft}$ $(2.4 \mathrm{~m})$. The record based on total waste volume indicates a surface height of $11.1 \mathrm{ft}(3.4 \mathrm{~m})$, but Figure 4.1a suggests a height of about $9 \mathrm{ft}(2.74 \mathrm{~m})$ where the count rate begins to vanish. Also, the record (Grigsby et al. 1992) indicates an ILL of $4.4 \mathrm{ft}(1.3 \mathrm{~m})$, while the salt well liquid level is $3.3 \mathrm{ft}$

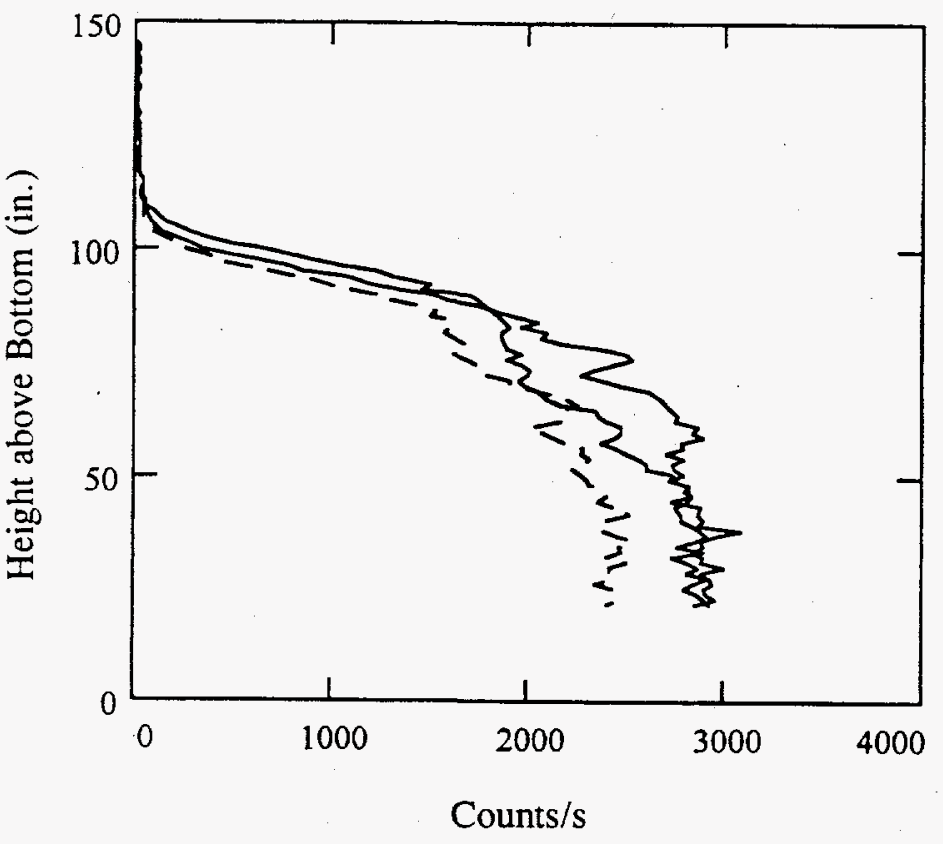

Figure 4.1a. Three Neutron Probe Scans of Tank TX-118 


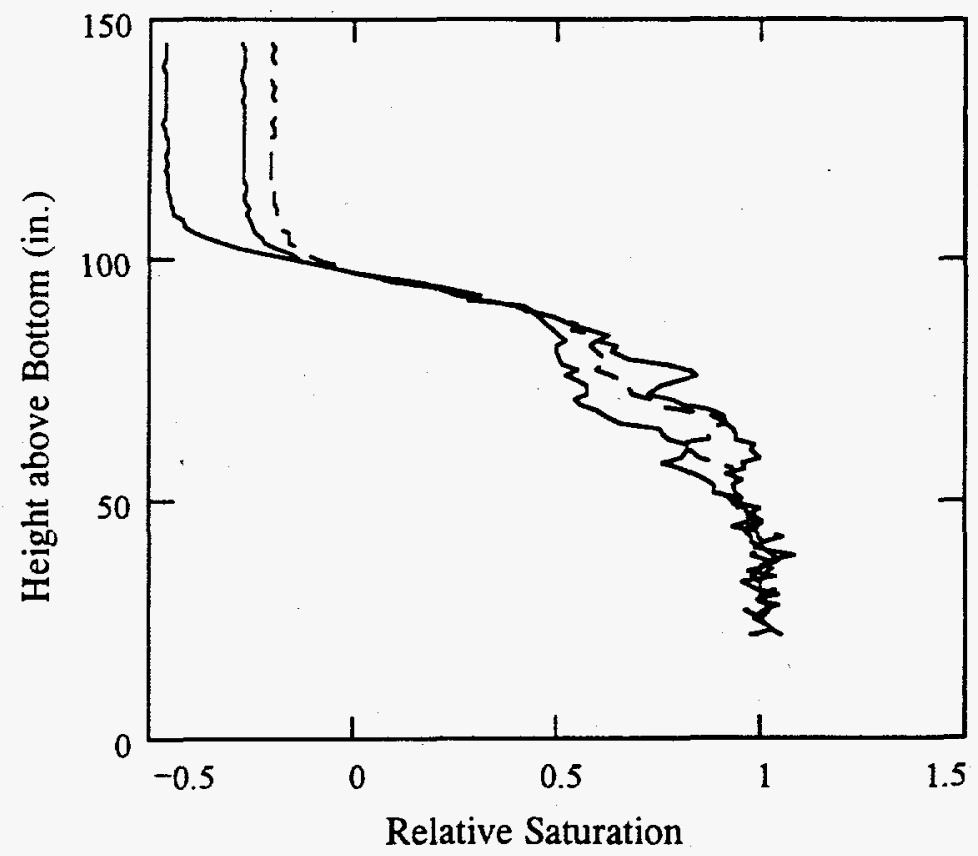

Figure 4.1b. Neutron Probe Scans in Terms of Relative Saturation for Tank TX-118. Original data shown in Figure 4.1a. Dash curve for 10-23-92 is now in the middle. An upward redistribution of water over time is indicated by the relative saturation increase (assuming no external sources of water).

$(1 \mathrm{~m})$. This suggests that either the holdup height is about $1.1 \mathrm{ft}(0.34 \mathrm{~m})$ above a saturated saltcake zone, or there is a sludge-like waste on the bottom going up to about $4 \mathrm{ft}(1.2 \mathrm{~m})$ high in this tank (assuming a 6-in. [15.2-cm] holdup instead), where the relative saturation has remained about the same over the years. This tank, however, is supposed to contain entirely saltcake waste by inventory records.

\subsection{Modeling Applications}

The model for steady upward unsaturated flow has been applied to Tanks TX-105 and BY-104 to test it. These tanks have a waste moisture profile that is more complicated than that of Tank TX-118; they appear to display layers or possibly moisture variations associated with anomalies around the LOW. Examples are reviewed here briefly. A challenge in applying the model was to find effective parameters that represent the possible layer patterns of moisture as viewed, or measured, by the neutron probe scan.

Figure 4.2 shows the Brooks-Corey retention curve for $b=2.2$ and ho $=6$ in. compared to a recent moisture profile expressed in terms of relative saturation. A height for relative saturation equal to zero was arbitrarily selected below the surface to indicate where the minimum residual moisture of $5 \mathrm{wt} \%$ is likely to occur. The sludge is indicated by a nearly vertical fluctuating trace with a relative saturation of about unity. In the sludge, near the bottom, the relative saturation decreases below one, 


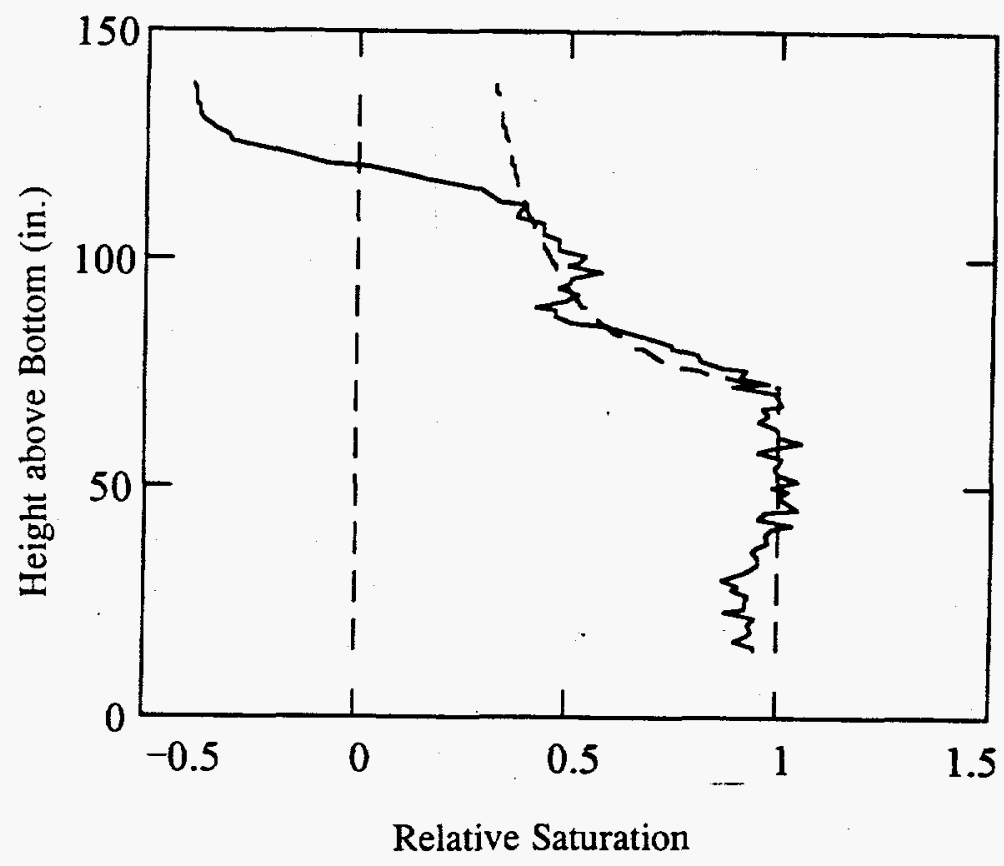

Figure 4.2. Relative Saturation Profile for Tank BY-104 (scanned 3-30-94) Compared with Brooks-Corey Retention Curve. The curve (dashed line) is given by $\log (H / h)=b \log (S)$, where $H=6$ in. is the holdup height, $b=2.2$ is the pore-size index, $S$ is relative saturation, and $h$ is the capillary rise height.

Fluctuating solid line is the neutron scan converted to relative saturations. The ILL is set 72 in. from the bottom.

possibly because the sludge is more compressed or consolidated there than near the interface with the assumed water-saturated saltcake. A pore-size index of 0.77 for an absolute porosity of 50 vol\% was determined initially from the pumping response. Such a pore-size index would, however, define a retention curve that falls far below the relative saturation obtained from the neutron scan. Thus, the pore-size index determined from pumping for this saltcake-over-sludge profile would not be representative.

In Figure 4.3, four material layers were introduced into the model with a pore-size index of 1.8 , $2.2,1.8$ and holdup height of $12,8,10,12$ in. ordered from the waste bottom to the top. Parameter values were selected to give a reasonable match with the estimated relative saturation profile. The result was then converted back to weight percent water, as plotted in the figure. Absolute porosity is $50 \mathrm{vol} \%, 46 \mathrm{vol} \%, 50 \mathrm{vol} \%$, and $47 \mathrm{vol} \%$ in the layers from the bottom up. Absolute porosity as given and a residual 8 vol\% liquid content are used to convert the relative saturation to volumetric liquid content, which is converted to weight percent water by assuming particle density of $2.1 \mathrm{~g} / \mathrm{cc}$ and liquid density of $1.43 \mathrm{~g} / \mathrm{cc}$, with $52 \mathrm{wt} \%$ water in the interstitial liquid. A steady upward liquid flux equivalent to $3.6 \mathrm{~W} / \mathrm{m}^{2}$ of heat transfer via evaporation is maintained for permeability of 2.2 darcy (hydraulic conductivity is $2.5 \times 10^{-4} \mathrm{~cm} / \mathrm{s}$ and liquid velocity is $2 \times 10^{-7} \mathrm{~cm} / \mathrm{s}$ for brine viscosity of $12.5 \mathrm{cP}$. A substantial heat flux of $3.6 \mathrm{~W} / \mathrm{m}^{2}$ was associated with the evaporative moisture flux. 


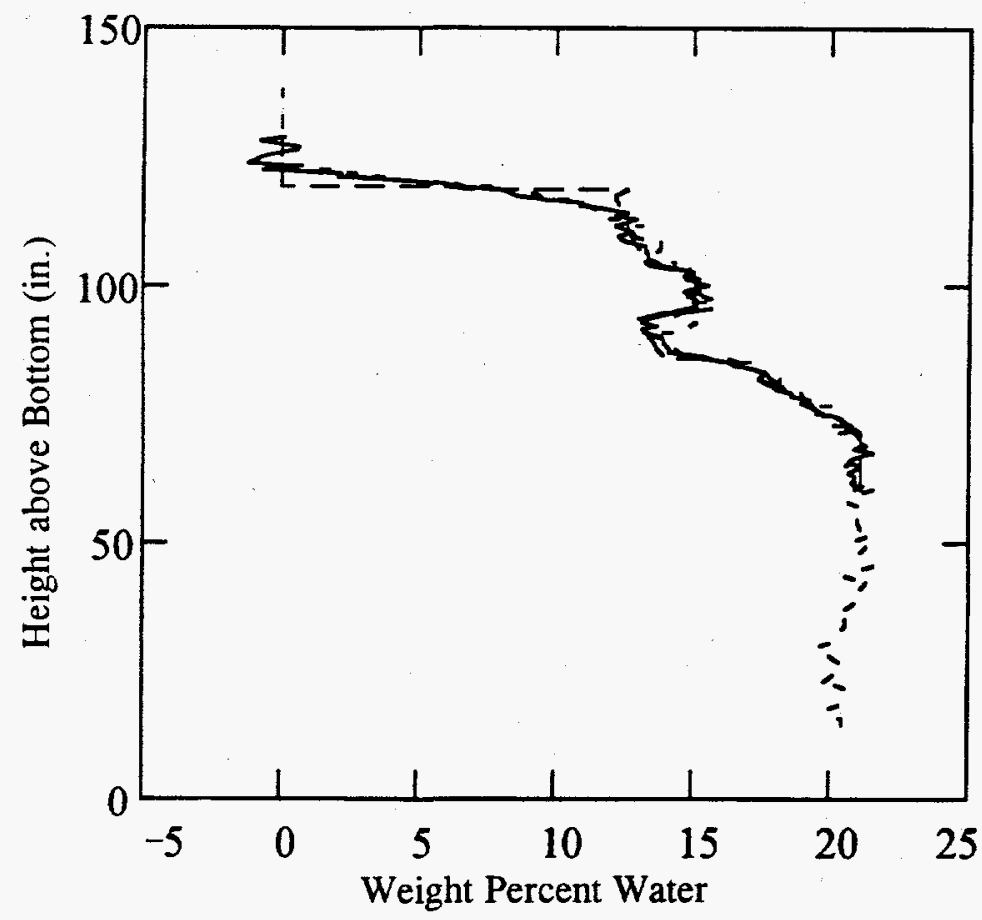

Figure 4.3. Moisture Content Profile in Tank BY-104 Estimated by Steady State Model. Dashed line is the analytical model prediction, and the fluctuating solid line represents the measurement as viewed by a simulated neutron scan. Actual scan measurements converted to weight percent water are indicated by a black dot line.

That value is slightly greater than the expected total heat load passing out of the waste surface. A minimal permeability within the range of the known values for simulant saltcake was assumed ( 2.2 darcy). Still, the surface is only slightly dried from the condition where no evaporative flux is present: $12.9 \mathrm{wt} \%$ water for no flux to $12.4 \mathrm{wt} \%$ water for $3.6 \mathrm{~W} / \mathrm{m}^{2}$. Beck et al. (1992), using auger samples taken 6 in. below the surface, reported about $15 \mathrm{wt} \%$ to $17 \mathrm{wt} \%$ water in the Tank BY-104 waste. Not until the drying flux is $14.6 \mathrm{~W} / \mathrm{m}^{2}$ does surface moisture reduce to $11 \mathrm{wt} \%$. The surface dries to the residual level when the evaporative flux is greater than about $17.9 \mathrm{~W} / \mathrm{m}^{2}$; this is the critical value for which complete surface dryout would occur. It is far in excess of the entire heat load but still only about five times greater. Handy's (1975) value of 22 darcy for permeability would allow about 10 times greater flux before dryout occurs.

Figure 4.4 shows how the ideal moisture retention distribution, assuming uniform hydraulic properties, compares with the actual neutron probe scan for Tank TX-105. The pore-size index of 1.82 obtained from the pumping response analysis, which used the reported drainable porosity, was found to describe the average distribution fairly well. The physical surface is about 200 in. above the tank bottom, and the neutron scan indicates that the surface is dried out to about 40 in. below the surface. 


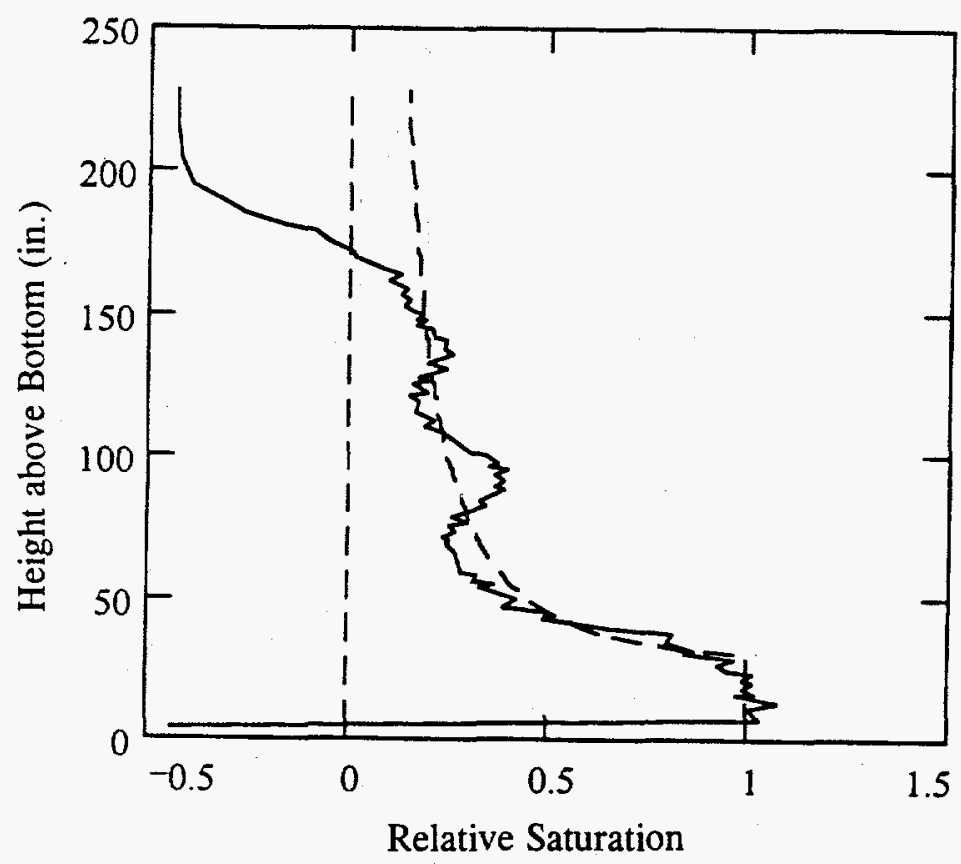

Figure 4.4. Moisture Profile in Tank TX-105 in Terms of Relative Saturation. Solid line is based on neutron count rate of 800 count/sec corresponding to $8 \mathrm{vol} \%$ liquid ( $5 \mathrm{wt} \%$ water); maximum counts/sec corresponds to 50 vol\% porosity ( $20 \mathrm{wt} \%$ water). The ILL is 30 in. from the bottom; holdup height is 6 in.

However, the theoretical average retention curve indicates that moisture content remains greater than the residual value up to the surface. This disparity may be caused by a salt dissolution cavity (cone shaped) around the LOW near the surface.

In Figure 4.5, six layers with slightly different hydraulic properties were assumed to make up the profile. The moisture content was converted to weight percent water using the same physical properties assumed for Tank BY-104 saltcake and liquid, as given in Figure 4.3. Notice that the residual moisture content is approached near the surface in this case, in contrast to Tank BY-104, which was wetter at the surface. The pattern of moisture variation over the profile, might also be attributed to contact anomalies between the LOW and saltcake profile, but this possibility is not known. Nevertheless, the example is a test of the model's capability for simulating a variable moisture profile.

\subsection{Determining the Pore-Size Index from Pumping}

This section describes how the pore-size index of the Brooks-Corey liquid retention model can be estimated from the pumping response of waste tanks. The data provided by DeWeese (1988) is used to estimate the pumping response, which is the amount of liquid withdrawn from a tank when the drop in ILL is measured. Pumping response is usually quantified as the decrease in ILL measured in a salt well 


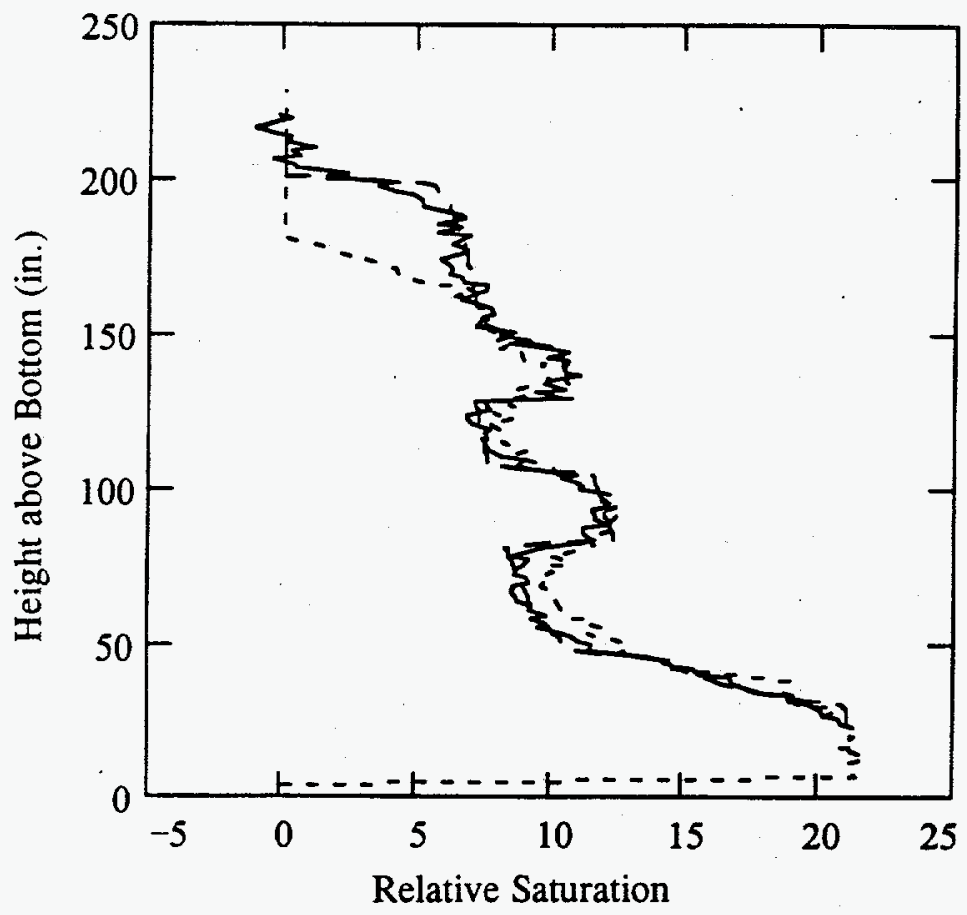

Figure 4.5. Moisture Profile in Tank TX-105 Based on Modeling and Neutron Counting Scan. Scan data converted to moisture weight percent is shown by dotted line. Fluctuating solid curve is the modeling result as viewed by a simulated neutron scan. The theoretical prediction of the model is the dashed curve, as determined for six different layers of saltcake. An evaporative flux equivalent to $0.17 \mathrm{~W} / \mathrm{m}^{2}$ of heat transfer is sustained at the surface by the steady upward flow model. Note that the actual neutron scan indicates complete drying to about $40 \mathrm{in}$. below the surface.

when the waste profile is initially saturated with liquid. DeWeese (1988) used the concept of "drainable porosity" to express the volume of liquid that could be extracted from an initially saturated volume of waste.

After being pumped down to an equilibrium condition or drained, the distribution of liquid in a waste profile is determined by the capillary rise as described by a retention relation. The liquid retention relation is assumed to be given by the Brooks-Corey equation in terms of the pore-size index.

At equilibrium (static conditions), for a known height to the waste surface measured from the standing liquid level at $\mathrm{h}=0$, the integral of VLC over height, $\mathrm{h}$, gives the total liquid storage when that integral is multiplied by the tank's base area. The change in liquid storage when an initially saturated saltcake profile is pumped down equals the pumped liquid volume. By equating the known pumped volume to the calculated storage change given by the Brooks-Corey equation, the unknown value of the pore-size index can be estimated, provided the other retention parameters (holdup height, porosity, and residual VLC) are known. 


\subsubsection{Drainable Porosity}

Tank farm waste management engineers use the term "drainable porosity" as a relative measure of how much liquid can be removed from a waste profile when pumped. DeWeese (1988) reported the pumpability of 26 tanks, mainly from the BY and TX Tank Farms, using the reevaluation of drainable porosity to estimate the pumpable liquid volume expected in all tanks based on the known volume of waste.

In this document, drainable porosity is defined as the ratio of pumped liquid volume to the volume of waste drained. The volume of waste drained is indicated by the drop in height of the ILL multiplied by the tank base area. Apparently, a controversy has existed for some time about what the collective average or representative drainable porosity is for all tanks. Because drainable porosity is not the absolute porosity and depends on capillary retention, DeWeese reported a distribution of values ranging from 12 to $52 \%$ by volume. The distribution found by DeWeese peaks at around 32 to $36 \%$.

DeWeese suggested $35 \%$ as the best value to predict pumpable interstitial liquid volume. A value of $45 \%$, however, has been used to administratively stabilize tanks.

Because the drainable porosity varies from tank to tank or can be assigned a range of values, there may be some confusion about the absolute porosity is for typical saltcake waste. The absolute porosity determines the volume of liquid that can be held in the interstices when the porous matrix is saturated, and it is greater than the drainable porosity. Variation in the drainable porosity seen in Figure 4.6 shows that saltcake profiles of different tanks have different capillary retention or different relative storage of liquid.

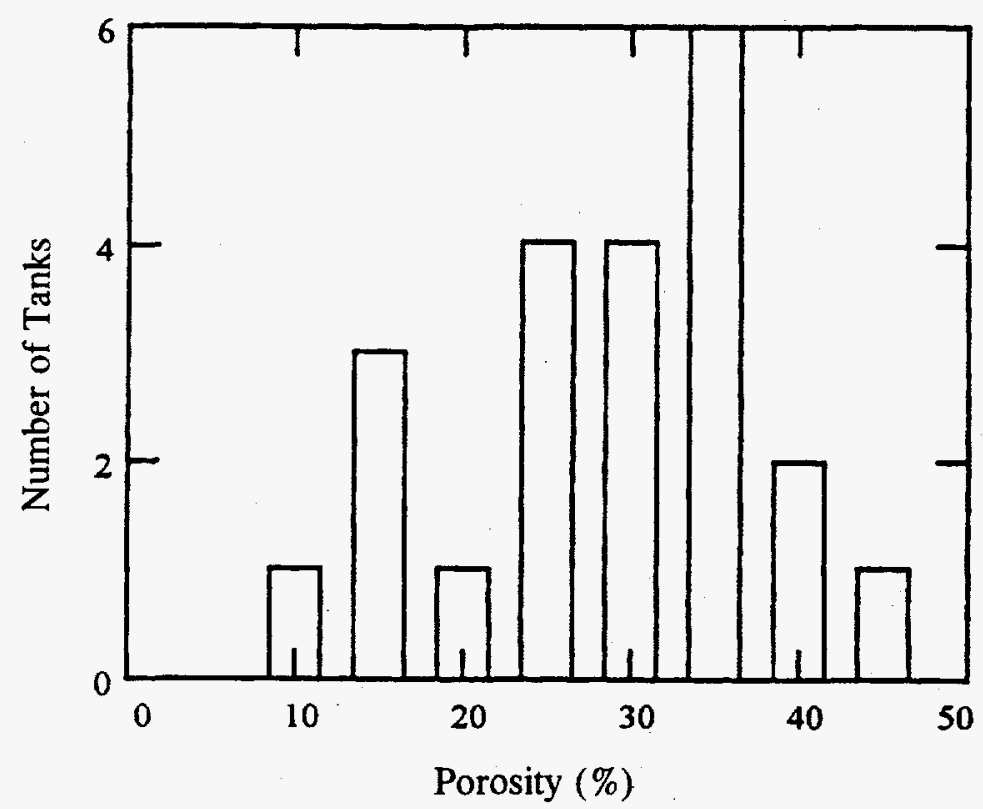

Figure 4.6. Drainable Porosity for Pumped Saltcake Tanks Reported by DeWeese (1988). The drained saltcake volume equals $2.75 \mathrm{kgal} / \mathrm{in}$. multiplied by the decline in the interstitial liquid level (in.) as measured in a salt well. 
The original data of DeWeese included greater porosity values for Tanks BY-110, BY-111, and BY-112 equal to 43,52 , and $42 \mathrm{vol} \%$, respectively. These values were recalculated, subtracting the waste volume decrease (with stabilization) from the measured total pumped liquid to better estimate the pumped interstitial liquid amount for the final profile's size. The calculation removes the supernatant volume from the total pumped volume to give only the interstitial contribution. The level decline was also recalculated by subtracting the actual reported liquid level from the final profile height, which is based on the summary volume of waste consistent with Hanlon (1993). This procedure decreased the estimated porosities to 42,37 , and $38 \mathrm{vol} \%$ for the three tanks. The estimated pumped interstitial liquid also decreased, especially for Tank BY-111. The same calculation applied to Tanks BY-101 and BY-104 did not substantially alter the estimates, so the original values were kept.

When pumped, the liquid level decline from a saturated condition to a stabilized equilibrium moisture distribution was correlated with the waste profile depth, as shown in Figure 4.7. The profile depth should usually be greater than the liquid level decline, as seen in the figure.

As seen in Figure 4.8, the saltcake tanks separate into two groups for pumping response. The regression estimates of drainable porosity for each group, 43 and $45.5 \mathrm{vol} \%$ based on slope, are about the same, however. These values probably reflect the absolute porosity rather than the variable values suggested in Figure 4.1. The line intercept for liquid level decline for zero amounts of pumped liquid are different for each group, as seen in Figure 4.8. These lines should not be extrapolated to a zero liquid level decline below the range of measurements.

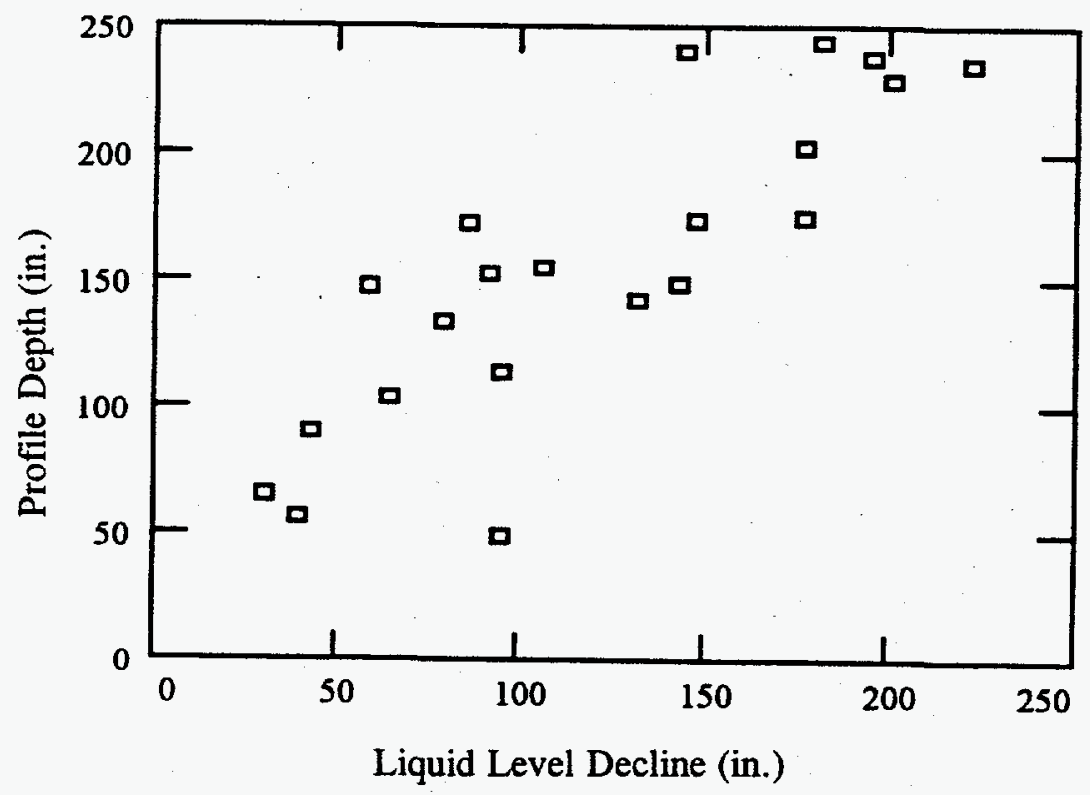

Figure 4.7. Correlation Between Saltcake Profile Depth and Liquid Level Decline After Pumping of Interstitial Liquid from a Tank. Profile depth is determined from waste volumes reported by DeWeese (1988). Correlation coefficient is 0.857 . 


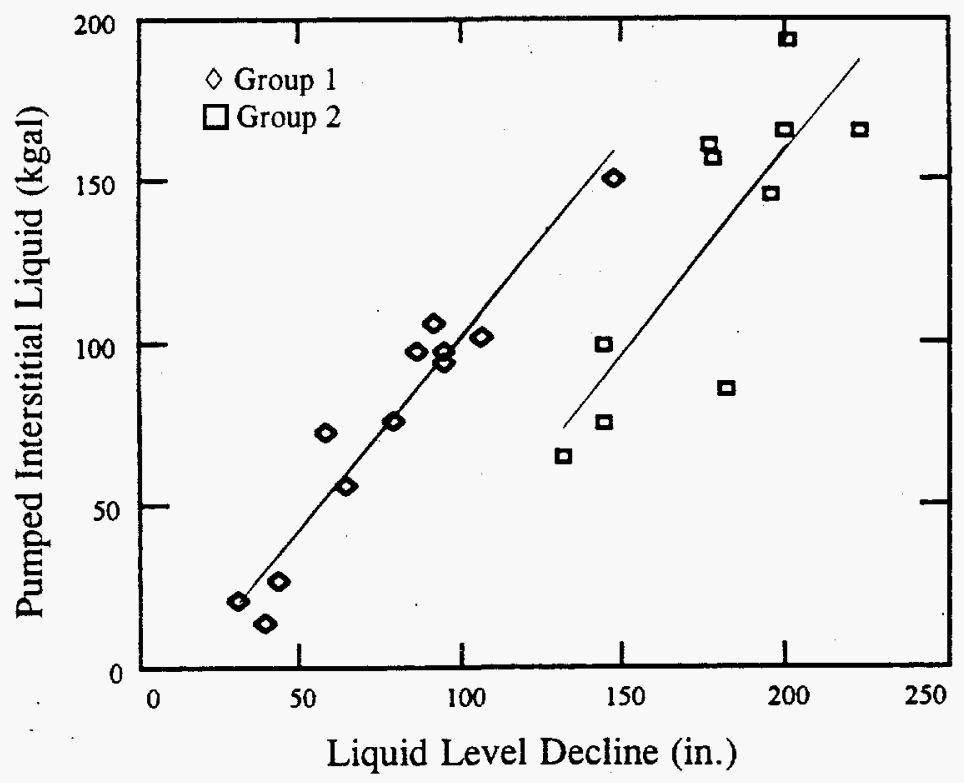

Figure 4.8. Pumped Interstitial Liquid for Two Tank Groups. Estimated drainable porosity is the slope of each line divided by $2.75 \mathrm{kgal} / \mathrm{in}$. Porosity is $43 \mathrm{vol} \%$ (group 1 ) and 45.5 vol\% (group 2). Group 2 have interstitial liquid declines 130 to 220 in. These tanks have greater profile depth (see Figure 4.7). Correlation coefficients are 0.968 and 0.813 .

Using a common set of parameters from each group, Figure 4.9 demonstrates the correlation of the model-estimated pumped interstitial liquid with the actual amount. For a distinct set of parameters the match can be made exact. But the absolute porosity and pore-size index change for each tank. In actuality, the absolute porosity and residual liquid content for each tank are not known, and they vary.

Figure 4.10 provides the final water retention curves for the two groups. Interpretation of these curves is further explained in the following section. Surface moisture is given in Figure 4.11, based on Figure 4.10.

\subsubsection{Surface Moisture Content}

Typical estimates of weight percent water in saltcake waste profiles are provided in Figure 4.10. The two curves correspond to two distinct tank groups that appear to exhibit different retention behavior when stabilized by pumping down the ILL. The curves give the weight percent water associated with a specific height above the standing liquid level in a salt well. Stabilized tanks have been pumped down to the maximum amount possible. Less completely pumped tanks would have smaller liquid level declines from the surface, thereby leaving the surface at a greater weight percent water content corresponding to smaller height above a tank's ILL. Figure 4.11 shows that surface moisture decreases with higher profiles (greater depth to liquid level). 


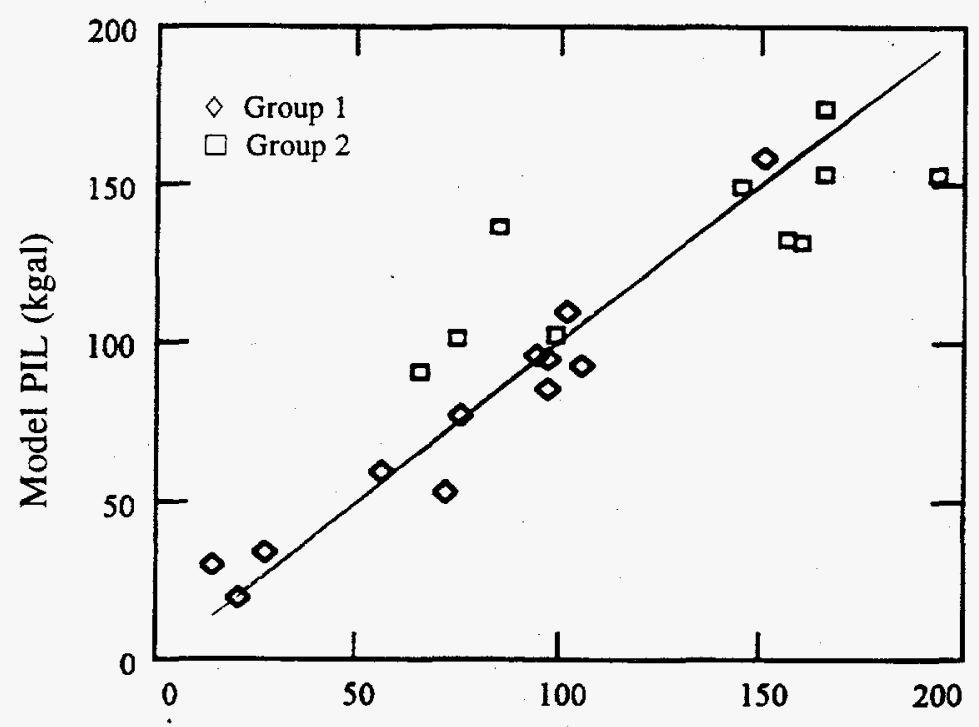

Actual PIL (kgal)

Figure 4.9. Model Estimated Pumped Interstitial Liquid (PIL) Compared with the Actual. Model pumped interstitial liquid is based on the Brooks-Corey retention curve for capillary holdup in the waste profile. Change in the interstitial liquid storage from the saturated profile condition to the equilibrium drained condition after pumping determines the pumped interstitial liquid amount. Correlation coefficients are 0.967 and 0.812 for groups 1 and 2.

In the first group of waste profiles in Figure 4.11, which mainly correspond to a smaller liquid level decline, the moisture content reaches a residual value at about 20 or 25 in from the surface. (A neutron scanner would detect this transition in moisture content with height.) The second tank group does not display an abrupt transition and remains much wetter near the surface. When drained, however, these later tanks have much deeper profiles. More interstitial liquid is pumped from this second group; the liquid level decline is at least about 120 in. (see Figure 4.8). The first group has no more than about a 150-in. liquid level decline. Liquid level decline is correlated with profile depth, as shown in Figure 4.7. In fact, the profile depth must be greater than level decline.

How well the capillary retention model in Figure 4.10 fits the pumped interstitial liquid amounts compared with actual measurements is shown in Figure 4.9. The model is based on a best-fit set of parameters for each of the two tank groups. In actuality, each tank's saltcake profile would have its own set of retention parameters and would potentially have a distinct curve similar to that shown in Figure 4.10. 


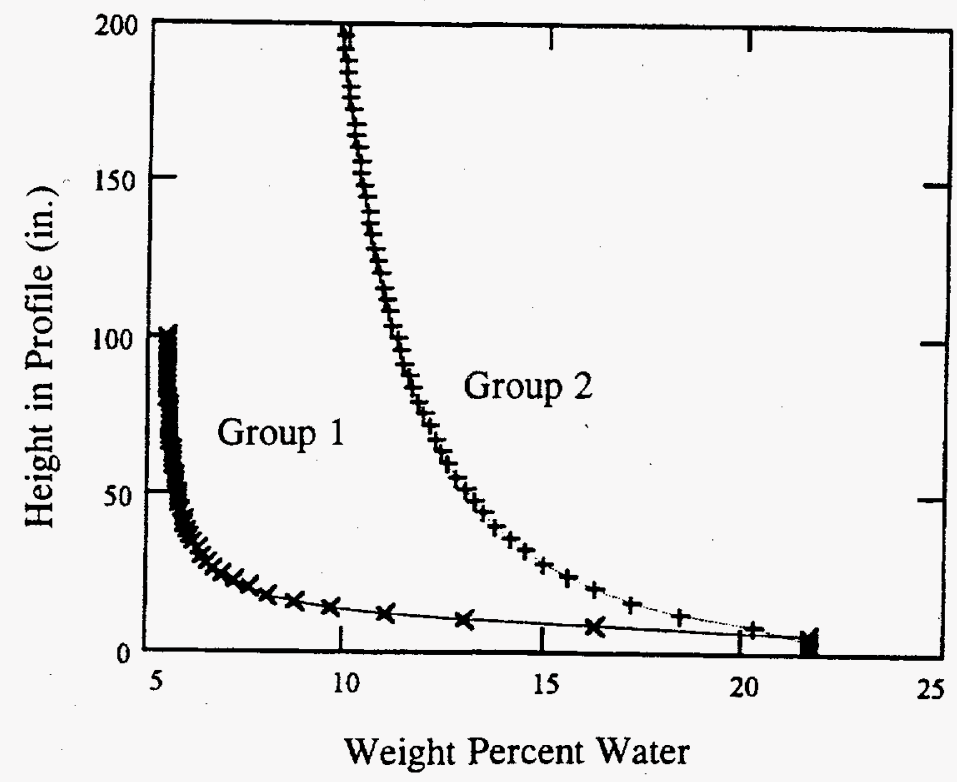

Figure 4.10. Moisture Retention in Profiles of Drained Saltcake Waste Tanks. Profile height is measured above the standing liquid level in a salt well. Pore-size index for the Brooks-Corey curve is 0.5 (group 1) and 2.14 (group 2). Absolute porosity of $50 \mathrm{vol} \%$ and residual moisture of $5 \mathrm{wt} \%(8 \mathrm{vol} \%)$ are used. Capillary holdup is 6 in. (Handy 1975) for both tank groups. To convert volumetric liquid content to weight percent water, salt grain density of $2.1 \mathrm{~g} / \mathrm{cc}$ and liquid density of $1.5 \mathrm{~g} / \mathrm{cc}$ with $52 \mathrm{wt} \%$ water in supernatant are used.

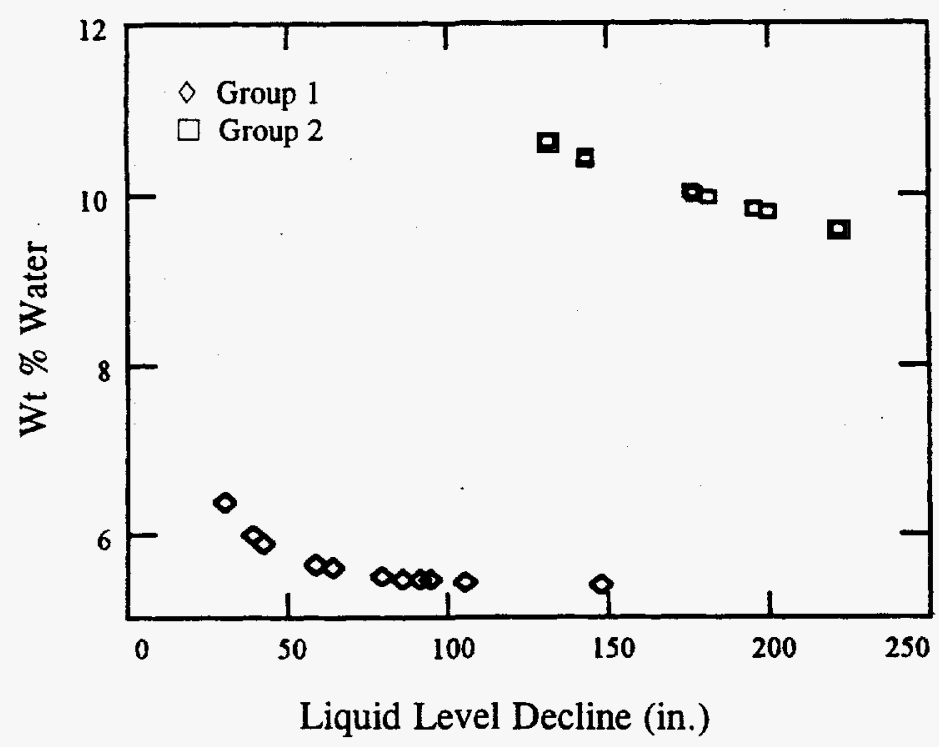

Figure 4.11. Weight Percent Water at the Surface of Each Stabilized Tank with the Retention Parameters of the Two Groups 
The capillary holdup of 6 in. was used to obtain Figure 4.10. Twelve inches of holdup in the capillary fringe could be applied to some tank profiles, however, depending on the assumed absolute porosity. Absolute porosity of 40 to $60 \mathrm{vol} \%$ could be accepted for various saltcake profiles. The implication of this is unknown, but it may reflect considerable interstitial structural differences among saltcake profiles.

The conversion of VLC to actual water content held in the interstices could be accomplished with specific information about salt grain crystal density and liquid density, when used along with the weight percent water in the salt-saturated brine. The correct absolute porosity would also be needed to make an accurate conversion from volume percent liquid to weight percent water for specific saltcake waste.

\subsubsection{Estimation Procedure Limitations}

This model has three main limitations. First, this estimation procedure should be used with caution to find the pore-size index. The model is simplified and does not directly include vertical layered heterogeneity, although in principle it can provided a neutron scan is available to define layers, as was demonstrated in the example situations. Each saltcake layer would have a different set of retention parameters, which produces a fluctuation in the retention curve with height above the ILL. Second, moisture associated with water chemically bound to the salt matrix is not taken into account; this water must be included also. Third, the model is entirely based on capillarity, although matched effectively to actual measurements. Nonisothermal evaporation and adsorption of moisture on hygroscopic salts could make the estimates inaccurate.

\subsubsection{Two Tank Groups}

Table 4.1 gives the exact pore-size index that produces the estimated pumped interstitial liquid amount for each tank. An absolute porosity of $50 \mathrm{vol} \%$ and holdup height of $6 \mathrm{in}$. were assumed. Recall that drainable porosity is the pumped interstitial liquid divided by the level decline multiplied by $2.75 \mathrm{kgal} / \mathrm{in}$. In a few cases, the absolute porosity must be increased to yield a solution for the poresize index; then the different absolute porosity used is indicated in parentheses. The model gives the pumped interstitial liquid as the difference between the initial liquid storage in the saturated profile and the final storage, as given by the Brooks-Corey capillary retention curve.

Generally, an increase in the holdup height would decrease the pore-size index, corresponding to a steeper decline in moisture retention with height. Increasing the value of absolute porosity would generally increase the pore-size index for a fixed holdup.

The value of the pore-size index 1 is 0.51 for group and 2.14 for group 2 . These values define the retention curves in Figure 4.5 and the surface moisture content in Figure 4.6. Forcing common values of the pore-size index in each group gives the deviation shown in Figure 4.9. Values in Table 4.1, however, exactly match the actual pumped interstitial liquid for each tank. Note that the pore-size index generally increases as drainable porosity decreases. 
Table 4.1. Pore-Size Index for an Exact Match of the Pumped Interstitial Liquid Amount

\begin{tabular}{|c|c|c|c|}
\hline Tank & $\begin{array}{c}\text { Drainable Porosity } \\
(\%)\end{array}$ & $\begin{array}{l}\text { Level Decline } \\
\text { (in.) }\end{array}$ & Pore-size Index \\
\hline \multicolumn{4}{|l|}{ Group 1} \\
\hline BY-104 & 34 & 106 & 0.774 \\
\hline BY-107 & 32 & 64 & 0.713 \\
\hline BY -108 & 23 & 43 & 1.14 \\
\hline BY -110 & 42 & 92 & $0.389(55 \%)$ \\
\hline BY-111 & 37 & 147 & 0.741 \\
\hline BY -112 & 38 & 94 & 0.409 \\
\hline TX-102 & 36 & 95 & 0.60 \\
\hline TX-103 & 25 & 31 & 0.637 \\
\hline TX-106 & 41 & 86 & $0.466(55 \%)$ \\
\hline TX-108 & 13 & 39 & 2.561 \\
\hline TX-109 & 45 & 58 & $0.234(60 \%)$ \\
\hline TX-118 & 35 & 79 & 0.588 \\
\hline \multicolumn{4}{|c|}{$\begin{array}{l}\text { Note: Usually, tanks with a pore-size index less than } 1 \text { are in the first group. The tanks } \\
\text { listed in group } 1 \text { with indexes greater than } 1 \text { likely should belong to group } 2 \text { or could be } \\
\text { included in the group } 2 \text { regressions. }\end{array}$} \\
\hline \multicolumn{4}{|l|}{ Group 2} \\
\hline BY-101 & 19 & 144 & 3.49 \\
\hline TX-105 & 30 & 200 & 1.82 \\
\hline TX-110 & 32 & 177 & 1.46 \\
\hline TX-111 & 18 & 131 & 3.62 \\
\hline TX-112 & 17 & 182 & 4.53 \\
\hline TX-113 & 35 & 201 & 1.17 \\
\hline TX-114 & 33 & 176 & 1.33 \\
\hline TX-115 & 25 & 144 & 2.25 \\
\hline TX-116 & 27 & 195 & 2.24 \\
\hline TX-117 & 27 & 222 & 2.37 \\
\hline
\end{tabular}




\subsubsection{Conclusions About Estimation Accuracy}

The consequence for the two groups is that nearly residual moisture at the surface is attained following stabilization for the first group, whereas the second group retains about $10 \mathrm{wt} \%$ on the average. However, the fact that most tanks in group 1 have a large layer of saltcake over sludge (BY tanks) suggests that substantial pumped interstitial liquid may come from the consolidated sludge when the saltcake overburden increases, as a result of decreased buoyancy of the salt matrix. In other words, the pumped interstitial liquid derived from the saltcake profile may be overestimated, so a greater liquid storage decrease in the saltcake is required to account for the pumped liquid.

This possibility is supported by Tank BY-101, which falls into group 2 . In the original data given by DeWeese, the amount of sludge did not decrease with pumping, though it did in the other BY tanks. In this case, apparently, all pumped liquid was derived from the saltcake; the retention curve was similar to that obtained for the purely saltcake profiles of TX tanks.

The model should probably be made more complex to account for the liquid expelled from the sludge below into the saltcake through consolidation caused by pumping. An inferred retention curve for the entirely saltcake-containing TX tanks is probably a more accurate description of saltcake retention behavior.

Thus, it should not be concluded that BY tanks are actually drier at the surface than TX tanks. More likely, the fact that tanks fall into two groups by retention behavior suggests that sludge or saltcake consolidation plays an important part. In particular, if the larger pore-size index value of group 2 were applied to the BY tanks, giving a smaller predicted storage change or pumped interstitial liquid, then the additional liquid storage change following stabilization would need to come from the sludge profile to account for the actual total pumped interstitial liquid. At this time, however, the data are not sufficient to confirm the hypothesis that consolidation of sludge or saltcake is causing the differences in the retention curves.

DeWeese and originally Kirk (1980) attributed 12.5 vol\% drainable porosity to sludge. This value is used to estimate in Kirk's empirical model the expected pumpable liquid from the initial histogram volumes of tank waste types. That model also assumes a 2 - $\mathrm{ft}$ capillary holdup for $66 \mathrm{kgal}$ of undrainable liquid held in a sludge profile, provided the sludge profile height is larger than the holdup. The capillary holdup in sludge is generally known to be an order of magnitude greater than this. Therefore, if sludge contributes to the pumped interstitial liquid, it is likely via the mechanism of consolidation caused by either a saltcake overburden or the sludge's self-weight. The 12.5 vol\% used in Kirk's model likely constitutes an average fraction of liquid loss from sludge when undergoing consolidation in typical tanks. Drainable porosities obtained for entirely sludge profiles show much smaller values, supporting the fact that sludge does not readily drain by gravity alone. Thus, incorporating the process of consolidation is necessary to estimate the pumpability of waste profiles with saltcake layered over sludge. 


\subsection{Surface Dryness Sensitivity}

This section examines how sensitive the model's predictions of surface moisture content are to hydraulic properties and evaporative flux. Figure 4.12a shows the surface moisture content as weight percent water depending on the evaporative flux and the height of the saltcake waste profile. The surface moisture content is predicted by the steady upward flow model assuming a waste profile with uniform hydraulic properties. The graphical floor shown in Figure 4.12a is the domain of flux and depth (or profile height) values for which the waste's surface dries out to the minimum residual level of $5 \mathrm{wt} \%$. Figure 4.12a shows that dryout occurs when the evaporative flux and the depth are sufficiently large. Typical hydraulic parameters of 22 darcy for permeability and pore-size index of 2.1 are assumed to describe the waste profile.

Figure $4.12 b$ provides a more quantitative description of when surface dryout will occur. The curves are slices of the graphical surface shown in Figure 4.12a for particular values of evaporative flux. Evaporative fluxes of $0.1,0.3$, and $2 \mathrm{~W} / \mathrm{m}^{2}$ were selected. The middle value is in the range expected to apply for water evaporation driven by the thermal gradient near the surface of typical tank waste. According to the curves, which begin to diverge when the depth becomes greater than 100 in., the surface does not dry out for $0.1 \mathrm{~W} / \mathrm{m}^{2}$ of evaporative flux but certainly does for $2 \mathrm{~W} / \mathrm{m}^{2}$, a value having the magnitude of a tank's entire surface heat load.

When the saltcake permeability is reduced to 2 darcy, with the same pore-size index, the domain of dryout (floor region) is greater, as seen in Figure 4.13a. Figure 4.13b shows that the surface would dry out for a profile depth approaching $150 \mathrm{in}$. for an evaporative flux of only $0.1 \mathrm{~W} / \mathrm{m}^{2}$. Recall that a permeability of 2 darcy is the minimum value estimated for a laboratory simulant of saltcake.

Figures 4.14 and 4.15 demonstrate that dryout of surface moisture is very sensitive to the pore-size index, which describes how well moisture is retained by capillarity in a saltcake waste profile. These figures are based on the 22 darcy permeability value. For a smaller pore-size index of 1.5 , a waste surface of sufficient height will dry out for the entire range of evaporative flux. On the other hand,

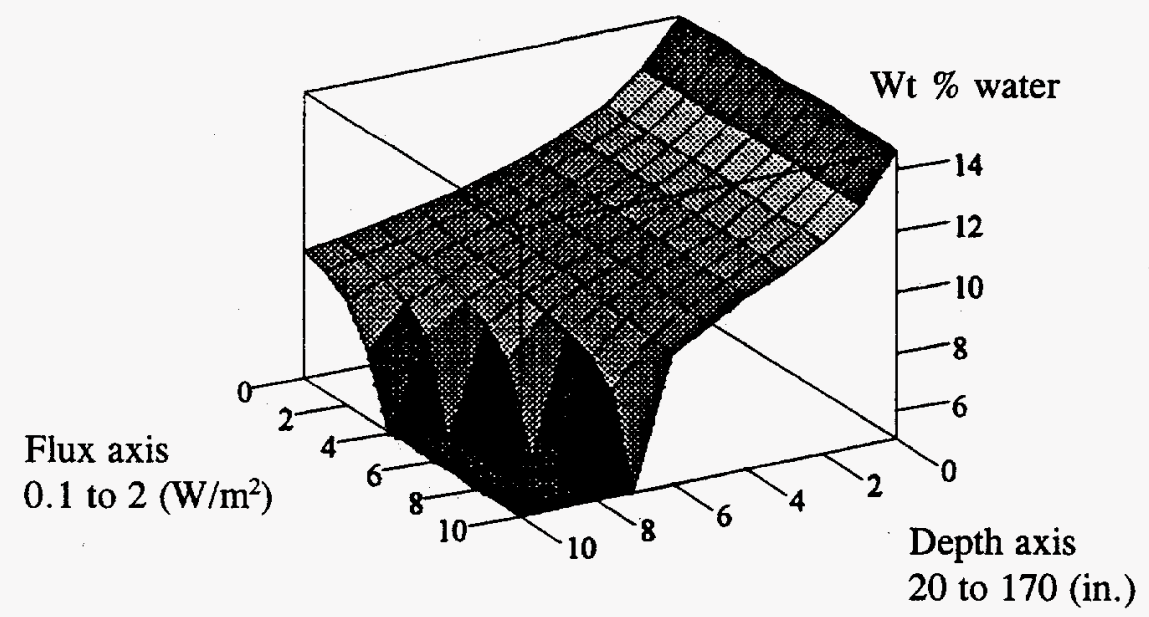

Figure 4.12a. Surface Moisture Content for Permeability of 22 darcy and Pore-Size Index of 2.1 


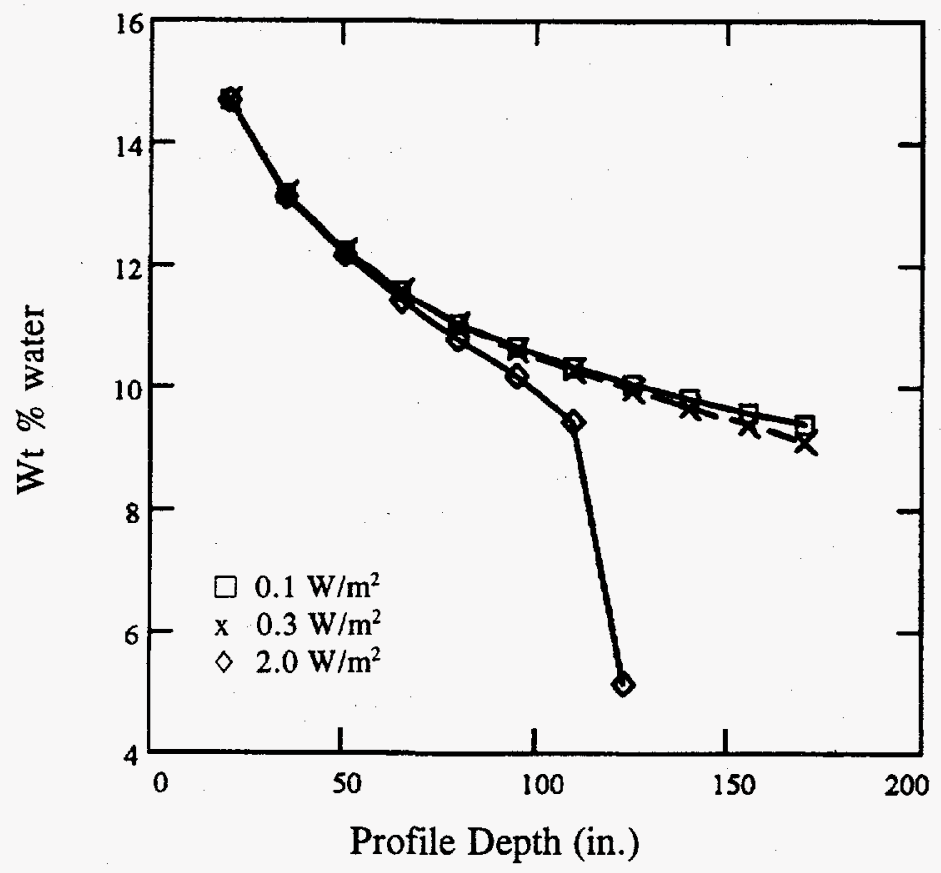

Figure 4.12b. Surface Moisture Content as Weight Percent Water Depending on Evaporative Flux. Pore-size index is 2.1 and permeability is 22 darcy.

Flux axis

0.1 to $2\left(\mathrm{~W} / \mathrm{m}^{2}\right)$

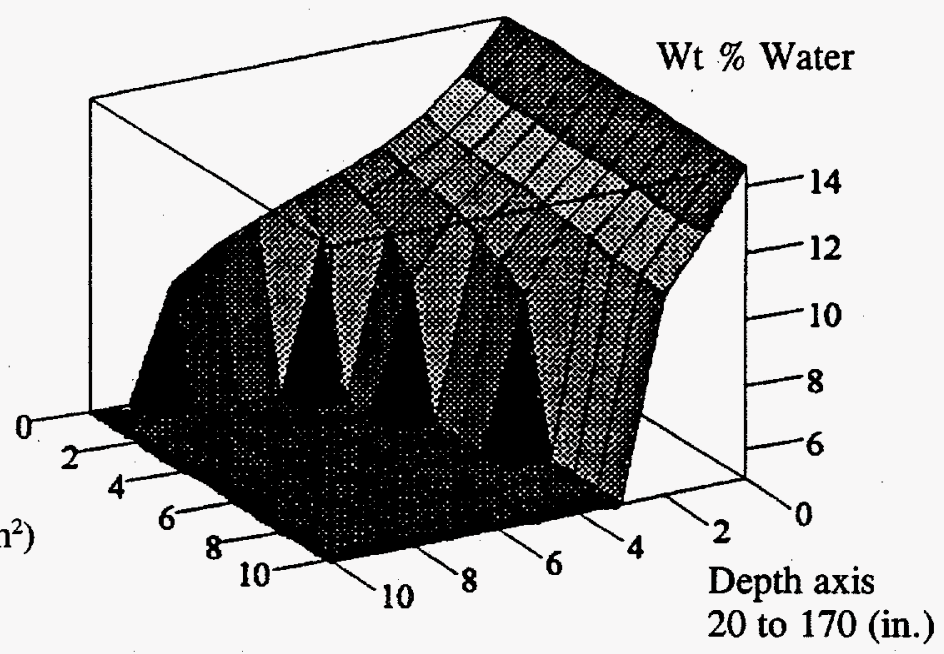

Figure 4.13a. Surface Moisture Content for Permeability of 2 darcy and Pore-Size Index of 2.1 


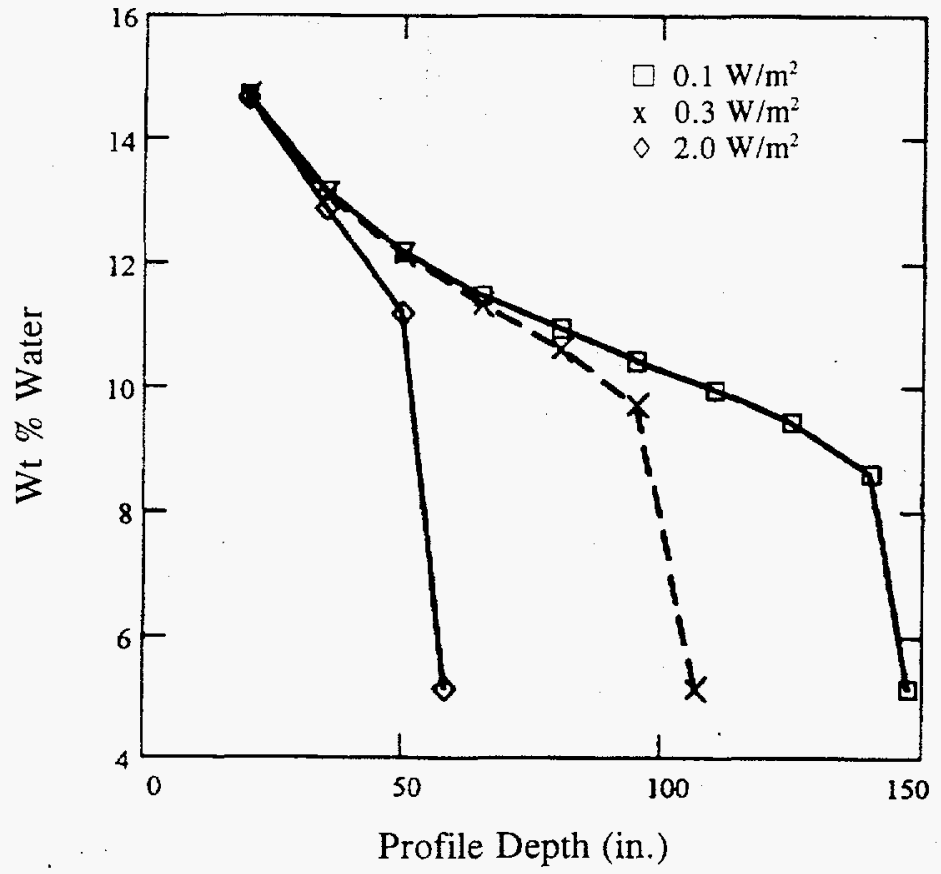

Figure 4.13b. Surface Moisture Content as Weight Percent Water for Permeability of 2 darcy and Pore-Size Index of 2.1

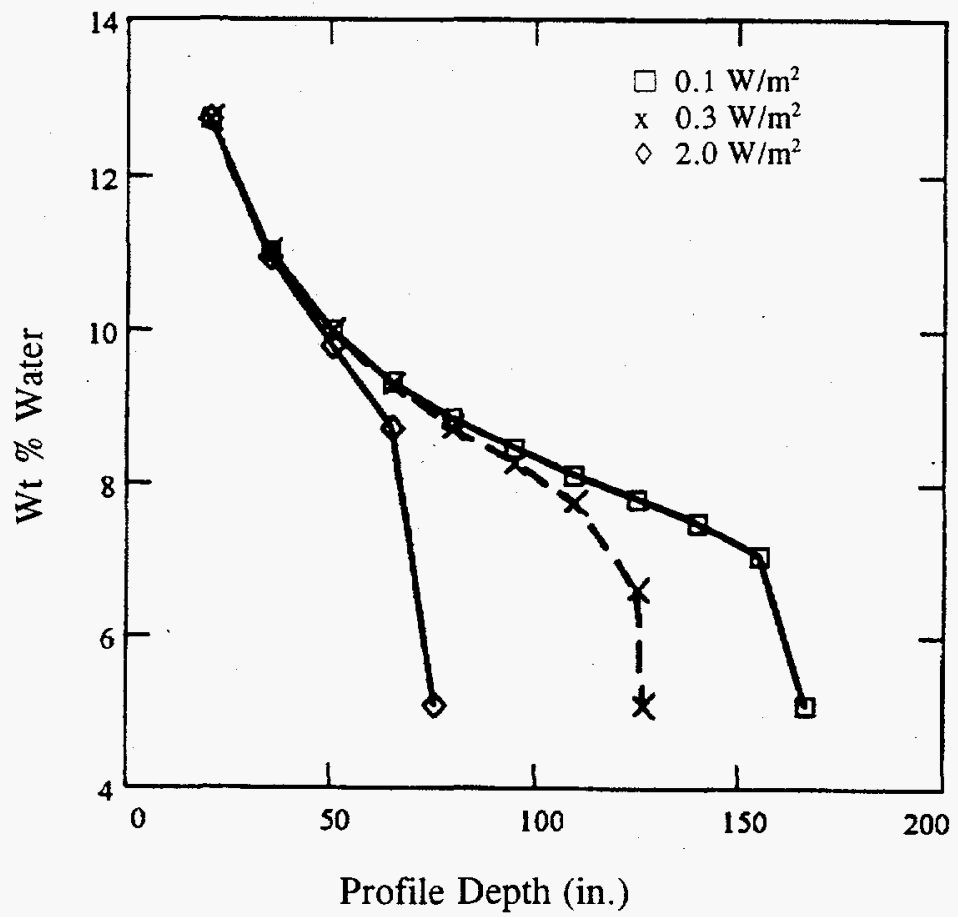

Figure 4.14. Surface Moisture Content for Evaporative Flux with Pore-Size Index Reduced to 1.5 


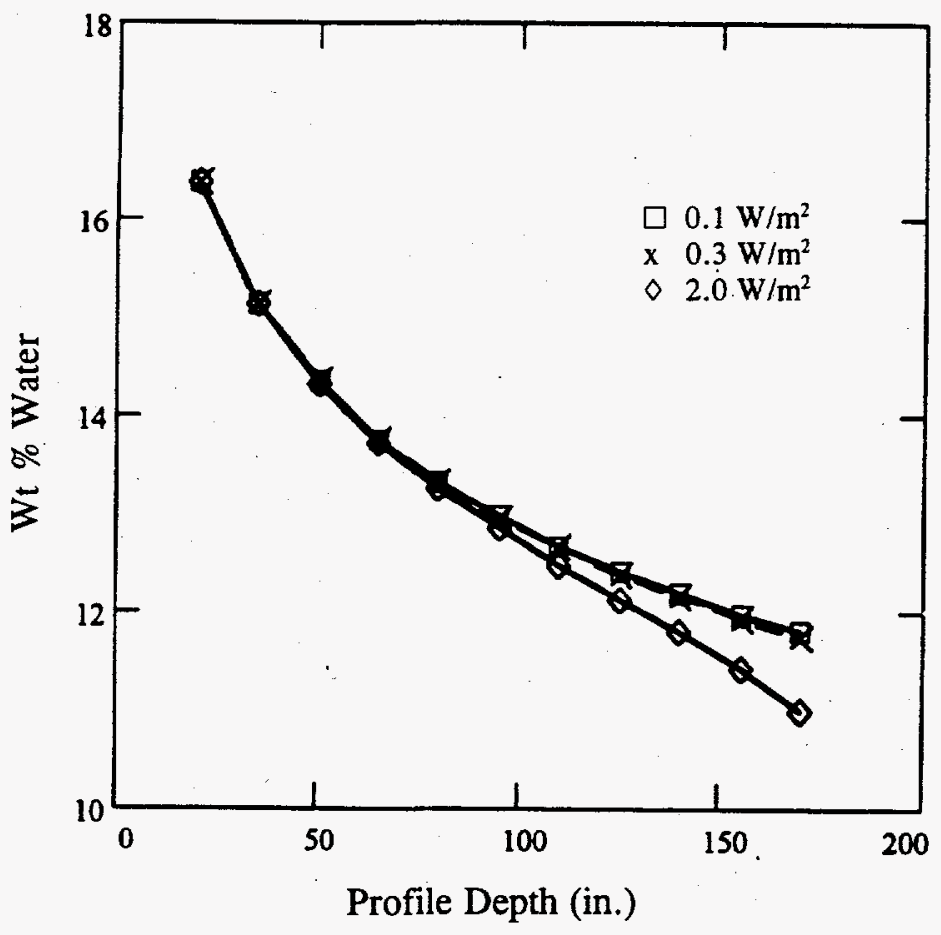

Figure 4.15. Surface Moisture Content for Evaporative Flux with Pore-Size Index Increased to 3

Figure 4.14 shows that the surface will resist drying out if the profile depth to the ILL is less than 50 in. In contrast, Figure 4.1 b shows that the waste surface would not dry out for depths less than $100 \mathrm{in}$. when the pore-size index is 2.1. For a larger pore-size index of 3 , as found for some of the pumping responses of TX tanks, Figure 4.15 shows that profiles as high as 170 in. would not be dried out for the full range of evaporative fluxes.

These sensitivity results show that the surface moisture content is very dependent on the specific values of permeability and pore-size index that characterize the saltcake waste. However, as intuition might suggest, the surface can still remain moist if the profile depth is sufficiently small, and the ILL is near the surface, regardless of how large the evaporative flux is. Clearly, to make better estimates of waste surface moisture, a better estimate of the unknown evaporative flux is required. More advanced modeling of water vapor flow is required for nonisothermal waste conditions to better pin down the relevant evaporative flux.

\subsection{Modeling Limitations}

The model represents a first step in connecting evaporation with interstitial liquid flow controlled by capillarity. Liquid flow and water vapor movement in the unsaturated zone under nonisothermal conditions in the waste profile still need to be fully coupled to accurately assess the potential for dryout. 
The possibility of deliquescence near the cooler surface is not taken into account. This hygroscopic phenomenon depends on the extent of lowering the saturation vapor pressure by the particular salt composition near the surface.

Depending on the thermal gradient in the profile, upward vapor flow may nearly balance a downward flow of liquid driven by gravity. Thus the excess liquid condensed near the surface may produce a net downward flow, which would result in higher moisture content near the surface than in the static equilibrium condition. The possibility of such a moisture cycle acting within a waste profile cannot be examined until the model incorporates more complete and correct physics, as described by Nassar and Horton (1989). Better estimates of the hydraulic parameters and the water vapor pressure's dependence on the salt composition of the waste would also be required.

Also, as the liquid flows either up or down, depending on the hydraulic and thermal gradients, dissolved salts will be transported. This salt migration, if substantial, would affect the porous matrix structure over time. A relatively small change in pore-size distribution can drastically influence the hydraulic properties and the moisture retention behavior, and this aspect must also be considered. An experimental study under controlled laboratory conditions may be necessary to accurately determine the magnitude of the mechanisms that would move both water and dissolved salt when subjected to a thermal gradient.

\subsection{Conclusions}

A simplified model was developed for calculating the moisture distribution in a saltcake waste profile that has been stabilized by removing all drainable liquid. The model neglects nonisothermal vapor flow and the possible movement of dissolved saltcake, and it is one-dimensional. The basic physical properties and hydraulic parameters required to estimate the moisture content in a saltcake waste profile were identified for waste characterization purposes. Model parameters can be found by matching its prediction of the moisture distribution to the relative saturation determined from neutron probe scanning measurements.

The model can be used best to determine how great an evaporative flux can be maintained at the waste surface without causing dryout. Precise values for the surface moisture content, however, cannot be determined without taking vapor movement into account. A more advanced model is required to account for vapor movement in the waste profile.

The model showed that the surface of saltcake in Tank BY-104 would have about 12 wt\% water content, whereas that of Tank TX-105 would be dried to the residual of $5 \mathrm{wt} \%$. The height of the saltcake profile appears to be the primary variable determining whether surface dryout will occur for given hydraulic parameter values. 


\subsection{References}

Arya, L. M., and J. F. Paris. 1981. “A Physiocoempirical Model to Predict the Soil-Moisture Characteristic from Particle-Size Distribution and Bulk-Density Data." Soil Sci. Soc. Am. J. 45:1023-1030.

Atherton, J. A. 1974. Prediction of Liquor Retention in Salt Cake and Sludges. ARH-CD-230, Atlantic Richfield Hanford Company, Richland, Washington.

Beck, M. A., D. B. Bechtold, and B. E. Hey. 1992. Analysis Report for 241-BY-104 Auger Samples. WHC-SD-WM-TI-540, Westinghouse Hanford Company, Richland, Washington.

Campbell, G. S. 1985. Soil Physics with BASIC Transport Models for Soil-Plant Systems. Elsevier, New York.

Cash, R. J., J. E. Meacham, and G. T. Dukelow. 1995. Quarterly Report on the Ferrocyanide Safety Program for the Period Ending March 31, 1995. WHC-EP-0474-16, Westinghouse Hanford Company, Richland, Washington.

Das, B. M. 1979. Introduction to Soil Mechanics. Iowa State University Press, Ames, Iowa.

Das, B. M. 1983. Advanced Soil Mechanics. Hemisphere Publishing, New York.

DeWeese, G. C. 1988. Observed Porosity of Single-Shell Tank Waste Salt Cakes and Sludges. WHC-SD-WM-TI-328, Westinghouse Hanford Company, Richland, Washington.

Dombrowski, H. S., and L. E. Grownell. 1954. "Residual Equilibrium Saturation of Porous Media." Industrial and Engineering Chemistry 46(6):1207-1219.

Epstein, M., H. K. Fauske, D. R. Dickinson, M. D. Crippen, J. D. McCormack, R. J. Cash, J. E. Meacham, and C. S. Simmons. 1994. Ferrocyanide Safety Program: An Assessment of the Possibility of Ferrocyanide Sludge Dryout. WHC-EP-0816, Westinghouse Hanford Company, Richland, Washington.

Fauske, H. K., M. Epstein, D. R. Dickinson, R. J. Cash, D. A. Turner, and J. E. Meacham. 1995. The Contact-Temperature Ignition (CTI) Criteria for Propagating Chemical Reactions Including the Effect of Moisture and Application to Hanford Waste. WHC-SD-WM-ER-496, Westinghouse Hanford Company, Richland, Washington.

Gardner, W. R. 1958. "Some Steady-State-Solutions of the Unsaturated Moisture Flow Equation with Application to Evaporation from a Water Table." Soil Science 85:228-232. 
Grigsby, J. M., A. K. Postma, R. J. Cash, J. E. Meacham, D. R. Dickinson, M. A. Lilga, H. K. Fauske, and M. Epstein. 1996. Assessment of the Potential for Ferrocyanide Propagating Reaction Accidents. WHC-SD-WM-SARR-038, Westinghouse Hanford Company, Richland, Washington.

Grigsby, J. M., D. B. Bechtold, G. L. Borsheim, M. D. Crippen, D. R. Dickinson, G. L. Fox, D. W. Jeppson, M. Kummerer, J. M. McLaren, J. D. McCormack, A. Padilla, B. C. Simpson, and D. D. Stepnewski. 1992. Ferrocyanide Waste Tank Hazards Assessment-Interim Report. WHC-SD-WM-RPT-032, Rev. 1, Westinghouse Hanford Company, Richland, Washington.

Handy, L. L. 1975. Flow Properties of Salt Cake for Interstitial Liquid Removal/Immobilization Development Program. ARH-C-6, Atlantic Richfield Hanford Company, Richland, Washington.

Hanlon, B. M. 1993. Tank Farm Surveillance and Waste Status Summary Report for June 1993. WHC-EP-0182-63, Westinghouse Hanford Company, Richland, Washington.

Jeppson, D. W., and J. J. Wong. 1993. Ferrocyanide Waste Simulant Characterization. WHC-EP-0631, Westinghouse Hanford Company, Richland, Washington.

King, C. V. 1994. Ferrocyanide Safety Program: Results of Relative Humidity Experiments Using Ferrocyanide Waste Simulants. WHC-SD-WM-TRP-215, Rev. 0, Westinghouse Hanford Company, Richland, Washington.

Kirk, J. J. 1980. Permeability, Porosity and Capillarity of Hanford Waste Material and Its Limits of Pumpability. RHO-CD-925, Rockwell Hanford Operations, Richland, Washington.

Marshal, T. J., and J. W. Holmes. 1979. Soil Physics. Cambridge University Press, London.

Meacham, J. E., H. Babad, R. J. Cash, G. T. Dukelow, S. J. Eberlein, D. W. Hamilton, G. D. Johnson, J. W. Osborne, M. A. Payne, D. J. Sherwood, and D. A. Turner. 1995. Approach for Tank Safety Characterization of Hanford Site Waste. WHC-EP-0843, Westinghouse Hanford Company, Richland, Washington.

Metz, W. P. 1976. A Topical Report on Interstitial Liquid Removal from Hanford Salt Cakes. ARH-CD-545, Atlantic Richfield Hanford Company, Richland, Washington.

Mishra, S., J. C. Parker, and N. Singhal. 1989. "Estimation of Soil Hydraulic Properties and Their Uncertainty from Particle Size Distribution Data." Jour. of Hydrology 108:1-18.

Nassar, I. N., and R. Horton. 1989. "Water Transport in Unsaturated Nonisothermal Salty Soil: II. Theoretical Development." Soil Sci. Soc. Am. J. 53:1330-1337.

Porter, H. F., Schurr, G. A., Wells, D. F., and K. T. Semrau. 1984. "Solids Drying and Gas-Solid Systems." In Perry's Chemical Engineers' Handbook, Sixth Edition, Section 20, eds R. H. Perry and D. W. Green, McGraw-Hill, New York. 
Postma, A. K., J. E. Meacham, G. S. Barney, G. L. Borsheim, R. J. Cash, M. D. Crippen, D. R. Dickinson, J. M. Grigsby, D. W. Jeppson, M. Kummerer, J. M. McLaren, C. S. Simmons, and B. C. Simpson. 1994. Ferrocyanide Safety Program: Safety Criteria for Ferrcyanide Watch List Tanks. WHC-EP-0691, Westinghouse Hanford Company, Richland, Washington.

Sridharan, A., and G. V. Rao. 1973. "Mechanisms Controlling Volume Change of Saturated Clays and the Role of the Effective Stress Concept." Geotechnique 23(3):359-382.

Strachan, D. M. 1975. Permeability, Capillarity, and Pore Volume of Synthetic Hanford Salt Cake. ARH-ST-129, Atlantic Richfield Hanford Company, Richland, Washington.

Tyler, S. W., and S. W. Wheatcraft. 1989. "Application of Fractal Mathematics to Soil Water Retention Estimation.” Soil Sci. Soc. Am. J. 53:987-996.

Wanner, D. D. 1993. Justification of Saltcake Simulants. WHC-SD-WM-TI-545, Westinghouse Hanford Company, Richland, Washington. 
Appendix A

Models of Column Drainage 


\section{Appendix A}

\section{Models of Column Drainage}

Suspension settling and porous conduction models: Each process depends on the same variable, the relative apparent saturation, $S$, defined equivalently by

$$
S=\frac{e-e_{f}}{e_{o}-e_{f}} \quad \text { and } \quad S=\frac{\theta-\theta_{f}}{\theta_{o}-\theta_{f}}
$$

Exponential decrease applies to both models, over time, $t$ :

$$
S=\exp \left(-\frac{t}{\tau}\right) . \quad \text { for a time constant } \tau \text {. }
$$

Suspension Settling

Stoke's particle settling velocity $v_{s}=\frac{g \cdot \Delta \rho \cdot d^{2}}{18 \cdot \mu} \quad \Delta \rho=\rho_{p}-\rho_{L}$

$$
\tau=\frac{10 \cdot \mathrm{L}}{v_{s}} \cdot \frac{\phi_{o}}{\phi_{f}}
$$

\section{Porous Conduction}

Brooks-Corey conductivity function $K(S)=\mathrm{Ko} \cdot \mathrm{S}^{\beta}$ for $\quad \beta=1$

$$
\tau=\frac{L}{G} \cdot \frac{K_{0}}{K_{0}} \cdot\left(\theta_{f}\right)
$$

where

$\theta$ is apparent volumetric liquid content (based on a fixed initial sample volume)

e is void ratio

$\phi$ is volumetric solids fraction These variable are related by

$\mathrm{L}$ is column length

$$
\phi=\frac{1}{1+\mathrm{e}} \text { and } \frac{\theta}{\theta_{\mathrm{o}}}=\frac{\mathrm{e}}{\mathrm{e}_{\mathrm{o}}}
$$

$\mathrm{d}$ is particle size diameter

$\mathrm{g}$ is gravity acceleration

$\rho$ is density (subscript $p$ for particle density; subcript $L$ for liquid density) 
Ko is liquid conductivity at starting void ratio (units lenght/time)

$\mathrm{G}$ is liquid hydraulic gradient or specific gravity

Consolidation-Conduction (Thin Layer)

$$
\tau=-\frac{\mathrm{L}^{2} \cdot \mathrm{Av}}{2 \cdot \mathrm{Ko} \cdot\left(1+\mathrm{e}_{\mathrm{o}}\right)}
$$

Assuming

$$
e=e_{0}-A v \cdot\left(\sigma^{\prime}-\sigma_{o}^{\prime}\right)
$$

defines the consolidation characteristic curve, where

$e_{o}$ is starting void ratio

$e_{f}$ is final void ratio at equilibrium under compression

$\sigma^{\prime} \quad$ is effective stress head (length units of water column height)

$\sigma^{\prime} \circ$ is the initial effective stress head

Av is the coefficient of compressibility (units $1 /$ length).

Note: $\frac{\mathrm{Av}}{1+\mathrm{e}_{\mathrm{o}}} \quad \begin{aligned} & \text { is called the coefficient of volume compressibility, } \\ & \text { a relative measure }\end{aligned}$

$\mathrm{Cv}=\frac{\mathrm{Ko} \cdot\left(1+\mathrm{e}_{\mathrm{o}}\right)}{\mathrm{Av}} \quad$ is called the coefficient of consolidation

$\frac{\mathrm{Cv} \cdot \mathrm{t}}{\mathrm{L}^{2}} \quad$ is called the time factor (dimensionless) for each time, $t$, 
Thus, the void ratio satisfies the following equation for the consolidation-conduction model:

$$
\begin{aligned}
& \frac{e-e_{f}}{e_{o}-e_{f}}=\exp (-2 \cdot T f) \\
& (1-S) \cdot 100 \text { is called the degree of consolidation, in percent }
\end{aligned}
$$

This model assumes also that the conductivity depends on the void ratio as given by

$$
\mathrm{K}=\mathrm{Ko} \cdot\left(\frac{1+\mathrm{e}}{1+\mathrm{e}_{\mathrm{o}}}\right)
$$

as the void ratio decreases. 
Appendix B

Equivalent Viewpoints of Drainage During Consolidation 


\section{Appendix B}

\section{Equivalent Viewpoints of Drainage During Consolidation}

Formulas for the liquid drainage from a sludge column are derived in this appendix based on both a porous medium and a particle suspension perspective. The formulas demonstrate that the draining system can be conceptualized as a consolidating deformable porous medium or as a settling suspension of particles. This derivation relates the intrinsic permeability to the Stoke's sedimentation velocity of a single sludge particle. The system is assumed to remain saturated during the entire process, so that the porosity remains liquid filled.

A suspension viewpoint and porous medium viewpoint of drainage during consolidation can be brought into correspondence by noting that the liquid that would have accumulated above a settling suspension must drain through an open bottom at a rate that matches the decline in the sludge surface.

\section{Suspension SettlingViewpoint:}

The consolidation velocity for the decrease in column length was discovered by Powers in 1939 (see Tadros 1980) to satisfy the following relationship:

$$
v_{\text {con }}=0.1 \cdot v_{s} \cdot \frac{\phi_{f}-\phi}{\phi}
$$

where the Stoke's settling velocity for particles is given by

$$
v_{s}=\frac{g \cdot(\Delta \rho) \cdot d^{2}}{18 \cdot \mu_{L}}
$$

and where $\phi$ is the particle volume concentration. This particle settling velocity depends on the following parameters

$\mathrm{g}$ is gravitational acceleration

$\Delta \rho$ is density difference between solid particles and supernatant

$\mu$ is liquid viscosity (for subscript $L$ )

$\mathrm{d}$ is a mean diameter of particles

$\phi$ is also called solidosity or solid volume fraction

Letting $\mathrm{X}$ denote the column height, the kinetic expression for settling is

$$
\frac{\mathrm{d}}{\mathrm{dt}} \mathrm{X}=(-\mathrm{v} \text { con })
$$


Conservation of particle volume is expressed by

$$
\phi \cdot X=\phi_{0} \cdot X_{0}
$$

Using equations (B.1) with (B.3) and (B.4) yields a differential equation for the particle volume fraction:

$$
\frac{\mathrm{d}}{\mathrm{dt}} \phi=\frac{\mathrm{v}_{\mathrm{s}} \cdot \phi \cdot\left(\phi_{\mathrm{f}}-\phi\right)}{10 \cdot \phi_{\mathrm{o}} \cdot \mathrm{X}_{\mathrm{o}}}
$$

where the subscripts " $\mathrm{f}$ " and "o" refer to the final and initial conditions, respectively. Solving equation (B.5) gives

$$
\frac{\phi}{\phi_{\mathrm{o}}} \cdot\left(\frac{\phi_{\mathrm{f}}-\phi_{\mathrm{o}}}{\phi_{\mathrm{f}}-\phi}\right)=\exp \left(\frac{\mathrm{t}}{\tau}\right)
$$

where the time constant, $\tau$, is given by

$$
\frac{1}{\tau}=0.1 \cdot \frac{v_{s}}{X_{o}} \cdot\left(\frac{\phi_{f}}{\phi_{o}}\right)
$$

Usually, the void ratio, $\mathrm{e}$, is employed to describe the condition of a deformable porous medium, because it is the ratio of void volume to the fixed solids volume. In terms of the volumetric liquid content, $\theta$, the void ratio is given by

$$
\mathrm{e}=\frac{\theta}{1-\theta}
$$

Because in a saturated sludge medium the pore space is filled with liquid, the conservation of volume is expressed by

$$
\theta+\phi=1
$$

Substituting (B.9) into (B.8) for $\theta$, gives the relationship between particle volume fraction and void ratio,

$$
\phi=\frac{1}{1+e}
$$

The equation (B.10) can be used to express equation (B.6) in terms of the void ratio as follows.

$$
e=\left(e_{o}-e_{f}\right) \cdot \exp \left(-\frac{t}{\tau}\right)+e_{f}
$$


Notice that the void ratio by equation (B.11) conforms to a simple exponential decline, as compared with the more complicated expression for solidosity in equation (B.6).

To compare consolidation by suspension settling with gravity driven drainage, it is helpful to introduce the relative void ratio given by

$$
S=\frac{e-e_{f}}{e_{o}-e_{f}}
$$

In terms of the variable $S$, the settling described by equation (B.11) then satisfies a simple exponential equation given by

$$
S=\exp \left(-\frac{t}{\tau}\right)
$$

Drainage Viewpoint:

Now consider the drainage of liquid from a deformable porous medium that obeys Darcy's law. A fundamental assumption is that the liquid conductivity, $\mathrm{K}$, can be expressed as a function of void ratio. Then by liquid conservation and Darcy's law, flow satisfies

$$
\frac{d}{d t}(X \cdot \theta)=(-G) \cdot K(e)
$$

where $\mathrm{X}$ is the variable column length, and $\mathrm{G}$ is the liquid gravitational gradient. (It is assumed that the system has a small length so that a single value of liquid content or void ratio describes the entire system. The gradient of liquid pressure associated with particle adsorptive forces is neglected also.) A general flow theory is provided by Narasimhan and Witherspoon (1977).

To draw a similarity with flow in a partially saturated system, the concept of an apparent volumetric liquid content is introduced. The apparent volumetric liquid content is defined by $\theta^{\prime}=$ (liquid volume/initial medium volume). Note that the initial medium (both liquid and solid) volume is a fixed reference volume. Now the apparent liquid content and void ratio are related by

$$
\frac{\theta^{\prime}}{\theta^{\prime}}=\frac{\mathrm{e}}{\mathrm{e}_{\mathrm{o}}}
$$

And the storage of liquid in the deformable medium can be written as

$$
\mathrm{X} \cdot \theta=\mathrm{X}_{0} \cdot \theta^{\prime}
$$


By using equation (B.15), the variable $S$ is found to be identical with the relative apparent liquid content (called effective saturation), given by

$$
S=\frac{\theta^{\prime}-\theta_{f}^{\prime}}{\theta_{0}^{\prime}{ }^{-} \theta_{f}^{\prime}}
$$

Then in terms of equation (B.17), which is the same as equation (B.12), the flow equation (B.14) becomes

$$
\left(\theta^{\prime} \circ-\theta^{\prime} f\right) \cdot X \cdot \frac{d}{d t} S=(-G) \cdot K(S)
$$

The liquid conductivity in equation (B.18) is now expressed as a function of S. In unsaturated flow theory, the conductivity is written as $K(S)=K o f(S)$ where Ko is the initial maximum value, and the function $f(S)$ is called the relative conductivity, which satisfies $f(0)=0, f(1)=1$, and $0<\mathrm{f}(\mathrm{S})<1$ for $0<\mathrm{S}<1$.

An accepted functional model for relative conductivity is the Brooks-Corey equation given by

$$
f(S)=S \cdot S^{\beta-1}
$$

For partially saturated conditions, $\beta>1 ;$ but $\beta=1$ when the pores of the medium remain liquid filled. The second term raised to the $\beta-1$ power is associated with pores that become emptied of liquid during unsaturated drainage. As long as the medium remains saturated, then this nonlinear term will not enter into consideration. Narasimhan and Witherspoon (1977) indicate that an exponential form for conductivity is more commonly found to apply. Moreover, such exponential conductivity does not vanish when the value ef is reached. However, if the minimum conductivity is subtracted, and the difference between eo and ef is small, then the conductivity minus its minimum value will be approximately proportional to the variable $\mathrm{S}$. This is exactly what is implied by the suspension solution of equation (B.13).

By using the following identity

$$
\left(\theta^{\prime}{ }^{\prime}-\theta_{f}^{\prime}\right)=\theta_{o} \cdot\left(1-\frac{e_{f}}{e_{o}}\right)
$$

another time constant is defined in terms of hydraulic parameters, as given below 


$$
\frac{1}{\tau}=\frac{G}{X_{o}} \cdot \frac{K_{0}}{\theta_{o}} \cdot\left(1-\frac{e_{f}}{e_{o}}\right)^{-1}
$$

For a deformable medium that remains saturated, $\beta=1$, the drainage driven by the gravitational gradient is then found to satisfy

$$
\frac{\mathrm{d}}{\mathrm{dt}} \mathrm{S}=\left(\frac{-1}{\tau}\right) \cdot \mathrm{S}
$$

The solution of equation (B.22) is formally the same exponential equation (B.13) found for suspension settling. Equality of the time constants for each viewpoint is imposed so that the processes are observed to take place at the same rate. Taking the time constants as equal results in an equation for maximum liquid conductivity and the intrinsic permeability, $\mathrm{k}$ :

$$
\begin{gathered}
K o=\frac{\rho_{w} \cdot g}{\mu_{L}} \cdot k \\
k=\frac{\Delta \rho}{180 \cdot G \cdot \rho_{w}} \cdot\left(\frac{\theta_{0}-\theta_{f}}{1-\theta_{0}}\right) \cdot d^{2}
\end{gathered}
$$

To derive equation (B.24) the following identity is useful:

$$
\theta_{o} \cdot\left(1-\frac{e_{f}}{e_{o}}\right)=\left(\frac{\theta_{o}-\theta_{f}}{1-\theta_{o}}\right)
$$

Another useful identity is

$$
\left(\frac{\theta_{0}-\theta_{f}}{1-\theta_{0}}\right)=\frac{\phi_{f}}{\phi_{0}}-1
$$

So far, the liquid gradient appearing in the permeability equation (B.24) has not been specified. For gravity drainage, the gradient $G$ may vary as the load of the sludge weight is transferred from being entirely born by the liquid to being carried by interparticle contacts or by electrolytic repulsion of particles. An exact dynamic consolidation theory would be required to describe the time-dependence of $G$ as drainage occurs. However, describing the limits of $\mathrm{G}$ is simple and is given below.

$G=\rho / \rho_{w}$ (sludge specific gravity) when suspension is saturated and entirely suspended

$\mathrm{G}=\rho_{\mathrm{L}} / \rho_{\mathrm{w}}$ (liquid specific gravity) when sludge is unsaturated 
Because sludge density and liquid density are not substantially different, $G$ does not vary greatly in equation (B.24).

Discussion:

Although this derivation of a connection between settling and porous conduction is suggestive, it can not prove that the sludge is actually a settling suspension. It is possible to obtain a similar expression for intrinsic permeability by making use of "resistance to flow models" of Darcy's law. With such models, permeability is estimated based on the drag exerted by a viscous fluid flow over a particle of porous medium. Bear (1972) reviews the theory. A formula for permeability was derived by Harleman et al.(1963) as given by Bear (1972):

$$
\mathrm{k}=\frac{\alpha}{18} \cdot \frac{\theta^{2}}{1-\theta} \cdot \mathrm{d}^{2}
$$

where $\alpha$ is an empirical factor.

Still another formula for permeability due to Kozeny-Carman includes the same 180 factor appearing in the denominator of equation (B.24). However, that permeability equation is derived from a "hydraulic radius model." Although these permeability models are not as accurate as equation (B.24) when applied to In Farm 2 simulant sludge, they do suggest alternate explanations for the physical origin. That is, other physical conceptualizations of permeability for sludge can result in a liquid conductivity that is consistent with Darcy's law operating in a porous medium. It would be necessary to demonstrate that sludge particles are actually settling rather than liquid flowing around particles that are more or less bound in place.

The derivation of drainage based on equations (B.18) and (B.19) (a constitutive model for conductivity) allows the possibility of a nonlinear behavior leading to a lower value for $\theta_{\mathrm{f}}$ than indicated by the current range of observations. On the other hand, the suspension model's fit depends on identifying the asymptotically approached final particle volume concentration for settling.

The main conceptual limitation in the suspension derivation of consolidation is that it requires a priori knowledge of the final solid volume fraction. Also, it essentially has built in the presumption that drainage ceases at the end of the settling stage. On the other hand, for the porous conduction perspective, equation (B.14), does not depend on introducing a final void ratio, except at the shrinkage limit for which saturated conditions end. Also, the liquid conductivity in equation (B.14) does not vanish (unless imposed by a further physical constraints based on retention behavior) even when reaching the shrinkage limit, because drainage could occur into the unsaturated flow regime as well. 
An important generalization of equation (B.14) by (B.18) is that the air entering the original volume as consolidation takes place could be either distributed within pores or contained in macroscopic cavities, as long as there is a phenomenological conductivity function that applies in terms of the apparent liquid content for these different circumstances. The In Farm 2 column is forming air-filled cavities, and by the centrifugation tests, it can be expected that no air actually enters drained pores. That is, In Farm 2 simulant sludge remains saturated when consolidated by centrifugation to lower void ratio than observed in the draining column. In.a true suspension, however, the inflowing air should only fill the head space above the consolidated profile.

\section{References:}

Bear, J. 1972. Dynamics of Fluids in Porous Media, Dover Publications. Inc., New York.

Narasimhan, T. N. and P. A. Witherspoon. 1977. "Numerical Model for Saturated-Unsaturated Flow in Deformable Porous Media, 1. Theory." Water Resources Research, 13: 657-664.

Tadros, T. F. 1980. "Physical Stability of Suspension Concentrates." Adv. in Colloid and Int. Sci., 12: 141.

\section{Example Calculation:}

Harleman et al. in 1963 (see Bear 1972) reported a coefficient $\mathrm{C}$ for $\mathrm{k}=\mathrm{C} \mathrm{d}^{*} \mathrm{~d}(\mathrm{~d}$ in $\mathrm{cm}$ ) based on a fit to experimental data:

$$
\mathrm{C}:=6.54 \cdot 10^{-4}
$$

For

$$
\mathrm{d}:=0.7 \cdot 10^{-6} \cdot \mathrm{m}
$$

the permeability gives

$$
C \cdot\left(\mathrm{d} \cdot 100 \cdot \frac{\mathrm{cm}}{\mathrm{m}}\right)^{2}=3.205 \cdot 10^{-12} \cdot \mathrm{cm}^{2}
$$

Equation (B.24) using equation (B.26) gives

$$
\mathrm{k}:=4.36 \cdot 10^{-12} \cdot \mathrm{cm}^{2}
$$


with parameters

$$
\begin{aligned}
& \phi_{\mathrm{O}}: 0.3 \quad \phi_{\mathrm{f}}:=0.35 \\
& \Delta \rho: \square(2.38-1.27) \cdot \frac{\mathrm{gm}}{\mathrm{cm}^{3}} \quad \mathrm{G}:=1.27 \text { liquid sp. gravity }
\end{aligned}
$$

The maximum conductivity, Ko, based on this later permeability and 2.8 cpoise for liquid viscosity gives

$$
\text { Ko }:=0.013 \cdot \frac{\mathrm{cm}}{\text { day }}
$$

The fit of equation (B.13) to the draining column of In Farm 2 simulant sludge is essentially perfect over the range of 600 days drainage. However, note the assumed final asymptotic value of the solid volume fraction is discernible in the data, or at least apparently so. At earlier times, say less than a year, the value could not be judged.

The suspension mechanism of drainage will come to an end upon reaching $\phi f$. However, without including a description of the liquid retention mechanism, the suspension model does not account for the possibility that liquid conductivity will not vanish, and liquid will continue to drain from the consolidated unsaturated sludge medium. 
Appendix C

Consolidation of a Thin Sample of Porous Material in a Tempe Cell 


\section{Appendix C}

\section{Consolidation of a Thin Sample of Porous Material in a Tempe Cell}

Consider the compression of a thin sample of deformable porous medium in a Tempe cell with a porous outflow plate. Liquid conductivity of the outflow plate is assumed known and is $\mathrm{Kp}$. A non-wetting phase air pressure is applied above the sample which is covering the outflow plate. The applied pressure expelles liquid from the sample through the plate. For simulant sludge, by experimental observation, the applied air pressure that constitutes a compression load does not enter the pores of the sample, and the sample remains saturated. Relative to the pressure, $p$, of the pore-liquid inside the sample at any time, the pressure at the outflow side of the plate is atmospheric, at $p=0$. The pressure at the inside against the plate is called $\mathrm{p}_{\mathbf{i}}$.

The equation for the rate of liquid outflow from the cell, based on Darcy's law, is

$$
\frac{\mathrm{d}}{\mathrm{dt}}(\theta \cdot \mathrm{L})=(-1) \cdot \mathrm{K}(\mathrm{e}) \cdot \frac{\mathrm{p}-\mathrm{p}_{\mathrm{i}}}{\left(\frac{\mathrm{L}}{2}\right)}
$$

The rate of outflow given above also equals the rate of flow through the plate by conservation of liquid. Thus,

$$
(-1) \cdot K(e) \cdot \frac{p-p_{i}}{\left(\frac{L}{2}\right)}=(-1) \cdot K p \cdot \frac{p_{i}}{b}
$$

In equation (C.1), $\quad \theta \cdot \mathrm{L} \quad$ is the liquid storage in the sample, where

$\mathbf{p}$ is pore-liquid pressure (viewed as acting at the sample's center)

$p_{i}$ is pressure at interface between sample and plate

$\mathrm{e}$ is void ratio

$\theta$ is liquid volumetric content, volume of liquid per unit bulk volume $\mathrm{K}(\mathrm{e})$ is liquid conductivity as a function of void ratio in the sample $\mathrm{Kp}$ is plate conductivity

$L$ is sample thickness at any time, with an initial value Lo

$\mathrm{b}$ is the plate thickness 
$\mathrm{L}$ and $\theta$ are related to the void ratio by the following identities:

$$
\theta=\frac{\mathrm{e}}{1+\mathrm{e}} \quad \text { and } \quad \mathrm{L}=\mathrm{Lo} \cdot\left(\frac{1+\mathrm{e}}{1+\mathrm{e}_{\mathrm{o}}}\right) \quad \text { (no shrinkage from side) }
$$

Equation (C.2) and these identities give

$$
\mathrm{p}_{\mathrm{i}}=\frac{\gamma}{1+\gamma} \cdot \mathrm{p} \quad \text { with } \quad \gamma=\frac{2 \cdot \mathrm{b} \cdot \mathrm{K}}{\mathrm{Lo} \cdot \mathrm{Kp}} \cdot\left(\frac{1+\mathrm{e}_{\mathrm{o}}}{1+\mathrm{e}}\right)
$$

Equation (C.1) becomes, upon using equation (C.3),

$$
\left(\frac{\mathrm{Lo}}{1+\mathrm{e}_{\mathrm{o}}}\right) \cdot \frac{\mathrm{d}}{\mathrm{dt}} \mathrm{e}=(-1) \cdot \frac{\mathrm{Kp}}{\mathrm{b}} \cdot\left(\frac{\gamma}{1+\gamma}\right) \cdot \mathrm{p}
$$

Now the consolidation curve of the sample, $\sigma^{\prime}(e)$, which is a relation between the effective stress and the void ratio, e, relates $p$ and $e$ in equation (C.4). By definition of the effective stress, $\sigma^{\prime}$, we have also

$$
\sigma(e)=\sigma-p
$$

Consider expulsion of liquid over a step change in the applied air pressure load, $\sigma$. Initially, a load $\sigma_{0}$ is applied; and at equilibrium, the pore-liquid pressure is zero. Later, the air pressure load is step increased to $\sigma_{1}$, and the increase is transfer immediately into the liquid before being expelled. Eventually, after some time, the pore-liquid pressure returns to atmospheric conditions outside, $p=0$; and the new load is carried by the solid matrix. The change in conditions satisfy

$$
\begin{aligned}
& \sigma^{\prime}\left(e_{o}\right)=\sigma_{0} \quad \text { for } t<0 \\
& \sigma^{\prime}\left(e_{0}\right)=\sigma_{0}-p \quad \text { with } p=\sigma_{0} \text { for } t=0, \text { that is, } \sigma^{\prime}=0 . \\
& \sigma=\sigma_{1} \quad \text { for } t>0
\end{aligned}
$$

Therefore, at $\mathrm{t}=0, \quad \mathrm{p}=\sigma_{1}-\sigma_{0} \quad$ which is the increment in applied pressure.

The void ratio given by equation (C.4) then satisfies

$$
\left(\frac{\mathrm{Lo}}{1+\mathrm{e}_{\mathrm{o}}}\right) \cdot \int_{\mathrm{e}_{\mathrm{o}}}^{\mathrm{e}}\left(\frac{1+\gamma}{\gamma}\right) \cdot \frac{1}{\mathrm{p}} \mathrm{de}=(-1) \cdot \frac{\mathrm{Kp}}{\mathrm{b}} \cdot \mathrm{t}
$$


To integrate equation (C.6) and solve it, equation (C.5) and $\mathrm{K}(\mathrm{e})$ must be specified. Assume that the curve for consolidation is linear,

$$
\mathrm{e}=\mathrm{e}_{\mathrm{o}}-\operatorname{Av} \cdot\left(\sigma^{\prime}-\sigma^{\prime}{ }_{\mathrm{o}}\right)
$$

Now initial and final pore-liquid pressure conditions imply

$$
\sigma^{\prime}=\sigma_{1}-p \text { and } \quad e_{1}=e_{0}-A v \cdot\left(\sigma^{\prime}{ }_{1}-\sigma^{\prime}{ }_{0}\right) \text { or } e_{1}=e_{0}-A v \cdot\left(\sigma_{1}-\sigma_{0}^{\prime}\right)
$$

Therefore, $p$ and $e$ are related by

$$
\mathrm{p}=\frac{\mathrm{e}-\mathbf{e}_{1}}{\mathrm{Av}}
$$

Assume also a linear dependence of $\mathrm{K}$ on e given by:

$$
\mathrm{K}=\mathrm{Ko} \cdot\left(\frac{1+\mathrm{e}}{1+\mathrm{e}_{\mathrm{o}}}\right)
$$

Substituting equations (C.8) and (C.9) into equation (C.6) gives

$$
\int_{e_{0}}^{e} \frac{1}{e-e_{1}} d e=\left[\frac{-1 \cdot\left(1+e_{0}\right) \cdot t}{A v \cdot L o}\right] \cdot\left(\frac{L_{0}}{2 \cdot K_{0}}+\frac{b}{K p}\right)^{-1}
$$

Integrating equation (C.10) gives

$$
\ln \left(\frac{\mathrm{e}-\mathrm{e}_{1}}{\mathrm{e}_{\mathrm{o}}-\mathrm{e}_{1}}\right)=\frac{(-2) \cdot\left(1+\mathrm{e}_{\mathrm{o}}\right) \cdot \mathrm{Ko}}{\mathrm{Lo}^{2} \cdot \mathrm{Av} \cdot(1+\lambda)} \cdot \mathrm{t} \quad \text { with } \quad \lambda=\frac{2 \cdot \mathrm{b}}{\mathrm{Lo}} \cdot \frac{\mathrm{Ko}}{\mathrm{Kp}}
$$

When $\mathrm{Kp} \gg \mathrm{Ko}$, then $\lambda$ vanishes from equation (C.11), and this is the basis of the drainage equation given in Appendix A, independent of the plate's conductivity. 
Appendix D

Equilibrium Conditions in a One-Dimensional Column of Deformable (or Compressible) Porous Material 


\section{Equilibrium Conditions in a One-Dimensional Column of Deformable (or Compressible) Porous Material}

Consider a column of sludge with different boundary conditions when liquid pressure is at equilibrium with the weight supported by the sludge solids.

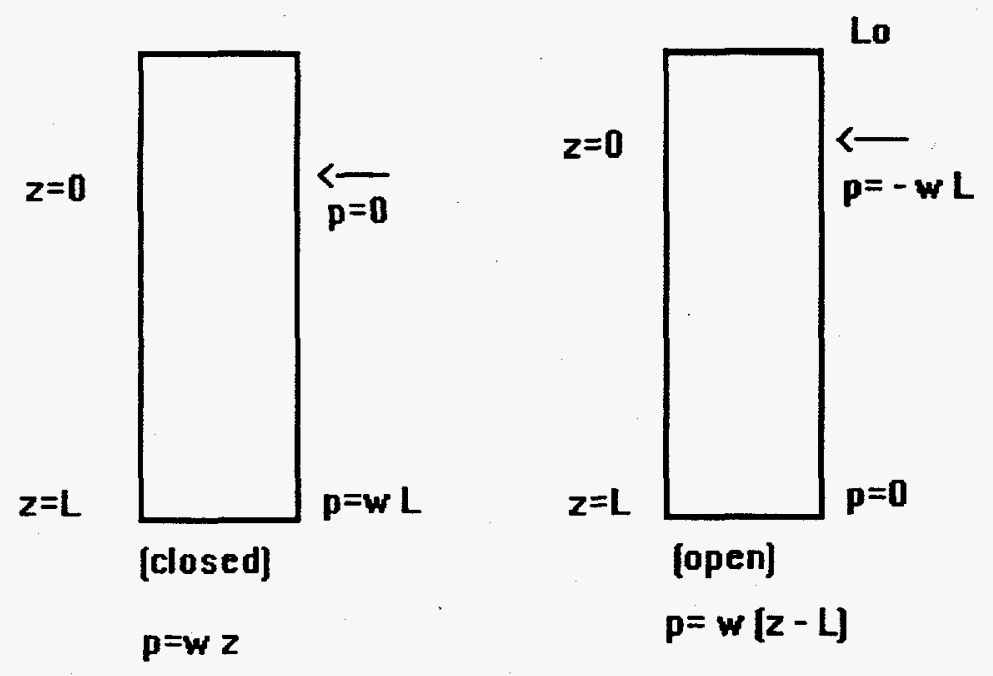

Figure D.1. Pore-Liquid Pressure for Closed and Open Boundary Conditions at the Bottom.

Figure D.1 shows the pore-liquid distributions for closed and open boundary conditions holding at the bottom of a column of sludge at equilibrium.

The self-weight of the deformable medium is responsible for the final distribution of solids and liquid in the column at equilibrium. A distribution of effective stress will be established in the equilibrium system so that it is consistent with the consolidation characteristic curve.

The load stress caused by the weight density of the bulk medium is given by the following:

$$
\text { Load_Stress }=\int_{0}^{z} w_{s}(z) d z
$$

Weight density, w, where subscript, $\mathrm{s}$, indicates sludge, is the density $(\mathrm{g} / \mathrm{ml})$ multiplied by the acceleration of gravity. 
Pore-liquid pressure, given in figure D.1, denoted by $p$, is the result of the liquid weight density distributions at equilibrium for which the total hydraulic potential is constant over depth, $z$. Equilibrium conditions prevail because there is no liquid flow under a constant total hydraulic potential.

The effective stress distribution with depth, regardless of equilibrium conditions, is given by

$$
\sigma^{\prime}=\int_{0}^{z} w_{s}(z) d z-p
$$

where

$\sigma^{\prime}$ is the effective stress (pressure units)

$h^{\prime}$ is the effective stress head $(\mathrm{cm})$, equal to divided by water weight density

Gs is the specific gravity of sludge, sludge weight density divided by water weight density.

$G$ is the specific gravity of the liquid

$\mathrm{Gp}$ is the specific gravity of the solid material particles

$\mathrm{e}$ is void ratio, equal to void volume/ solids volume

$\theta$ is volumetric liquid content, voids volume/bulk volume

$\phi$ is volumetric solids fraction, solids volume/bulk volume

In terms of head units (cm), the effective stress expressed in terms of specific gravities is given by

$$
\begin{aligned}
& h^{\prime}=\int_{0}^{z} \frac{(\mathrm{Gp}-\mathrm{G})}{1+\mathrm{e}} \mathrm{dz} \ldots \quad \text { (closed condition) } \\
& +\mathrm{G} \cdot \mathrm{L}
\end{aligned}
$$

Expressed in terms of a material coordinate, $m$, the effective stress head can be written as

$$
\begin{aligned}
& h^{\prime}=(G p-G) \cdot m+h^{\prime} o \\
& \mathbf{m}=\int_{0}^{z} \frac{1}{1+e} d z
\end{aligned}
$$


The material coordinate is the integrated solids fraction to depth, $z$. Even though the final depth, $\mathrm{L}$, of the consolidated medium depends on the particular specific gravities of solid and liquid, the maximum value of material coordinate remains the same for media having the same initial void ratio, $e_{0}$, and column length, $L_{0}$. The maximum is $m_{0}=L_{o} /\left(1+e_{o}\right)$.

Further suppose the deformable medium has an overburden of rigid medium with specific gravity, $\mathrm{Gb}$, and thickness, $D$. The the additional effective stress, given as $h_{b}=G b D$, will appear as part of $h^{\prime} \mathrm{o}$ : $h^{\prime} \mathrm{o}=h_{b}{ }_{b}$ (closed bottom) and $=G L+h_{b}$ (open bottom).

The void ratio and volumetric liquid content and solid fraction are related as follows:

$$
\theta=\frac{\mathrm{e}}{1+\mathrm{e}} \quad \text { and } \quad \phi+\theta=1
$$

As a result of these above relations, the total liquid storage, denoted by $S$, in the profile to any depth, satisfies

$$
S=z-m \quad \text { where } S=\int_{0}^{z} \theta d z
$$

The storage function provides the connection with the final settled equilibrium as determined by the consolidation characteristic of the medium. Let $\mathrm{e}=\mathrm{E}\left(\mathrm{h}^{\prime}\right)$ denote the function for the consolidation characteristic curve. Then the liquid storage to the full profile depth is given by

$$
\begin{array}{ll}
S_{L}=\int_{0}^{m_{o}} & E\left[h^{\prime}{ }_{o}+(G p-G) \cdot m\right] d m \\
\text { with } & S_{L}+m_{o}=L
\end{array}
$$

These equations for liquid storage determine the unknown profile depth $L$ for both cases. In the case of the open bottom, $h_{0}{ }_{0}$ depends on $L$ via the term $G L$; and $L$ must be solved for implicitly to satisfy both equations above. 
For each value of $m$ up to $m_{0}$, the storage can be computed with the following:

$$
S=\int_{h^{\prime}}^{h^{\prime} o_{0}^{+\Delta \cdot m}} \frac{E\left(h^{\prime}\right)}{\Delta} d h^{\prime} \text { with } \Delta=G p-G
$$

When $\mathrm{L}$ is known, by computing it as described above, each value of $\mathrm{m}$ gives an $\mathrm{S}$ and a depth, $z$, corresponding to a void ratio $\mathrm{e}(\mathrm{z})=\mathrm{E}\left(\mathrm{h}_{\mathrm{o}}{ }_{\mathrm{o}}+(\mathrm{Gp}-\mathrm{G}) \mathrm{m}\right)$. Through the relationship between the void ratio and volumetric liquid content, this calculation determines the profile liquid distribution for either boundary condition. Because the open condition imposes greater stress everywhere, by adding an additional stress term , G.L, the profile will contain less liquid than under the closed bottom condition. The difference in storage amounts, when multiplied by the base area, gives an estimate of pumpable liquid volume required to arrive at a drained equilibrium condition - i.e., stablized.

Note: The particle density (specific gravity of particles), Gp, is essentially an effective parameter that depends on the apparent volume occupied by the solids in the sludge. Particle density will depend on how it is measured, and whether all liquid is first removed. Here Gp is calculated based on measurement of the sludge bulk specific gravity, Gs, and the associated void ratio: $\mathrm{Gp}=\mathrm{Gs}(1+\mathrm{e})-\mathrm{G} \cdot \mathrm{e}$. 
Appendix E

Evaporation from Sludge 


\section{Appendix E}

\section{Evaporation from Sludge}

Conversion from Percent Moisture Loss to Wt\% Water Content

$w t \%=\frac{f w \cdot(100-X w)}{100-f w \cdot X w} \cdot 100$

$\mathrm{Xw}$ is percent moisture loss from original amount available

fw is fraction of water in the sludge initially

Water Content on Dry-Weight Basis

$$
w=\frac{f w}{1-f w} \cdot(100-X w) \quad \text { Percent }
$$

where

$M$ is sludge initial mass

$\mathrm{Mw}$ is water initial mass

$\mathrm{fw}=\mathrm{Mw} / \mathrm{M}$ is water fraction

$\mathrm{W}=(1-\mathrm{Xw} / 100) \mathrm{MW}$ is the mass of water in sludge

$\mathrm{w}=\mathrm{W} /(\mathrm{M}-\mathrm{Mw})$ is fraction of dry-weight

Liquid Diffusion Coefficient Determination:

$\ln \left(\frac{w-w f}{w i-w f}\right)=(-1) \cdot A \cdot t \quad \begin{aligned} & \text { for } w>\text { wd or } t<T d \text { (Dividing values) } \\ & \text { (for first } D \text { value) }\end{aligned}$

$\ln \left(\frac{w-w f}{w d-w f}\right)=(-1) \cdot A^{\prime} \cdot(t-T d) \quad \begin{aligned} & \text { for } w<w d \text { or } t>T d \\ & \text { (for second } D^{\prime} \text { value) }\end{aligned}$

and

$$
\begin{array}{ll}
\ln \left(\frac{w d-w f}{w i-w f}\right)=(-1) \cdot A \cdot T d & \multicolumn{1}{c}{\begin{array}{c}
\text { "i" for initial value } \\
\text { "f" for final value }
\end{array}} \\
A=\left(\frac{\pi}{2}\right)^{2} \cdot \frac{D}{L^{2}} \quad \text { where } & \begin{array}{l}
D \text { is diffusion coefficient }(\mathrm{cm} \mathrm{cm} / \text { day }) \\
\mathrm{L} \text { is sample thickness }(\mathrm{cm})
\end{array}
\end{array}
$$


Evaporative Flux Scaling:

$$
\begin{aligned}
& W=W o-A \cdot \int_{0}^{t} q d t \quad \text { for } \quad W o=M w=f w M \\
& q(w)=(-1) \cdot(1-f w) \cdot \frac{M}{A} \cdot \frac{d}{d t} w \text { or } \quad q(X w)=f w \cdot \frac{M}{A} \cdot \frac{d}{d t} \frac{X w}{100}
\end{aligned}
$$

where $\mathrm{q}$ is the water flux, and $\mathrm{A}$ is area.

Assume $\mathrm{q}$ is proportional to the relative humidity, $\mathrm{RH}$, difference, $\mathrm{RH}(\mathrm{w})-\mathrm{RHo}$.

Then

$$
q^{\prime}(w)=\frac{R H(w)-R H ' o}{R H(w)-R H o} \cdot q(w) \quad \text { is a new flux at } R H^{\prime} \circ \text { exposure. }
$$

Water content, $w^{\prime}$, for RH'o exposure, depending on new time, $t^{\prime}$, satisfies:

$$
\frac{\mathrm{d}}{\mathrm{dt} \mathrm{t}^{\prime}} \mathrm{w}^{\prime}=(-1) \cdot \frac{\mathrm{A}}{(1-\mathrm{fw})} \cdot \overline{\mathrm{M}} \cdot \mathrm{q}^{\prime}\left(\mathrm{w}^{\prime}\right)
$$

Integration and change to variable $t$ gives

$$
-(1-f w) \cdot \frac{M}{A} \cdot \int_{0}^{t} \frac{1}{q^{\prime}(w(t))} \cdot \frac{d}{d t} w d t=t^{\prime}
$$

Let

$$
r(t)=\frac{R H(w(t))-R H^{\prime} o}{R H(w(t))-R H o} \quad \text { so that } \quad q^{\prime}(w(t))=r(t) \cdot q(w(t))
$$

Then, the new scaled time satisfies

$$
\int_{0}^{t} \frac{1}{r(t)} d t=t^{\prime}
$$

Equation (E.2) defines the scaling transformation to the new time.

Note that $w(t)$ is the measured drying curve for the RHo exposure.

The transformed drying curve, $w^{\prime}=w(t)$, is the value at the corresponding $t^{\prime}$ for each $t$. 
Appendix F

Steady Upward Unsaturated Flow in a Layered Porous Profile 


\section{Appendix F}

\section{Steady Upward Unsaturated Flow in a Layered Porous Profile}

\section{Darcy's Law}

The permeability of a porous medium is $k=(\mathrm{Q} / \mathrm{A}) \mu \mathrm{L} / \Delta \mathrm{P}$

where

$\mathrm{Q}$ is flow rate or discharge rate $\left(\mathrm{cm}^{3} / \mathrm{s}\right)$

A is flow area $\left(\mathrm{cm}^{2}\right)$

$\mathrm{L}$ is flow length $(\mathrm{cm})$

$\mathbf{P}$ is pressure (atmospheres)

$\mu$ is liquid viscosity (centipoise)

and

$\mathrm{q}=\mathrm{Q} / \mathrm{A}$ is specific discharge rate or Darcy velocity $(\mathrm{cm} / \mathrm{s})$.

Permeability is expressed in units of darcies. A permeability of 1 darcy produces a specific discharge of $1 \mathrm{~cm} / \mathrm{sec}$ for a liquid with $1 \mathrm{cP}$ of viscosity under a hydraulic gradient, $\Delta \mathrm{P} / \mathrm{L}$, of $1 \mathrm{~atm} / \mathrm{cm}$. Permeability is equivalent to a flow area of $10^{-8} \mathrm{~cm}^{2}$ in cgs units.

For pressure expressed in terms of liquid head, h, Darcy's law becomes

$$
q=-(k \rho g / \mu) \Delta h / L
$$

where

$\mathrm{K}=\mathrm{k} \rho \mathrm{g} / \mu$ is the liquid's hydraulic conductivity $(\mathrm{cm} / \mathrm{sec})$

$\rho$ is liquid density $\left(\mathrm{g} / \mathrm{cm}^{3}\right)$

$\mathrm{g}$ is acceleration of gravity, $980 \mathrm{~cm} / \mathrm{s}^{2}$

$\mathrm{h}$ is liquid height $(\mathrm{cm})$

$\mu$ is liquid viscosity (centipoise) for 1 poise $=1$ dyne-sec $/ \mathrm{cm}^{2}$

If pressure is expressed in terms of water head, $h_{w}$, then

$$
\Delta \mathrm{P} 10^{+6}=\rho_{\mathrm{w}} \mathrm{g} \Delta \mathrm{h}_{\mathrm{w}}=\rho \mathrm{g} \Delta \mathrm{h}
$$

and the hydraulic conductivity, $K_{w}$, is based on the water density, $\rho_{w}$.

Note that the hydraulic conductivity, using pure water, can not be determined for a soluble porous medium such as saltcake. A saltcake-saturated solution must be used to find $K$. This is because pure water would dissolve the pore structure and change the intrinsic permeability, $\mathrm{k}$. 


\section{Unsaturated Flow}

By taking into account the total hydraulic potential, which equals the sum of the matric and gravitational potential, Darcy's law becomes

$$
q=-K(d h / d z+1)=-K_{w}\left(d h_{w} / d z+\rho / \rho_{w}\right)
$$

Here $\mathrm{q}$ is positive for upward flow with the vertical coordinate, $z$, as positive when downward.

For unsaturated flow, $\mathrm{h}$ is the matric suction head, which is the height of liquid that can be held up against gravity by capillarity in a porous matrix. Matric suction head is the capillary pressure divided by the weight density, $\rho \mathrm{g}$, of the liquid, and it is a positive (non-negative) quantity above the reference point where the liquid pressure equals the atmospheric pressure. Suction head is also the negative of the liquid's local matric potential energy per unit weight. By this convention, $h$ would be negative when corresponding to positive hydrostatic pressure in the saturated zone below the reference point.

In the unsaturated state, the matric suction, $\mathrm{h}$, and liquid conductivity, $\mathrm{K}$, are functions of the local volumetric liquid content, $\theta$. A conventional constitutive relationship between $h, K$ and $\theta$ is the Brooks-Corey model for the unsaturated hydraulic properties:

$$
\mathrm{h}=\mathrm{h}_{\mathrm{s}} \cdot \mathrm{s}^{-\mathrm{b}} \quad \mathrm{K}=\mathrm{K}_{\mathrm{s}} \cdot \mathrm{s}^{\mathrm{\beta}}
$$

where $S$ is the relative degree saturation defined by

$$
S=\frac{\theta-\theta_{r}}{\theta_{s}-\theta_{r}}
$$

Here the subscripts "s" and " $r$ " refer to saturated and residual liquid content, respectively. The liquid conductivity vanishes at residual liquid content and capillary pore flow ceases. Parameters of the model are the holdup height, $h_{s}$, the saturated conductivity, $\mathrm{K}_{\mathrm{s}}$, and the pore-size index, $\mathrm{b}$. Ideally, $\beta=2 b+3$, by a capillary pore flow theory (Campbell 1985).

Using equations (F.1) and (F.2), Darcy's law for flow can be expressed entirely in terms of the variable $h$. The conductivity employed in equation (F.1) is

$$
\mathrm{K}(\mathrm{h})=\mathrm{K}_{\mathrm{s}} \cdot\left(\frac{\mathrm{h}_{\mathrm{s}}}{\mathrm{h}}\right)^{\mathrm{c}} \quad \text { for } \quad \mathrm{h} \geq \mathrm{h}_{\mathrm{s}}
$$

and $\mathrm{K}$ equals $\mathrm{K}_{\mathrm{s}}$ otherwise, when $\mathrm{h}$ is less than $h_{s}$, and where $\mathrm{C}=2+3 / \mathrm{b}$. 
For steady, upward flow conditions, $\mathrm{q}$ is a nonnegative constant, and the porous region is $z>0$ below the surface at $z=0$. Using equation (F.4) substituted into equation (F.1), the solution for $h(z)$, within a part of the profile where the model parameters remain the same, i.e., a layer, is given by integration:

$$
Z_{0}-Z=\int_{h_{0}}^{h} \frac{1}{\left(\frac{R}{\operatorname{Kr}(h)}+1\right)} d h
$$

for $R=q / K_{s}$ where $K r(h)=K(h) / K_{s}$ is the relative conductivity; $Z_{o}$ is a reference depth for a specified $h_{0}$.

Equation (F.5) determines h implicitly as a function of z. Once $h(z)$ is calculated, it is substituted into the liquid retention relation of (F.2) to determine $S$ at each depth and the $\theta$ profile.

\section{Heterogeneous Layered Profiles}

Let

$$
Z f\left(h, h_{0}, a\right)=\int_{h_{0}}^{h} \frac{1}{\left(\frac{R}{K r(h)}+1\right)} d h
$$

where $a=\left(R, b, h_{s}\right)$ is the set of model parameters for each material layer. Starting at the profile bottom with the first layer, the value of $h_{1}$ at the top of that first layer is determined by

$$
Z_{0}-Z_{1}=Z f\left(h_{1}, h_{0}, a_{1}\right)
$$

where the layer thickness is

$$
\delta Z_{1}=Z_{0}-Z_{1} \quad \text { and } \quad \delta Z_{i}=Z_{i-1}-Z_{i} \text { (layer } i \text { ). }
$$

The sequence of solutions to the top of each layer is found by repeating the calculation:

$$
\delta Z_{i}=Z f\left(h_{i}, h_{i-1}, a_{i}\right)
$$

The profile for $h(z)$ within each layer is then found by solving for each $z$ up to $Z_{i}$

$$
\left(Z_{i-1}-z\right)=Z f\left(h(z), h_{i-1}, a_{i}\right)
$$


A complication to solving equation (F.7) is that $h$ becomes infinite if a layer is too thick to sustain the given flux q. For certain functions $\mathrm{Kr}(\mathrm{h})$, the integral (F.6) can be calculated as an analytical expression. However, in general, the integral must be obtained numerically for the Brooks-Corey model (F.2). Also, the integral (F.6) is difficult to calculate because h may vary over many orders of magnitude.

A transformation of variable is used to facilitate calculation of equation (F.6). Let $\eta=\ln (h)$. Then

$$
q=(-1) \cdot J(\eta) \cdot\left(\frac{d}{d z} \eta+e^{-\eta}\right)
$$

where

$$
\begin{array}{ll}
J(\eta)=J_{s} \cdot \exp \left[-\lambda \cdot\left(\eta-\eta_{s}\right)\right] & \eta \geq \eta_{s} \\
J(\eta)=K_{s} \cdot e^{\eta} & \eta<\eta_{s}
\end{array}
$$

with $\lambda=\mathrm{C}-1$ and

$$
J_{s}=K_{s} \cdot e^{\eta_{s}} \quad \eta_{s}=\ln \left(h_{s}\right)
$$

Expressed in terms of the transformed variable $\eta$, the integral of equations (F.5) or (F.6) becomes

$$
\operatorname{Zf}\left(\eta, \eta_{0}, a\right)=\int_{\eta_{0}}^{\eta} \frac{1}{\left(\frac{q}{J(\eta)}+e^{-\eta}\right)} d \eta
$$

where

$$
\begin{array}{cc}
\eta_{0}=\ln \left(h_{0}\right) & \\
\text { with } & \frac{q}{J(\eta)}=R \cdot \exp \left[\left[(\lambda+1) \cdot \Phi\left(\eta-\eta_{s}\right)-1\right] \cdot\left(\eta-\eta_{s}\right)\right] \\
R=\frac{q}{J_{s}} \quad \lambda=1+\frac{2}{b}
\end{array}
$$

$\Phi(\mathrm{x})$ equals 1 when $\mathrm{x}$ is non-negative and equals 0 otherwise. Parameters of equation (F.11) are now $a=\left(R, \lambda, \eta_{s}\right)$. Note that the integral can be evaluated analytically when $\eta$ becomes sufficiently large because the term $\exp (-\eta)$ vanishes relative to $R \exp \left(\lambda\left(\eta-\eta_{0}\right)\right)$ in the integrand of equation (F.11). 
For sufficiently small $\varepsilon>0$, let $\eta_{c}$ satisfy

$$
\eta_{c}>\eta_{s} \quad \text { and } \quad \frac{e^{-\eta}}{R \cdot \exp \left[\lambda \cdot\left(\eta-\eta_{s}\right)\right]} \leq \varepsilon
$$

when $\eta>\eta_{c} \quad$ Then

$$
\eta_{c}=\frac{\lambda \cdot \eta_{s}-\ln (R \cdot \varepsilon)}{\lambda+1}
$$

The approximate integration of equation (F.11) is then found as

$$
Z f\left(\eta, \eta_{c}, a\right)=\frac{1}{R \cdot \lambda} \cdot\left[\exp \left[-\lambda \cdot\left(\eta_{c}-\eta_{s}\right)\right]-\exp \left[-\lambda \cdot\left(\eta-\eta_{s}\right)\right]\right]
$$

The exact integral is between equation (F.14) and (F.14) multiplied by $1 /(1+\varepsilon)$. Thus, the maximum layer thickness is given by

$$
\operatorname{Max} \delta Z=Z f\left(\eta_{c}, \eta_{0}, a\right)+Z f\left(\infty, \eta_{c}, a\right)
$$

when $\eta_{c}>\eta_{0}$

Otherwise, equation (F.14) with $\eta_{\mathrm{o}}$ substituted for $\eta_{\mathrm{c}}$ can be used to calculate equation (F.11).

For points, $z$, less than $Z_{o}-\operatorname{Max} \delta Z$, the liquid content is at the residual value. However, for $z$ greater than $Z_{o}-\operatorname{Max} \delta Z$ (i.e., below the layer surface of maximum thickness), $h(z)$ has a finite value associated with $\theta(z)$ greater than $\theta_{\mathrm{r}}$. 


\section{Moisture Content Conversion}

Given the volumetric liquid content $\theta(z)$ at each profile depth $z$, the weight percent water is found as follows.

$$
W t \%(\theta)=\frac{P w \cdot \rho_{L} \cdot \theta}{\rho_{p} \cdot\left(1-\theta_{s}\right)+\rho_{L} \cdot \theta}
$$

where

$$
\begin{array}{ll}
\rho_{L} & \text { is liquid density } \\
\rho_{p} & \text { is particle grain density } \\
P_{w} & \text { is percent water in liquid } \\
\theta_{S} & \text { is saturated volumetric liquid content. }
\end{array}
$$

Note that the particle density and saturated liquid content would vary for each layer. 


\section{Distribution}

No. of

Copies

\section{OFFSITE}

2 DOE/Office of Scientific and Technical Information

C. S. Abrams

1987 Virginia

Idaho Falls, ID 83404

K. K. Bandyopadhyay

Brookhaven National Laboratory

Upton, NY 11973

\section{J. S. Byrd}

University of South Carolina

Department of Electrical and Computer

Engineering

Swearingen Engineering Center

Columbia, SC 29208

D. O. Campbell

102 Windham Road

Oak Ridge, TN 37830

F. N. Carlson

6965 North 5th West

Idaho Falls, ID 83401

Greg R. Choppin

Florida State University

Department of Chemistry B-164

Tallahassee, FL 32306

E. D. Collins

Oak Ridge National Laboratory

P.O. Box 2008

7930, MS-6385

Oak Ridge, TN 37831-6385
No. of

Copies

3 R. S. Daniels

Science Applications International

Corporation

20300 Century Blvd, Suite 200-B

Germantown, MD 20874

2 Fauske and Associates, Inc.

16W070 W. 83rd St.

Burr Ridge, IL 60521

ATTN: M. Epstein

H. K. Fauske

M. W. First

Harvard University

295 Upland Avenue

Newton Highlands, MA 02161

C. W. Forsberg

Oak Ridge National Laboratory

P.O. Box 2008

MS-6495

Oak Ridge, TN 37831-6495

2 G \& P Consulting, Inc.

3640 Ballard Road

Dallas, OR 97338

ATTN: J. M. Grigsby

A. K. Postma

M. T. Gordon

State of Washington - Department of

Ecology

P.O. Box 47600

Olympia, WA $98504-7600$

C. Grelecki

Hazards Research Corporation

200 Valley Road, Suite 301

Mt. Arlington, NJ 07856

Distr.1 
No. of Copies

C. Hilland

U.S. Department of Energy

656 Quince Diamond Road

Room 235, EM-20.1

Gaithersburg, MD 20879

B. C. Hudson

202 Northridge Court

Lindsborg, KA 67456

M. S. Kazimi

MIT/Department of Nuclear Engineering

77 Massachusetts Ave.

Room 24-102

Cambridge, MA 02139

\section{J. L. Kovach}

Nuclear Consulting Services, Inc.

P.O. Box 29151

Columbus, $\mathrm{OH}$ 43229-0151

B. R. Kowalski

University of Washington

Center for Process Analytical Chemistry

Chemistry Department BG-10

Seattle, WA 98195

T. S. Kress

102-B Newridge Road

Oak Ridge, TN 37839

2 Los Alamos National Laboratory

P.O. Box 1663

Los Alamos, NM 87545

ATTN: S. F. Agnew

T. E. Larson

D. T. Oakley

Waste Policy Institute

555 Quince Orchard Road, Suite 600

Gaithersburg, MD 20878-1437
No. of

Copies

F. L. Parker

Vanderbilt University

P.O. Box 1596, Station B

Nashville, TN 37235

G. Powers

Design Science, Inc.

163 Witherow Road

Sewickley, PA 15143

W. R. Prindle

1556 Crestline Drive

Santa Barbara, CA 93105

2 Sandia National Laboratories

P.O. Box 5800

Albuquerque, NM 87185

ATTN: D. A. Powers, MS-0744

S. E. Slezak, MS-0741

G. E. Schmauch

Air Products \& Chemicals, Inc.

7201 Hamilton Blvd

Allentown; PA 18195-1501

A. Schneider

5005 Hidden Branches Drive

Dunwoody, GA 30338

A. Stone

Washington State Department of Ecology

1315 W. 4th Avenue

Kennewick, WA 99336

T. C. Temple

U.S. Department of Energy

Savannah River Operations Office

P.O. Box A

Aiken, SC 29808 
No. of

Copies

7 U.S. Department of Energy

EM-36, Trevion II

12800 Middlebrook Road

Germantown, MD 20874

ATTN: J. V. Antizzo, EM-36

C. O'Dell, EM-36 (5)

S. C. Grizzel, EH-15

A. S. Veletsos

Rice University

5211 Paisley

Houston, TX 77096

\section{ONSITE}

8 DOE, Richland Operations Office

R. E. Gerton

S7-54

R. G. Harwood

W. F. Hendrickson

D. H. Irby (2)

M. F. Jarvis

A. G. Krasopoulos

G. W. Rosenwald

39 Westinghouse Hanford Company

H. Babad

G. S. Barney

W. B. Barton

J. B. Billetdeaux

D. C. Board

W. S. Callaway

R. J. Cash (5)

M. D. Crippen

R. D. Crowe

G. T. Dukelow

J. D. Hopkins

M. N. Islam

D. W. Jeppson

G. D. Johnson

N. W. Kirch

$57-54$

S7-54

K8-50

A4-81

S7-54

S7-14

T5-12

R2-11

S7-15

S7-07

S3-90

S7-14

L5-31

$\mathrm{H} 0-32$

S7-14

R2-11

R3-08

L5-31

S7-14

R2-11
No. of

Copies

C. A. Kuhlman B3-30

E. J. Lipke A2-34

L. L. Lockrem - $\quad$ S3-90

J. E. Meacham (2) S7-14

N. J. Milliken A3-37

S. R. Moreno B3-06

M. A. Payne S7-84

T. V. Rebagay T6-30

F. R. Reich L5-55

J. F. Relyea T6-50

D. A. Reynolds R2-11

E. F. Riedel $\quad$ S3-90

E. R. Siciliano H0-31

B. C. Simpson R2-12

D. A. Turner S7-14

W. T. Watson H0-32

A. B. Webb A3-37

W. D. Winkelman R2-12

W. D. Wittekind H0-32

\section{Pacific Northwest Laboratory}

R. T. Allemann

K7-15

Z. I. Antoniak

K7-15

S. Q. Bennett

K7-90

J. W. Brothers

K9-20

S. A. Bryan

P7-25

C. D. Carlson

P7-25

P. A. Gauglitz

R. T. Hallen

M. A. Lilga

S. D. Rassat

H. C. Reid

R. D. Scheele

P7-41

P8-38

P8-38

P7-41

K7-15

P7-25

C. S. Simmons (10)

K9-33

C. W. Stewart

K7-15

Y. Onishi

K9-33

J. J. Toth

K7-94

P. D. Whitney

T. W. Wood

K7-94

Information Release (5)
K5-12 